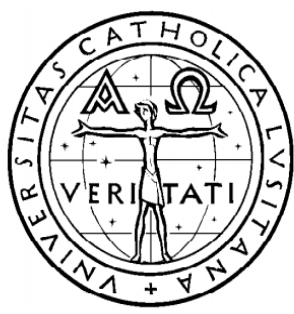

UNIVERSIDADE CATÓLICA PORTUGUESA

\title{
SOFRIMENTO MORAL: AVALIAÇÃO DE RISCO EM ENFERMEIROS
}

Tese apresentada à Universidade Católica Portuguesa para obtenção do grau de Doutor em Enfermagem na especialidade de História e Filosofia da Enfermagem

Por

Rafaela Schaefer

Instituto de Ciências da Saúde

Julho 2017 



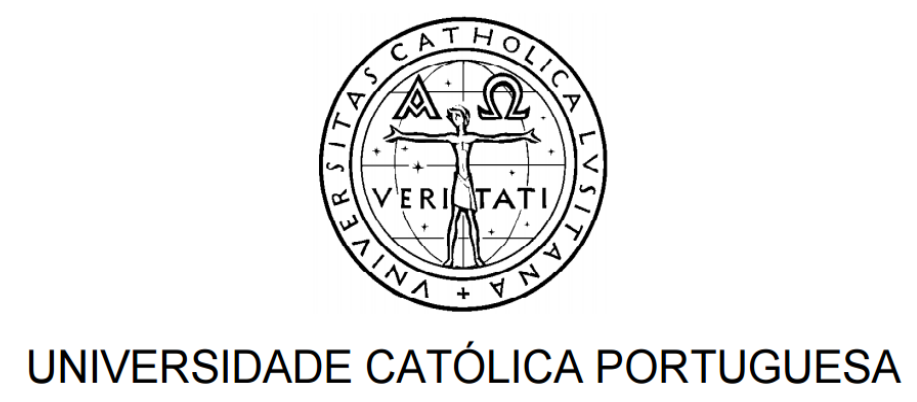

\section{SOFRIMENTO MORAL: AVALIAÇÃO DE RISCO EM ENFERMEIROS}

MORAL DISTRESS: RISK ASSESSMENT IN NURSES

Tese apresentada à Universidade Católica Portuguesa para obtenção do grau de Doutor em Enfermagem na especialidade de História e Filosofia da Enfermagem, com Dupla

Titulação pela Escola de Enfermagem da Universidade de São Paulo

$$
\text { Por }
$$

Rafaela Schaefer

Sob orientação da Professora Doutora Margarida M Vieira e co-orientação da Professora Doutora Elma LCP Zoboli

\section{Instituto de Ciências da Saúde}

Julho 2017 


Schaefer, Rafaela
Sofrimento moral: avaliação de risco em enfermeiros. Porto:
Universidade Católica Portuguesa: Instituto de Ciências da Saúde, 2017.
ISBN: 978-989-20-7810-6
Tese de Doutoramento - Instituto de Ciências da Saúde da Universidade
Católica Portuguesa
Orientadora: Professora Doutora Margarida M Vieira
Co-orientadora: Professora Doutora Elma LCP Zoboli
Palavras-chave: Enfermagem; Ética em enfermagem; Desenvolvimento
de instrumentos; Prática profissional; Sofrimento moral.

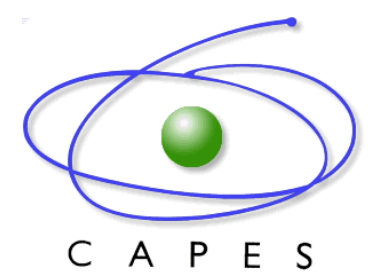

A elaboração desta tese foi apoiada pela Coordenação de Aperfeiçoamento de Pessoal de Nível Superior, através da Bolsa de Doutorado Pleno no Exterior [BEX 1050/13-3]. 


\section{AGRADECIMENTOS}

À professora Vania Schneider que, com sensibilidade, soube ver além da técnica e me mostrou o caminho do universo acadêmico.

Ao professor Roque Junges, mestre e amigo, grande incentivador, com quem aprendi todas as bases da investigação, da humanidade e da integridade.

À professora Rosângela Barbiani, por mostrar que a competência e a alegria de viver andam lado a lado.

À professora Elma Zoboli, exemplo e inspiração, pela co-orientação da tese e por ser refúgio nas tempestades.

À professora Margarida Vieira, pela orientação da tese e pela compreensão nos momentos difíceis.

À todos os professores que contribuíram de alguma forma na minha construção pessoal e acadêmica, meu mais sincero agradecimento e a promessa de que tudo farei para ser exemplo na vida dos meus futuros alunos, tanto quanto eles foram na minha.

Aos enfermeiros, portugueses e brasileiros, que contribuíram na construção do conhecimento, fica o meu agradecimento e o pedido para que nunca fechem os olhos diante das dificuldades.

Ao meu pai Lino e à minha mãe Lenita, meus maiores exemplos de coragem e determinação, pelo amor, pela confiança e por sempre acreditarem nos meus sonhos.

À minha grande família, que mesmo com o coração partido pela distância, foram meus maiores incentivadores, por me fazerem sentir como se nunca tivesse partido.

Aos meus amigos, de perto e de longe, que se fizeram presentes durante essa jornada, mostrando que a distância nunca é maior que um sentimento verdadeiro.

À vocês minha gratidão e o meu amor para sempre. 



\section{RESUMO}

O sofrimento moral é descrito na literatura como o sentimento resultante do impedimento à uma ação considerada moralmente apropriada, devido, sobretudo, a obstáculos institucionais, como a falta de recursos e a carga de trabalho. As consequências envolvem sintomas físicos, como mal estar, choro e desordens do sono e sintomas psicológicos, como frustração, impotência e culpa, além de implicações organizacionais, principalmente relacionadas com afastamentos e abandono do emprego. Considerando que o contexto de trabalho pode influenciar na vivência de situações moralmente problemáticas, o objetivo do estudo foi analisar o fenômeno do sofrimento moral em enfermeiros no Brasil e em Portugal. Trata-se de uma pesquisa metodológica para desenvolvimento, busca de evidências de validade e refinamento de um instrumento de pesquisa. A investigação partiu da análise de 38 estudos da literatura para construção de uma escala para identificação de fatores de risco para sofrimento moral. A busca por evidências de validade incluiu uma análise de juízes, para validação de conteúdo, e uma análise fatorial exploratória, para validação de constructo, com uma amostra de 268 enfermeiros brasileiros e 278 enfermeiros portugueses. O resultado foi uma escala com evidência de validade para ambos os países, com Alpha de Cronbach de 0,913 e 0,790, teste de Kaiser-Meyer Olkin de 0,869 e 0,914 e índice de Bartlett significativo $(p<0,001)$ para Brasil e Portugal, respectivamente. Cerca de 59,8\% da variância é explicada por 30 itens, divididos em sete fatores, na versão brasileira, e cerca de 53,9\% da variância é explicada por 20 itens, divididos em 4 fatores, na versão portuguesa. A vivência de fatores de risco para sofrimento moral foi considerada moderada no Brasil e baixa em Portugal. As variáveis que mostraram associação significativa com maiores médias totais de risco nos dois países foram o tipo de serviço, as horas de trabalho, estar em sofrimento moral e ter a intenção de deixar o emprego atual. Pesquisas no âmbito do sofrimento moral podem, entre outros aspectos, auxiliar na identificação dos desafios e das dificuldades que mais preocupam os enfermeiros em seu contexto de trabalho. No intuito de contribuir no desenvolvimento de estratégias de enfrentamento e melhorar a retenção e a satisfação profissional, pesquisas acerca do sofrimento moral podem refletir positivamente na qualidade dos cuidados.

Palavras chave: Enfermagem. Ética em enfermagem. Desenvolvimento de instrumentos. Prática profissional. Sofrimento moral. 

Moral distress is described as the feeling resulting from the impediment to an action considered morally appropriate, mainly due to institutional obstacles such as the lack of resources and the high workload. Main consequences are physical symptoms, such as malaise, crying and sleep disorders and psychological symptoms, such as frustration, impotence and guilt, as well as organizational implications, mainly related to withdrawal and abandonment of employment. Considering that the work context may influence the experience of morally problematic situations, the objective of these study was to analyze the phenomenon of moral distress among nurses in Brazil and in Portugal. It is a methodological research for development, searching for evidence of validity and refinement of a research instrument. The research started with the analysis of 38 studies for the construction of a scale to identify risk factors for moral distress. The search for evidence of validity included an analysis of judges, for content validation, and an exploratory factorial analysis, for construct validation, with a sample of 268 Brazilian nurses and 278 Portuguese nurses. The result was a scale with evidence of validity, Cronbach's Alpha of 0,913 and 0,790, Kaiser-Meyer Olkin test of 0,869 and 0,914 and a significant Bartlett ( $p<0,001$ ). About 59,8\% of the variance was explained by 30 items, divided into seven factors in the Brazilian version, and about 53,9\% of the variance was explained by 20 items, divided into four factors in the Portuguese version. The experience of risk factors for moral distress was considered moderate in Brazil and low in Portugal. The variables that showed a significant association with the highest risk for moral distress in both countries were the type of work context, the hours of work, being in moral distress and having the intention to leave the current job. Research in the field of moral distress can, among other things, help in identifying the challenges and difficulties that most concern nurses in their work context. In order to contribute to the development of coping strategies and to improve professional retention and satisfaction, researches about moral distress may positively reflect on the quality of care.

Keywords: Nursing. Nursing ethics. Instrument development. Professional practice. Moral distress. 

Tabela 1 - Caracterização das amostras ........................................................................... 53

Tabela 2 - Adaptação cultural das variáveis de caracterização da amostra para

Portugal 55

Tabela 3 - Variáveis de caracterização do sofrimento moral .......................................... 56

Tabela 4 - Mapeamento da literatura _................................................................................... 68

Tabela 5 - Lista de potenciais fatores de risco para sofrimento moral em enfermeiros

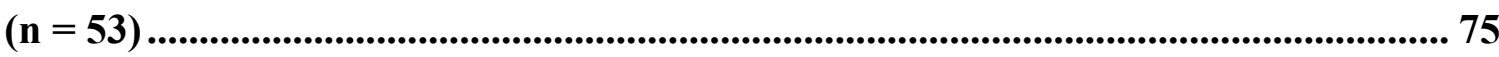

Tabela 6 - Fatores de risco e percentuais de relevância dos itens ................................. 82

Tabela 7 - Fatores e cargas fatorais dos itens da Escala de Risco de Sofrimento Moral,

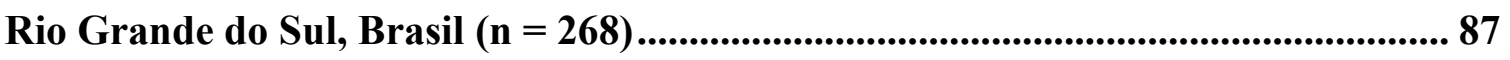

Tabela 8 - Fatores e cargas fatorais dos itens da Escala de Risco de Sofrimento Moral, Portugal $(n=278)$............................................................................................................ 92

Tabela 9 - Características sociodemográficas, de formação e de atividade profissional dos enfermeiros, Rio Grande do Sul, Brasil $(n=268)$.................................................. 102

Tabela 10 - Variáveis relativas ao local de trabalho dos enfermeiros, Rio Grande do Sul, Brasil $(\mathrm{n}=\mathbf{2 6 8})$ 105

Tabela 11 - Fatores de risco para sofrimento moral em enfermeiros: percentuais e

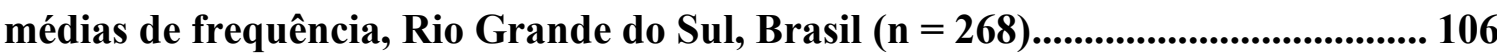
Tabela 12 - Variáveis de sofrimento moral, Rio Grande do Sul, Brasil $(n=268)$. 108 Tabela 13 - Características sociodemográficas, de formação e de atividade profissional dos enfermeiros, Portugal $(n=278)$ 110

Tabela 14 - Variáveis relativas ao local de trabalho dos enfermeiros, Portugal $(n=$ 278) 
Tabela 15 - Fatores de risco para sofrimento moral em enfermeiros: percentuais e

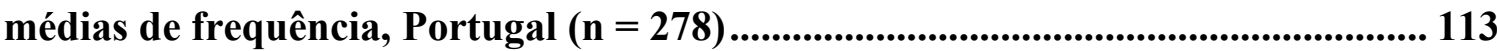

Tabela 16 - Variáveis de sofrimento moral, Portugal $(n=278)$................................. 114 Tabela 17 - Média total e média dos fatores da Escala de Risco de Sofrimento Moral (Brasil) 121

Tabela 18 - Diferenças na média total da escala e na média dos fatores em relação às variáveis sociodemográficas, formação, atividade profissional, local de trabalho e sofrimento moral, Rio Grande do Sul, Brasil $(n=268)$ 125 Tabela 19 - Média total e média dos fatores da Escala de Risco de Sofrimento Moral (Portugal) 128

Tabela 20 - Diferenças na média total da escala e na média dos fatores em relação às variáveis sociodemográficas, formação, atividade profissional, local de trabalho e sofrimento moral, Portugal $(n=278)$ 131 


\section{ÍNDICE DE FIGURAS}

Figura 1 - Processo de busca e seleção de estudos ........................................................ 60 



\section{ÍNDICE DE QUADROS}

Quadro 1 - Relação entre a finalidade do estudo e o plano de investigação .............. 50

Quadro 2 - Escala de Risco de Sofrimento Moral (versão pré final) .......................... 83

Quadro 3 - Escala de Risco de Sofrimento Moral (versão brasileira) ........................ 89

Quadro 4 - Escala de Risco de Sofrimento Moral (versão portuguesa) ...................... 93 



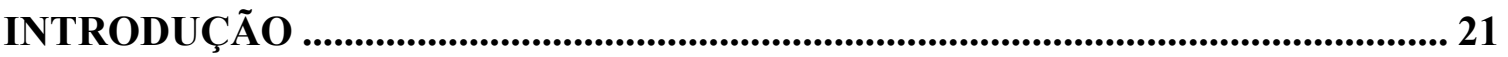

PARTE I - ENQUADRAMENTO TEÓRICO

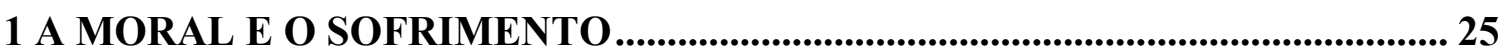

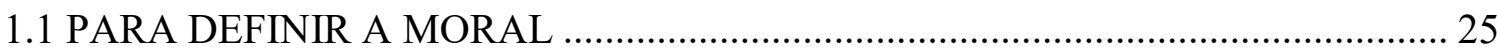

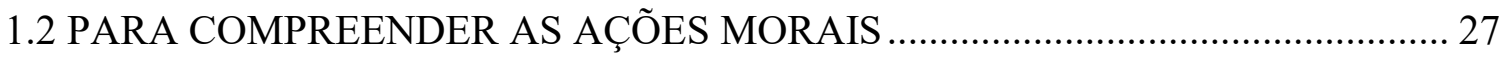

1.3 PARA DEFINIR E COMPREENDER O SOFRIMENTO MORAL.......................... 29

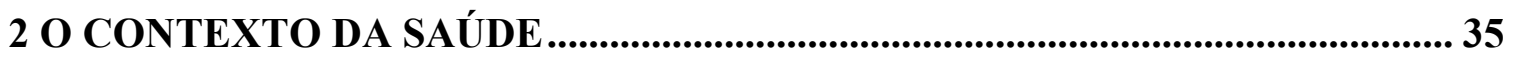

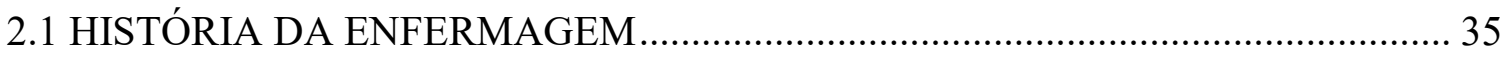

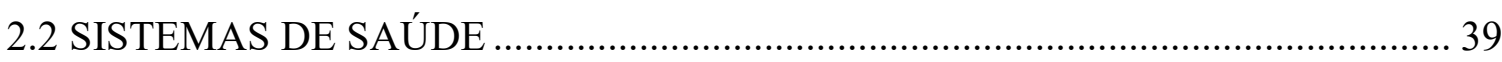

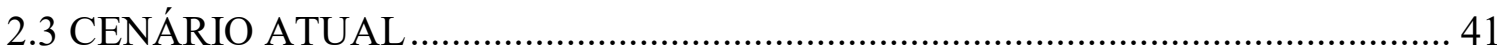

\section{PARTE II - ESTUDOS EMPÍRICOS}

1 DO PROBLEMA AO DESENHO DA INVESTIGAÇÃO .......................................... 47

1.1 DEFINIÇÃO DO PROBLEMA DE INVESTIGAÇÃO ................................................ 47

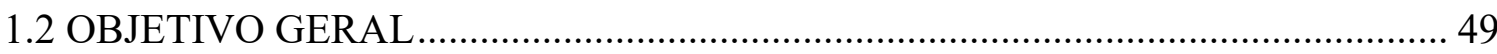

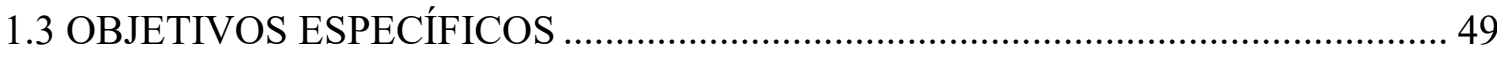

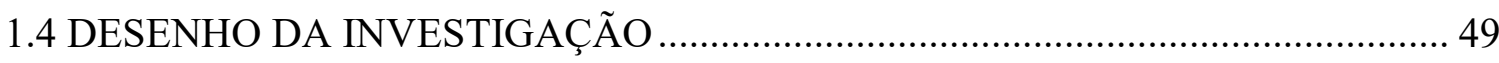

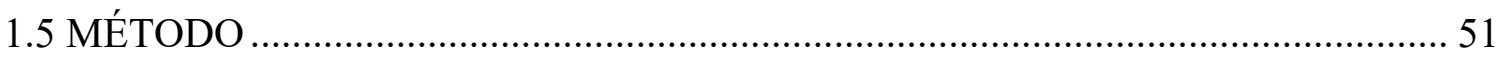

1.5.1 Tipo de estudo ................................................................................................................. 51 


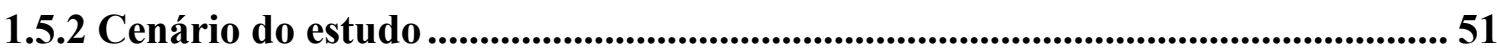

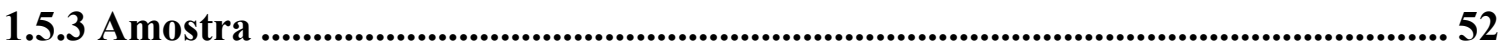

1.5.4 Recolha e análise de dados ...................................................................... 56

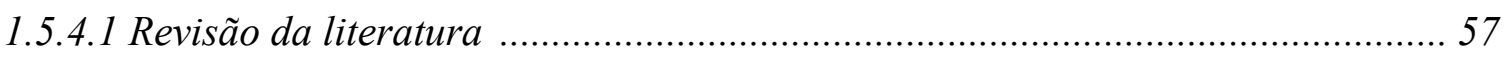

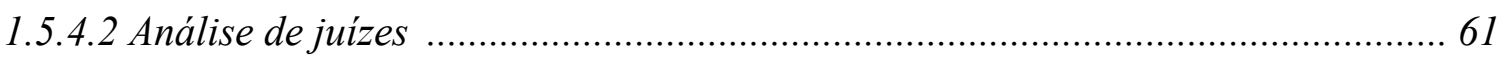

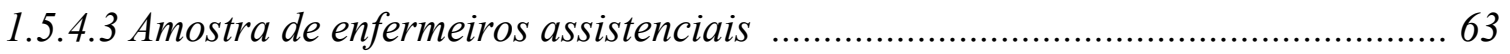

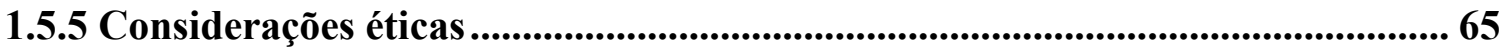

2 ESTUDO I - IDENTIFICAÇÃO DOS FATORES DE RISCO PARA

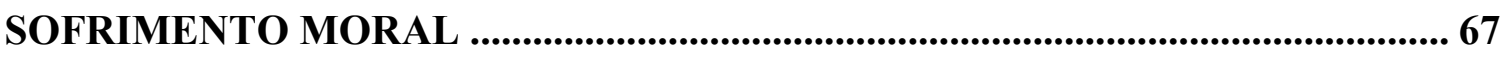

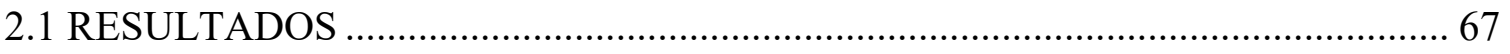

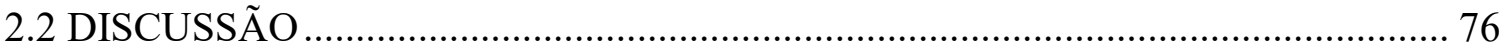

3 ESTUDO II - CONSTRUIR E BUSCAR EVIDÊNCIAS DE VALIDADE DA ESCALA DE RISCO DE SOFRIMENTO MORAL .............................................. 81

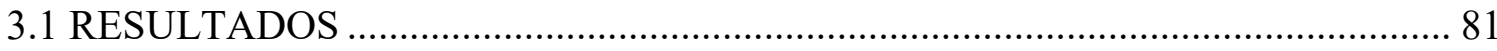

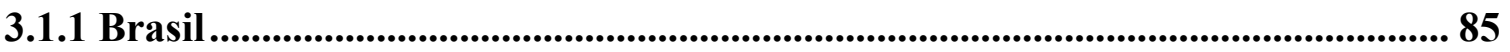

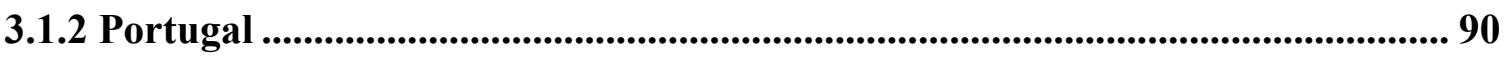

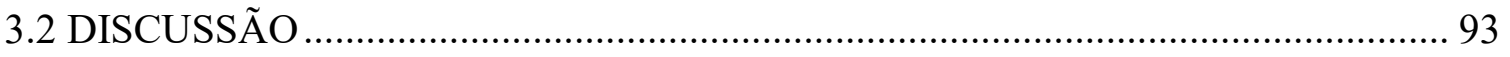

4 ESTUDO III - DESCREVER A FREQUÊNCIA DE VIVÊNCIA DE FATORES

DE RISCO DE SOFRIMENTO MORAL ..................................................................... 101

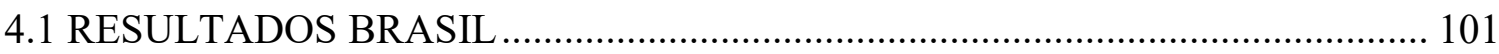

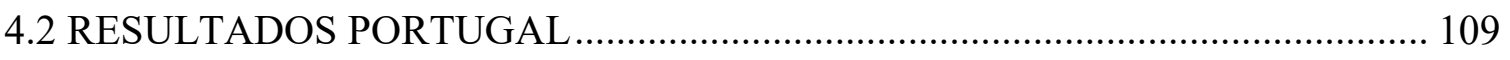

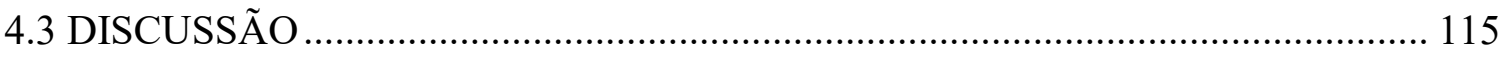


5 ESTUDO IV - VERIFICAR A ASSOCIAÇÃO ENTRE O RISCO DE SOFRIMENTO MORAL E AS VARIÁVEIS SOCIODEMOGRÁFICAS, FORMAÇÃO, ATIVIDADE PROFISSIONAL E LOCAL DE TRABALHO ....... 121

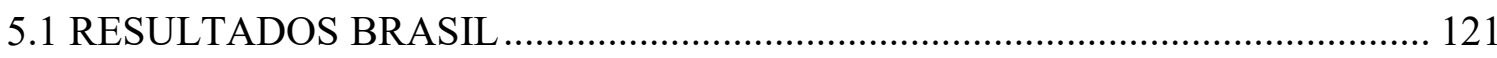

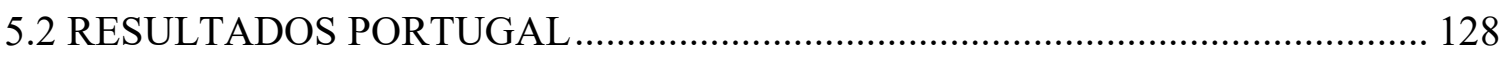

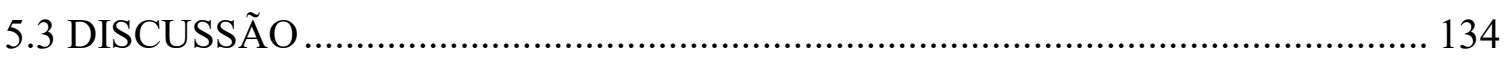

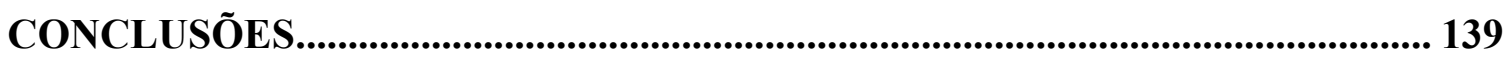

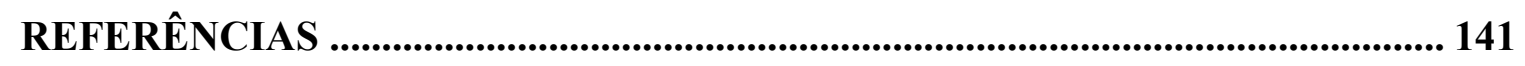

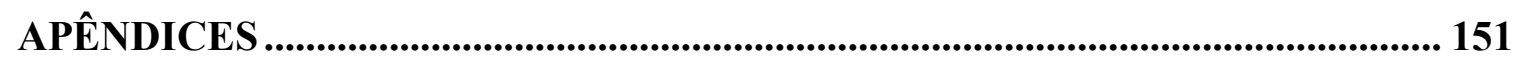

APÊNDICE A - CARTA CONVITE PARA PERITOS .............................................. 153

APÊNDICE B - TERMO DE CONSENTIMENTO LIVRE E ESCLARECIDO (BRASIL)

APENNDICE C - TERMO DE CONSENTIMENTO LIVRE E ESCLARECIDO

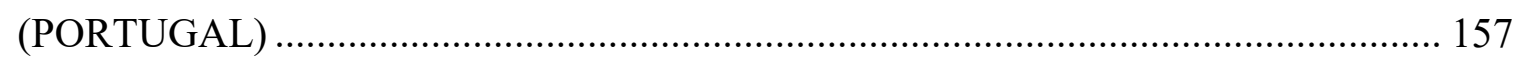

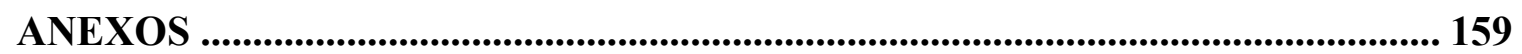

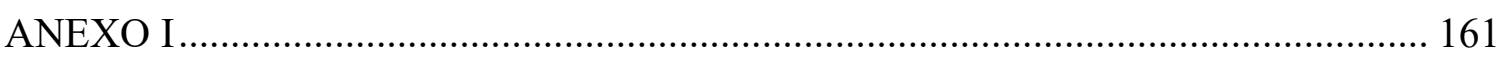

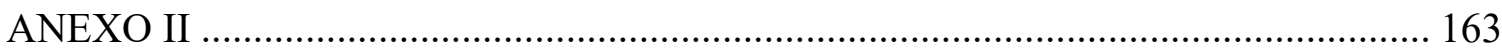

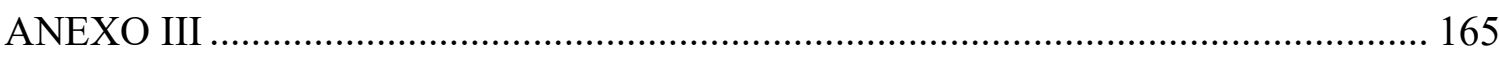

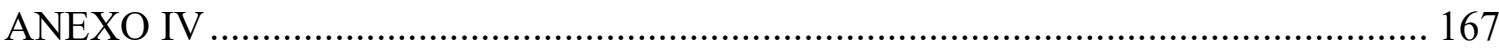

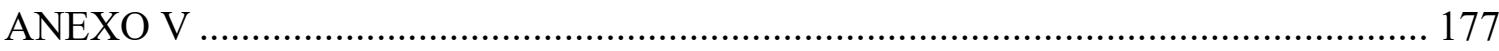

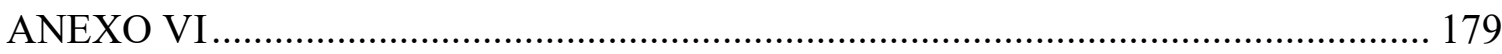

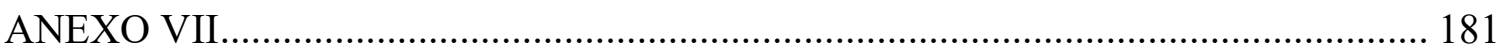

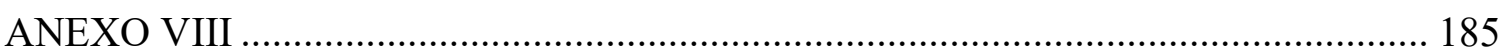


ANEXO IX

ANEXO X

ANEXO XI 


\section{INTRODUÇÃO}

Os desafios vivenciados pela enfermagem têm relação com aspectos próprios da organização do trabalho e estão arraigados em fundamentos históricos e filosóficos das profissões, dentro do contexto da saúde. O enfermeiro experimenta restrições que podem determinar práticas percebidas como incompatíveis com valores e princípios, resultando em um significativo constrangimento moral do papel profissional. O sofrimento moral é o resultado, portanto, de uma violação ao sistema de crenças do enfermeiro, frente a uma situação vivenciada na prática profissional.

Reconhecendo o sofrimento moral como um fenômeno com significativo impacto para a enfermagem, acredita-se que a identificação de fatores de risco nos contextos de trabalho, através do uso de escalas, pode contribuir para a melhoria de aspectos relacionados com a satisfação profissional e com a qualidade dos cuidados, entre outros. Nesse contexto, desenvolveu-se um processo de investigação com o intuito de analisar o sofrimento moral no Brasil e em Portugal, através da construção, validação e aplicação de uma escala de risco de sofrimento moral para enfermeiros assistenciais.

A presente tese resulta de um percurso que envolveu uma revisão da literatura científica de enfermagem, uma análise de juízes e uma análise fatorial exploratória. A escala, juntamente com outras variáveis de caracterização dos participantes e dos seus contextos de trabalho, foi utilizada para descrever o perfil e o risco para sofrimento moral dos enfermeiros, bem como para verificar associações significativas que pudessem determinar maiores médias de risco de sofrimento moral.

A tese está dividida em duas partes principais. A parte I ocupa-se do enquadramento teórico acerca da moral e da contextualização, tanto da enfermagem, quanto do contexto de trabalho em saúde. A parte II ocupa-se dos estudos empíricos, descrevendo o método, os resultados da investigação e discutindo os dados à luz da literatura científica atual.

Do processo investigativo resultaram, até o momento: três artigos científicos já publicados (Schaefer \& Vieira, 2015) (Schaefer, Zoboli, \& Vieira, 2016) (Schaefer, Zoboli, \& Vieira, 2017), um artigo científico submetido para publicação e outros em 
construção. Igualmente, a participação em diversos eventos científicos, com apresentação de resultados parciais e duas premiações de melhor comunicação.

A motivação para investigar o sofrimento moral nos enfermeiros é a busca contínua pelo desenvolvimento e pela qualificação da enfermagem, com a possibilidade de construção de resultados positivos tanto para os profissionais, quanto para os pacientes. 
PARTE I - ENQUADRAMENTO TEÓRICO 


\section{A MORAL E O SOFRIMENTO}

O primeiro capítulo percorre o campo da definição da moral, principalmente a partir das perspectivas filosófica de Kant e psicológica de Jean Piaget e Lawrence Kohlberg. A seguir, se ocupa da descrição do desenvolvimento da moral, da tomada de decisão moral e da ação moral em si. Por fỉm, trata do conceito e da descrição do sofrimento moral, para compreensão do fenômeno e objeto de investigação.

\subsection{PARA DEFINIR A MORAL}

No cerne da definição de moral, está o questionamento referente à necessidade de diferenciá-la, ou não, da ética. A ética provém do termo grego "ethos», que remetia à interioridade dos homens, de onde derivavam os seus atos e a moral do termo latim «mores», que refletia a natureza repetitiva desses atos. São, muitas vezes, adotados na literatura como sinônimos, por considerar que se referem aos mesmos conteúdos, mas há quem defenda a sua distinção, por isso, todo o trabalho que se propõe à uma reflexão ética e moral deve especificar o sentido que conferirá a estes termos (Renaud \& Renaud, 1996).

Segundo Ricoeur (1990), é possível notar uma tênue diferença entre ética e moral: a primeira está focada na estimativa do bom, ou seja, da vida boa; a segunda está focada no que se impõe como obrigatório, ou seja, na obediência às normas. Pode-se dizer que a ética preocupa-se com a fundamentação do agir, ao passo que a moral centra-se na formação, hierarquização e aplicação das leis morais (Renaud \& Renaud, 1996). A moral busca responder à pergunta: “como devo agir?” e a ética: “que vida quero viver?”. Essa diferença de sentido é conveniente porque permite diferenciar o que seria o objeto de estudo - a moral, da reflexão que incide sobre ele - a ética (LaTaille, 2006).

No campo da filosofia, ao distinguir ética e moral - vida boa e obediência às normas, faz-se o reconhecimento de duas heranças teóricas opostas: a perspectiva teleológica e a perspectiva deontológica. A primeira, provém de Aristóteles, na qual «telos» significa "fim", e defende que os deveres morais são bons em si mesmos. A segunda, provém de Kant, com o significado de "dever", que leva em consideração a racionalidade dos atos (Ricoeur, 1990). Seria dedutivo afirmar que a deontologia rege os 
deveres morais, contudo o contexto em que os fatos decorrem pode interferir na decisão. LaTaille (2006) exemplifica o debate entre as duas perspectivas com um exemplo: ao assumir que não mentir é um imperativo moral, omitir que estamos a esconder um fugitivo seria moralmente errado do ponto de vista kantiano, mas a consequência de levar um inocente à morte ao dizer a verdade, seria igualmente condenável. Uma vez que ambas perspectivas estão fundamentadas em um sentimento de obrigatoriedade, temos, nos dois casos, um sujeito moral, orientado pelo dever. Seria assim um erro considerar como absoluta apenas uma interpretação, fazendo-se do respeito à legitimidade de cada reflexão um imperativo (Renaud \& Renaud, 1996).

A diversidade teórica inerente à compreensão da moral nos permite conceituá-la em diferentes âmbitos, entre eles, os âmbitos da razão e da afetividade. A dimensão afetiva dos comportamentos morais, de Émile Durkheim e Sigmund Freud, é descrita por LaTaille (2006) como uma defesa da moral heterônoma, ou seja, quando o ser humano cresce e alcança a consciência reflexiva, encontra um sistema moral pronto, ao qual deve adaptar-se. A obediência aos mandamentos da sociedade não permite pensar que existe um desenvolvimento moral, mas sim a pura obediência pelas normas. Por outro lado, a dimensão racional da moral, de Jean Piaget e Lawrence Kohlberg, é descrita por LaTaille (2006) como a capacidade do ser humano de desenvolver-se moralmente e passar de uma moral heterônoma, para uma moral autônoma. A autonomia moral, considerada um evento raro na população em geral, acontece quando o sujeito submete os princípios e as normas morais à uma análise prévia à ação, deixando de simplesmente obedecê-los, para questioná-los (LaTaille, 2006).

A moral ocupa-se, portanto, da análise do percurso entre a lei moral absoluta e a compreensão da sua legalidade, ou seja, entre a heteronomia e a autonomia do agir. Esse processo de análise aplica-se aos mais diversos casos que surgem no decorrer da vida e tenta apontar o que seria o bem e o mal agir (Renaud \& Renaud, 1996). Esse sentimento de dever moral, que busca o bem agir, é experimentado pela maioria das pessoas, especialmente por aquelas que atuam em contextos complexos e permeados por conflitos, como é o caso dos enfermeiros. É fundamental compreender o que leva o sujeito a cometer uma transgressão à moral e por que o faz. Será por ser desprovido do sentimento de obrigatoriedade ou por este sentimento não ter sido forte o bastante para impedir as ações contrárias à moral (LaTaille, 2006)? 
Somente uma moral autônoma, livremente estabelecida e consentida pelo indivíduo merece o nome de moral. A moral autônoma é suportada pelo sentimento de obrigatoriedade, ancorado na reciprocidade, na equidade, na igualdade e no respeito, seguindo um ideal de justiça. Contudo, dizer que o agir moral é um dever não implica afirmar que quem o vivencia sabe exatamente o que fazer. Há situações nas quais o dever aparece claramente, há outras que não e, considerando a vasta diversidade de sistemas morais das diferentes culturas e construções sociais, a tarefa complica-se (LaTaille, 2006) (Renaud \& Renaud, 1996).

\subsection{PARA COMPREENDER AS AÇÕES MORAIS}

Nessa diversidade de sistemas morais existentes, há algum conteúdo que corresponde a exigências sociais consagradas pelo poder judiciário, como 'não matar' e 'não roubar', por exemplo, passíveis de sanções penais. Há algum conteúdo que corresponde a exigências morais socialmente impostas, sem a legitimidade jurídica, mas igualmente condenáveis, como 'não trapacear no jogo' e 'cumprir uma promessa'. Nesse meio, é possível encontrar pessoas que assumem para si deveres morais não exigíveis nem pela justiça, nem pela sociedade (LaTaille, 2006). Para dar um exemplo relacionado com a enfermagem, há profissionais que se sentem moralmente obrigados a conceder parte importante do seu tempo de trabalho para ouvir as inquietações de seus pacientes. Segundo LaTaille (2006), esse tipo de atitude seria admirável, mas não obrigatória, deixando claro que o sentimento de obrigatoriedade moral e, portanto, a ação moral, não está limitada apenas por exigências legais e sociais.

Cumprir com os deveres morais e com os ideais impostos por si mesmo é o que confere sentido à vida, sendo condição necessária à felicidade e ao bem estar subjetivo. As ações morais são um reflexo da expressão dos valores da própria pessoa e, portanto, só age moralmente quem sente essa obrigação como dever, ou seja, somente é moral quem assim o quer e somente respeita a moral quem, ao fazê-lo, respeita a si próprio (LaTaille, 2006).

A decisão moral está fundamentada em regras, princípios e valores. As regras, socialmente estabelecidas, se ocupam em dizer o que deve e o que não deve ser feito. Já os princípios e os valores são o que inspiram e fundamentam a decisão moral. Se a decisão 
moral não levar em conta os princípios e os valores, corre o risco de ser injusta e limitada, porque a mera aplicação da norma não é capaz de corresponder à complexidade da vida (LaTaille, 2006).

O agir moral pressupõe, portanto, uma decisão moral, um saber fazer a partir da percepção, da reflexão e do julgamento do sujeito acerca do que fazer, como fazer e quando fazer (LaTaille, 2006). A problemática do agir moral está em compreender em que se baseia essa decisão moral e, segundo Renaud \& Renaud (1996), a resposta está na razão. A razão significa que na motivação da ação está um conteúdo de valor, que lhe confere um sentido para além da vontade pessoal e da afetividade particular do sujeito. Busca-se adequar as normas morais no espaço e no tempo, de acordo com a particularidade de cada situação, superando assim a mera replicação das normas impostas.

Ao considerar que toda a decisão moral está pautada pela razão e que, portanto, é consciente e responsável, não se pode todavia garantir que toda a ação moral resultante nunca será má. É dever da consciência moral não permitir que o motivo da ação inverta a hierarquia de valores que deveríamos respeitar (Renaud \& Renaud, 1996). Segundo LaTaille (2006), o caminho para a melhor decisão moral passa pela ponderação e pela reflexão, transcendendo as ações realizadas por impulso, por intuição ou pela simples obediência às regras. Perceber os elementos morais de cada situação, pensar as decisões e levar em conta suas implicações são elementos necessários para a melhor decisão moral.

Essa capacidade de pensar a moralidade, ou seja, de tomar decisões morais, não é inerente ao indivíduo, mas, pelo contrário, se desenvolve ao longo da vida. As teorias de Piaget e Kohlberg descrevem os diferentes estágios do desenvolvimento moral, a saber: anomia, heteronomia e autonomia moral para Piaget; estágio pré-convencional, convencional e pós-convencional para Kohlberg. Importante é salientar que esse desenvolvimento moral tem relação com o desenvolvimento da inteligência e com o tipo de interação com o meio social ao qual o indivíduo é exposto ao longo da vida. Isso pode determinar o estágio por ele alcançado, tendo em consideração que as pesquisas de Kohlberg indicam que a maioria dos adultos não passa do nível mediano no que se refere ao desenvolvimento da moral (LaTaille, 2006).

Para além da decisão moral, ou seja, do saber fazer, há que se considerar que as ações morais dependem fundamentalmente de um querer fazer, ao qual se relaciona o sentimento de obrigatoriedade moral. LaTaille (2006) considera que o querer fazer tem 
relação com a dimensão afetiva da moral, sendo fundamentado pelos sentimentos de medo, amor, confiança, simpatia, indignação e culpa. Uma vez que o desenvolvimento da competência para a ação moral tem relação com a qualidade das relações sociais vivenciadas, o papel da educação no campo do desenvolvimento moral, não só para as crianças, mas também para os adultos, assume especial importância.

\subsection{PARA DEFINIR E COMPREENDER O SOFRIMENTO MORAL}

Para fundamentar a definição e a compreensão do sofrimento moral, é necessário rever algumas de suas características no campo da filosofia moral. Primeiro, a moral, por ser um fenômeno socialmente construído, é objeto constante de questionamento, principalmente acerca da validade de seus fundamentos e da legitimidade de suas normas (LaTaille, 2006). Há que se reconhecer que os conteúdos associados com a moral diferem nas diferentes épocas, culturas e indivíduos, sendo por isso, impossível, e até ingênuo, pensar ser possível determinar uma moral universal (Renaud \& Renaud, 1996). Também

que, o que é comum na moral, indiferente de seu conteúdo, é o sentimento de obrigatoriedade que a caracteriza, ou seja, ao vivenciar qualquer tipo de situação moral, o indivíduo se vê internamente obrigado a agir moralmente. Assim, presenciar ações imorais, ser impedido de realizar ações morais ou ser coagido a realizar ações imorais seria problemático, caracterizando fonte de infelicidade e mal-estar subjetivo (LaTaille, 2006).

No campo da enfermagem, a dificuldade em cumprir com a obrigação moral foi denominada de sofrimento moral em 1984, no estudo de Andrew Jameton, intitulado 'Nursing practice: the ethical issues'. Em sua tese, Jameton expõe a centralidade moral do enfermeiro na equipe de saúde, como defensor do paciente, explorando as dificuldades resultantes desse processo, em uma época em que o médico era o elemento central do cuidado e o paciente não era visto como parte do processo. Talvez por isso, na perspectiva do autor, esse impedimento à ação moral estivesse majoritariamente atrelado aos obstáculos institucionais, tais como: impedimentos gerados pela supervisão; estrutura do poder médico; políticas institucionais; considerações legais; entre outros (Jameton, 1984). A preocupação de Jameton com os desafios da prática profissional do enfermeiro foi um marco teórico para as diversas investigações que se seguiram, sendo o sofrimento moral 
um dos temas mais investigados na área da ética da enfermagem até aos dias de hoje (Vosner, Zeleznik, Kokol, Vosner, \& Zavrsnik, 2016).

Ainda na década de 1980, Judith Wikilson propôs o primeiro modelo explicativo para o sofrimento moral no estudo 'Moral Distress in nursing practice: experience and effect'. Segundo a autora, o sofrimento moral aparece como um desequilíbrio psicológico e estado de sentimento negativo, resultante do ato de se deparar com uma situação problemática e experimentar dificuldade em levar adiante sua responsabilidade moral. A autora vai além dos obstáculos institucionais como fonte de sofrimento moral e descreve diferentes situações da prática profissional que mais comumente levariam o enfermeiro a sentir que não está cumprindo com a sua obrigação moral. As principais situações fontes de sofrimento moral seriam: prolongar a vida de pacientes terminais; causar danos; ser incapaz de reduzir a dor e o sofrimento do paciente; e ser desumano (Wilkinson, 1987).

Como todo conhecimento científico, o campo do sofrimento moral segue em constante aperfeiçoamento teórico e adaptação. Em 1993, Andrew Jameton propôs, no estudo 'Dilemmas of moral distress: moral responsability and nursing practice', que o sofrimento moral fosse analisado a partir de duas perspectivas: a do sofrimento inicial, quando o enfermeiro se confronta com a restrição à ação, e a do sofrimento reativo, quando ocorre o efetivo impedimento à ação moral pretendida. Essa diferenciação fundamentou estudos sobre o sofrimento moral residual e o denominado 'crescendo effect' (Epstein \& Hamric, 2009).

Uma teoria para o sofrimento moral foi proposta em 2002, por Mary Corley, no estudo 'Nurse moral distress: a proposed theory and research agenda'. A teoria fundamenta o sofrimento moral a partir de fatores do contexto externo - relativo ao ambiente de trabalho, e do contexto interno - relativo às respostas psicológicas ao sofrimento, mantendo as restrições institucionais como foco principal. Assim, quando os enfermeiros sabem que estão envolvidos em um problema moral e não conseguem concretizar o fim moral pretendido, experimentam o sofrimento moral, com potencial impacto sobre pacientes, colegas e instituição de saúde (Corley M. , 2002).

O sofrimento moral tem feito parte da agenda de investigação da enfermagem em todo o mundo (Vosner, Zeleznik, Kokol, Vosner, \& Zavrsnik, 2016), chamando a atenção de instituições de referência para a enfermagem mundial, como é o caso da Associação Norte-Americana das Enfermeiras de Cuidado Crítico - American Association of Critical- 
Care Nurses $(A A C N)$. A AACN destaca o sofrimento moral como um sério problema para a enfermagem, uma vez que pode interferir na qualidade da assistência, bem como em aspectos relacionados à satisfação do enfermeiro com o trabalho (AACN, 2008). Ainda assim, recentemente, o sofrimento moral foi questionado e considerado um conceito controverso, filosoficamente falho e com pouca fundamentação empírica. O problema fundamental levantado para o questionamento estaria relacionado com o risco de imposição moral, por parte do enfermeiro, nas decisões e subsequentes ações consideradas moralmente apropriadas (Johnstone \& Hutchinson, 2015).

Em resposta a essas inquietações, investigadores brasileiros propuseram um novo modelo teórico para o sofrimento moral, que se preocupa em detalhar e justificar o processo de tomada de decisão que antecede ao bloqueio da ação. Segundo Barlem \& Ramos (2015), a decisão moral do enfermeiro resulta de um processo de deliberação moral, que envolve a aquisição de informações significativas, a busca de alternativas, a revisão de critérios, a decisão, a ação e a avaliação dessa decisão/ação. Isso para garantir que a situação, fonte de sofrimento moral, seja analisada em toda a sua complexidade e que a decisão considere todos os valores envolvidos. Nesse contexto, a literatura evidencia, inclusive, a importância de considerar a possibilidade desses erros de julgamento ao longo do processo. Segundo Weber (2016), assumir que o sofrimento moral pode ser consequência de um erro avaliativo é relevante para desenvolver estratégias de enfrentamento mais adequadas.

Outra fonte de crítica, seria o fato do sofrimento moral estar condicionado à vivência de algum obstáculo institucional pelo enfermeiro. Investigadores acreditam que outros elementos relacionais da prática profissional precisam ser levados em consideração, sob o risco de obscurecer o vínculo do sofrimento moral com a prática clínica (Hanna, 2005) (Pauly, Varcoe, Storch, \& Newton, 2009) (Lützén \& Kvist, 2012). Atualmente, a literatura considera que o sofrimento moral pode resultar de variadas situações, nem sempre atreladas aos obstáculos institucionais. É possível identificar, pelo menos, três fontes principais de sofrimento moral: as restrições externas, as restrições internas e as situações clínicas (McCarthy \& Gastmans, 2015).

As restrições externas, fontes de sofrimento moral, estão focadas nos obstáculos institucionais, tais como conflitos hierárquicos e desequilíbrios de poder, pressão para redução de custos e falta de recursos, políticas hospitalares em conflito com as necessidades do doente. As restrições internas refletem características do próprio 
indivíduo, como a falta de confiança em si mesmo e nas suas capacidades, a percepção de falta de autonomia e impotência para agir, a falta de conhecimento e compreensão da situação e a falta de competência. As situações clínicas, que já apareciam no trabalho de Wikilson em 1987, estão comumente relacionadas com decisões controversas e suporte agressivo aos pacientes em fim de vida, trabalhar com profissionais incompetentes e o uso inadequado dos recursos disponíveis (Hamric, Borchers, \& Epstein, 2012).

No sofrimento moral, o papel do enfermeiro é constrangido de forma significativa, quando o profissional se vê obrigado a agir de maneira incompatível com valores profundamente arraigados (McCarthy \& Gastmans, 2015). O enfermeiro percebe o comprometimento da sua integridade moral, que leva a uma sensação quase visceral, descrita por Hanna (2005) como uma aversão interior, resultando, na grande maioria das vezes, em consequências negativas, que envolvem além de sintomas físicos e psicológicos, implicações de natureza organizacional (McCarthy \& Gastmans, 2015). Os sintomas psicológicos que mais aparecem na literatura são a frustração, a impotência, a culpa e a raiva (Ferrell, 2006) (Harrowing \& Mill, 2010) (Zuzelo, 2007) e os sintomas físicos mais comumente encontrados são o mal-estar, o choro, a dor, as desordens do sono e a fadiga (Gutierrez, 2005) (Harrowing \& Mill, 2010).

Em relação aos aspectos organizacionais, o sofrimento moral parece estar relacionado com maiores índices de abandono do emprego, alta rotatividade de profissionais, aposentadoria precoce e afastamentos prolongados do trabalho (Barlem, Lunardi, Lunardi, Tomaschewski-Barlem, \& Silveira, 2013) (Corley, Minick, Elswick, \& Jacobs, 2005) (Woods, Rodgers, Towers, \& Grow, 2015) (Veer, Francke, Struijs, \& Willemsv, 2013). Além disso, grande parte da preocupação que cerca a pesquisa no tema reflete sobre a possibilidade de implicações para os resultados dos pacientes (Musto \& Schreiber, 2012) e para a qualidade do cuidado (Deady \& McCarthy, 2010).

O sofrimento moral pode afetar a vida pessoal do enfermeiro, causando impaciência, irritabilidade, dificuldade de concentração e sensação de ineficácia fora do ambiente de trabalho (McClendon \& Buckner, 2007). É que depois das situações geradoras do sofrimento moral inicial persiste, para o enfermeiro, a ferida moral, o sofrimento reativo de ter agido contra os valores pessoais e os padrões éticos profissionais (Epstein \& Hamric, 2009). 
Há poucas pesquisas sobre as possíveis reações positivas em decorrência do sofrimento moral, mas a literatura sustenta que depois de vivenciar uma situação de barreira à ação moral o enfermeiro pode ter como reações positivas: demonstrar mais vontade e empenho na defesa do paciente ao se deparar novamente com situação semelhante; passar a interessar-se ou aumentar o interesse por questões relacionadas à ética; relatar crescimento pessoal e profissional (Barlem, Lunardi, Lunardi, Tomaschewski-Barlem, \& Silveira, 2013) (Ferrell, 2006) (Gutierrez, 2005). Pesquisadores destacam, ainda, que o sofrimento moral pode ser visto como algo positivo quando o profissional é capaz de visualizar a dimensão ética dos problemas do cotidiano, o que indicaria uma competência ético-moral desenvolvida, fundamental para a mobilização de resistências e estratégias de enfrentamento (Barlem \& Ramos, 2015). 


\section{O CONTEXTO DA SAÚDE}

O segundo capítulo faz uma breve releitura da história da enfermagem, com atenção especial aos pormenores das enfermagens Portuguesa e Brasileira, bem como da organização dos sistemas de saúde nos respectivos países. O terceiro item vem contextualizar a realidade na qual esta tese foi construída, descrevendo informações relevantes do cenário atual da saúde, em geral, e da enfermagem, em particular, onde o sofrimento moral têm lugar.

\subsection{HISTÓRIA DA ENFERMAGEM}

A enfermagem foi reconhecida como profissão organizada somente no século XIX, apesar do cuidado ao outro ser tão antigo quanto a existência da humanidade. Relata a história que, a exemplo de Jesus Cristo, a caridade, enquanto caminho de santificação, levou muitas pessoas, sobretudo mulheres, a exercer a missão de cuidar dos enfermos e dos mais necessitados (Vieira, 2009).

Em Portugal, a enfermagem foi influenciada, sobretudo, pelas congregações religiosas que, entre os séculos XVI e XIX, eram responsáveis tanto pela administração dos serviços hospitalares, quanto pelo cuidado direto aos doentes. Os enfermeiros tinham, nessa época, pouca ou nenhuma formação, trabalhavam por longos e exaustivos períodos, em condições degradantes e em troca de baixíssima remuneração. A criação das escolas de enfermagem e a regulamentação do exercício profissional veio responder, sobretudo, à necessidade de desenvolver a enfermagem para melhorar a qualidade dos cuidados e das condições de trabalho (Vieira, 2009).

O primeiro curso de enfermagem em Portugal tomou lugar nos hospitais da Universidade de Coimbra, em 1881. Em 1887 foi criado um curso de enfermeiros, no Hospital de São José, do qual derivou a primeira escola profissional de enfermeiros, em 1910. Em 1886 foi criada a Escola de Enfermeiros no Hospital de Santo Antônio da Santa Casa de Misericórdia do Porto, a qual foi atribuída a designação de Curso de Enfermagem em 1918. Em 1912 foi criada a Escola de Enfermeiros, no Hospital de São Marcos, em Braga. A enfermagem passa, nesse período, por um importante processo de reestruturação 
profissional, fundamentalmente pautado em saberes técnicos. Em 1918, passa a existir o Curso Geral, com dois anos de duração, que habilitava profissionais para a atuação hospitalar, e o Curso Complementar, com um ano de duração, para ser realizado após o Curso Geral e, assim, habilitar o enfermeiro para as posições de chefia (Ordem dos Enfermeiros, 2004).

O desenvolvimento do ensino segue com a publicação do regulamento do Curso de Enfermagem Geral em 1920, com a criação e reestruturação de escolas em 1947 e com a criação da carreira de enfermeiro, em 1949 (Decreto-Lei no 37 418/99) (Ordem dos Enfermeiros, 2004). O alargamento do ensino por todo o país leva à uma reforma do Ensino de Enfermagem em 1952 e, em 1956, já não era possível exercer a profissão em Portugal sem um diploma, apesar de o registro obrigatório de todos os enfermeiros ter se concretizado apenas em 1998 (Vieira, 2009).

É perceptível, nessa época, uma transformação gradual do ensino tecnicista, para um ensino mais centrado em capacidades relacionais. Foram criados requisitos de admissão aos cursos de enfermagem e observou-se o início do curso superior de enfermagem. Em 1976 é estabelecido um programa único, de caráter nacional, para o ensino da enfermagem, com regulamentação das escolas de todo o país. Em 1988 a formação de enfermagem foi reconhecida como de nível superior e em 1989, as escolas de enfermagem foram convertidas em escolas superiores de enfermagem. $\mathrm{O}$ acesso a mestrados e doutoramentos foi possível a partir de 1990, sendo o primeiro mestrado em ciências da enfermagem lançado em 1992. A partir de 1994, a formação passa a ser uma licenciatura de quatro anos, sendo permitido o acesso a profissionais com formação complementar e, finalmente, em 1999, o Curso de Enfermagem passa para ciclo único de licenciatura (Ordem dos Enfermeiros, 2004).

O Regulamento do Exercício Profissional dos Enfermeiros (REPE), foi publicado em Portugal, em 1996, através do decreto-lei 161/96, com o objetivo de clarificar conceitos, caracterizar os cuidados de enfermagem, especificar a competência, as responsabilidades, os direitos e os deveres do enfermeiro (Decreto-lei 161/96). A Ordem dos Enfermeiros foi criada em 1998, através do decreto-lei 104/98, iniciando seus trabalhos através de uma Comissão Instaladora, que deu lugar à primeira Bastonária eleita já no ano seguinte. A Ordem dos Enfermeiros é de âmbito nacional e de organização regional, e existe no intuito de promover a defesa da qualidade dos cuidados de 
enfermagem, o desenvolvimento, a regulamentação e o controle do exercício profissional ético e deontológico (Decreto-lei 104/98) (Vieira, 2009).

A última atualização da carreira da enfermagem foi realizada em 1999, estabelecendo três possíveis áreas de atuação: a prestação de cuidados, a gestão e a assessoria técnica. Na prestação de cuidados, a carreira inclui as categorias de enfermeiro, enfermeiro graduado e enfermeiro especialista. Na gestão estão incluídas as categorias de enfermeiro-chefe, enfermeiro-supervisor e enfermeiro-diretor. À assessoria técnica corresponde o cargo de assessor de enfermagem. A progressão na carreira depende de variáveis como o tempo de trabalho, a formação especializada e a aquisição de habilitações específicas. Em relação ao regime de trabalho, os enfermeiros podem exercer a profissão em: tempo completo, que corresponde a $35 \mathrm{~h}$ semanais; tempo parcial, com duração de $20 \mathrm{~h}$ ou $24 \mathrm{~h}$ semanais; ou regime de horário acrescido, em 42h semanais (Vieira, 2009).

No Brasil, a enfermagem ganha espaço legal no país, ainda que indiretamente, em 1832, quando um Decreto sem $n^{\circ}$ de 3 de outubro, descreveu a primeira legislação para formação da parteira, considerando seu vínculo com as faculdades de medicina. A primeira escola profissional de enfermagem foi criada em 1890, através do Decreto 791 de 27 de setembro, atualmente a Escola de Enfermagem Alfredo Pinto, da Universidade do Rio de Janeiro (Oguisso, 2001).

Somente em 1931 foi lançado o Decreto $\mathrm{n}^{\circ} 20.109$, de 16 de junho, que tinha o propósito de regulamentar o exercício da enfermagem no Brasil, além de decretar condições para a equiparação das escolas de enfermagem existentes no país. É a partir desse período que se estabelece que somente poderiam usar o título de enfermeiro os profissionais diplomados por escola oficial, cujo diploma estivesse registrado no Departamento Nacional de Saúde Pública (Oguisso, 2001).

No ano de 1949, a Lei 775, de 6 de agosto, para regulamentação do ensino de enfermagem no país dispõe que, decorridos sete anos a partir da sua publicação, os hospitais, públicos ou privados, não poderiam mais contratar, para a direção dos serviços de enfermagem, outros profisssionais que não enfermeiros diplomados. Essa ordem foi de grande valia para a enfermagem e nunca foi revogada (Oguisso, 2001).

A enfermagem só passa a ser classificada como uma profissão técnico-científica de nível superior no Brasil em 1960, através da publicação da Lei nº 3.780, de 12 de julho. 
O Decreto 50.387, de 28 de março de 1961, definiu o exercício da enfermagem e todas as categorias que poderiam exercer legalmente a profissão, incluindo as obstetrizes e as parteiras. Havia, porém, uma certa falha na definição das funções das diferentes categorias profissionais. $\mathrm{O}$ enfermeiro já era diferenciado das demais categorias nesse documento e cabia a ele exercer funções acrescidas, tais como, administrar serviços de enfermagem, dirigir, inspecionar e ensinar em escolas de enfermagem, além de participar em bancas examinadoras de concursos (Oguisso, 2001).

A Associação Brasileira de Enfermagem (ABEn), foi a primeira organização profissional de enfermagem a surgir no país, em 1926, e foi a grande responsável pela posterior criação do Conselho Federal de Enfermagem (COFEN) e dos Conselhos Regionais de Enfermagem (COREN), através da Lei ${ }^{\circ}$ 5.905, de 13 de julho de 1973 (Oguisso, 2001).

Os atuais dispositivos legais do exercício da enfermagem são a Lei nº 7498 , de 25 de junho de 1986 e o Decreto 94.406, de 8 de junho de 1987, que estabelecem as categorias profissionais de enfermeiro, técnico e auxiliar de enfermagem e parteira, além de descrever as atividades que competem a cada categoria. Essa lei estabeleceu um prazo de 10 anos, a partir de sua vigência, para a obrigatoriedade de formação específica e extinção das demais categorias profissionais, como a de atendente de enfermagem. $\mathrm{Na}$ prática, devido à escassez de recursos humanos, a Lei $\mathrm{n}^{\circ} 8967$, de 28 de dezembro de 1994, veio assegurar a continuação do exercício profissional aos auxiliares de enfermagem admitidos antes da vigência da lei de 1986, para execução de atividades elementares de enfermagem, sob supervisão do enfermeiro (Oguisso, 2001).

Em 2001, foi publicada a Resolução $\mathrm{n}^{0}$ 3, de 7 de novembro, que institui as Diretrizes Curriculares Nacionais do Curso de Graduação em Enfermagem, elaboradas pelo Conselho Nacional de Educação e pela Câmara de Educação Superior. Esse documento define os princípios, fundamentos, condições e procedimentos para a formação de enfermeiros em nível nacional, determinando o perfil, os conhecimentos e as habilidades necessárias no processo. Segundo a Resolução, a formação do enfermeiro deve assumir um caráter generalista, humanista, crítico e reflexivo, capaz de dotar o profissional com competências e habilidades para o desenvolvimento da prática de atenção à saúde, da tomada de decisões, da comunicação, da liderança, da administração, do gerenciamento e da educação permanente (Brasil, 2001). 
A organização do trabalho em enfermagem caracteriza-se pela divisão de tarefas e pelo acompanhamento constante, seja por outros profissionais ou pelo próprio paciente/família. Regido pelas leis do mercado e sofrendo os reflexos da crise financeira, o trabalho em enfermagem tem sido apontado como uma significativa fonte de problemas éticos e de sofrimento moral (Varcoe, Pauly, Webster, \& Storch, 2012).

A falta de compreensão sobre o papel que os aspectos sociopolíticos de organização do trabalho desempenham na vivência do sofrimento moral, pode levar a uma culpabilização do profisssional e ao agravamento do desgaste relacionado ao trabalho, com consequências nos campos trabalhista e pessoal (Varcoe, Pauly, Webster, \& Storch, 2012). A compreensão do desenvolvimento da enfermagem enquanto profissão e a busca constante pela melhoria das condições de trabalho representam algumas das estratégias para evitar a ocorrência de eventos geradores de sofrimento moral no trabalho (Musto, Rodney, \& Vanderheide, 2015).

\subsection{SISTEMAS DE SAÚDE}

Durante muitos anos, o Estado português foi responsável, unicamente, pelos cuidados de saúde pública, período em que todos os demais cuidados de saúde eram de responsabilidade do indivíduo e da família. Esse cenário sofre as primeiras alterações em 1971, a partir da reforma do então sistema de saúde e assistência, que passa a garantir a todos os cidadãos o direito à saúde até aos limites dos recursos humanos, técnicos e financeiros disponíveis. Mas, apesar da reforma, não houveram mudanças significativas no modo de prestação de cuidados à saúde da população nos primeiros anos. Foi só em 1976, por força da Constituição da República, que o Serviço Nacional de Saúde (SNS) foi efetivamente criado, sendo implementado apenas três anos depois, em 1979. Os desafios dessa nova organização dos cuidados de saúde passavam pela limitação econômica e pela necessidade de integração das várias estruturas de cuidados de saúde existentes em um único sistema (Ordem dos Enfermeiros, 2004).

A baixa eficiência dos cuidados de saúde, aliada com o difícil acesso dos usuários aos serviços, revelava uma base estrutural frágil, que carecia de um modelo de organização e de gestão mais eficientes. Em 1990, a Lei de Bases da Saúde (Lei 48/90 de 
24 de Agosto) vêm definir as linhas gerais do atual sistema de saúde. A lei estabelece que do SNS fazem parte todas as entidades públicas que desenvolvem atividades de promoção, prevenção e tratamento na área da saúde, bem como todas as entidades privadas e todos os profissionais livres na mesma área, fortalecendo o direito dos cidadãos à saúde, independentemente de sua condição socioeconômica. Regula também a responsabilidade do Estado na definição da política de saúde, bem como na promoção e vigilância na sua execução (Ordem dos Enfermeiros, 2004).

Os desafios enfrentados para o completo êxito do SNS são muitos, entre eles, a disparidade na distribuição de renda, a assimetria na distribuição de recursos humanos concentrados nas grandes cidades - e as persistentes barreiras de acesso aos serviços, que prejudicam principalmente as famílias de menor renda. Com o objetivo de otimizar a eficiência do SNS, foi introduzida a Lei 27/2002 de 18 de Novembro e o Decreto-Lei $n^{\circ}$ 188/2003 de 20 de Agosto, referentes a estrutura e regime da gestão hospitalar, bem como o Decreto-Lei n ${ }^{\circ}$ 60/2003 de 1 de Abril, que definiu uma Rede de Cuidados de Saúde Primários. Os desafios para o SNS seguem, portanto, não tanto condicionados a esquemas jurídicos, mas principalmente a dificuldades financeiras e da adesão de profissionais, bem como da sociedade em geral (Ordem dos Enfermeiros, 2004).

No Brasil, até 1850, as atividades de saúde pública estavam limitadas a atribuições sanitárias menores e ao controle de navios e saúde dos portos. Foi somente no século XX que, pela primeira vez, se falou em políticas de saúde para enfrentar o quadro sanitário do país. Foram criadas, em 1923, as Caixas de Aposentadoria e Pensões (CAPs), substituídas, em 1933, pelos Institutos de Aposentadoria e Pensões (IAPs) - organizações de direito privado, criadas para grupos específicos de servidores e organizadas segundo princípios de seguro social, ou seja, um modelo em que os benefícios dependiam das contribuições dos segurados. Na mesma lógica, a criação do Instituto Nacional de Previdência Social, em 1966, manteve a prática privativa e empresarial da medicina (CONASS, 2011).

No início da década de 1970, uma acentuada crise econômica forçou uma reforma na estruturação da assistência. Com o objetivo de democratizar a saúde no Brasil, foi organizado, no final da década de 1970, o Movimento da Reforma Sanitária, responsável pela organização da $8^{\circ}$ Conferência Nacional de Saúde, em março de 1986, ocasião em que foi redigido o texto que viria a ser o artigo 196 da Constituição Federal de 1988, que define a saúde como um direito de todos e um dever do estado (CONASS, 2011). 
A Constituição de 1988 firmou as bases legais para a organização do Sistema Único de Saúde (SUS). Sua complementação veio através da aprovação das Leis Orgânicas da Saúde nº 8080/90, que dispõe sobre as condições necessárias à promoção, proteção e recuperação da saúde, organização e funcionamento dos serviços correspondentes (BRASIL, 1990) e da lei no 8142/90, que dispõe sobre a participação da comunidade na gestão do SUS e seu financiamento (BRASIL, 1990).

A partir de então, ficou formado o novo aparato institucional da gestão das políticas de saúde no Brasil (Giovanella \& Mendonça, 2008). Os maiores desafios para o êxito do Sistema Único de Saúde estão relacionados com a organização e a gestão do modelo de atenção, que migra de um cenário com prevalência de condições agudas, para um aumento acentuado das condições crônicas, exigindo uma reestruturação dos serviços como um todo. Além disso, os desafios do subfinanciamento dos serviços, que coloca em causa a máxima constitucional da garantia de saúde como um direito de todos e um dever do estado (Paim, Travassos, Almeida, Bahia, \& Macinko, 2011).

A similaridade dos sistemas de saúde vigentes nos dois países e dos próprios desafios na oferta dos cuidados pode determinar semelhanças com relação aos problemas éticos e ao nível de sofrimento moral vivenciado pelos enfermeiros. Estudos comparativos podem permitir a identificação de fatores influenciadores de bons e maus resultados, conduzindo à reflexão crítica sobre aspectos do desenvolvimento e organização dos sistemas de saúde e da própria profissão nos dois países (Monteiro \& Oguisso, 2007).

\subsection{CENÁRIO ATUAL}

Portugal é um país localizado no sudoeste da Europa, cujo território compreende uma zona continental e duas regiões autônomas: dos Açores e da Madeira. Com uma área total de 92.090 mil quilômetros quadrados, Portugal têm pouco mais de 10 milhões de habitantes. É considerado um país desenvolvido, com elevado Índice de Desenvolvimento Humano e qualidade de vida. Os principais problemas de saúde estão associados às doenças crônicas não-transmissíveis, nomeadamente as doenças cardiovasculares, cerebrovasculares e o cancro (WHO, 2004). 
Os desafios para a enfermagem, em um cenário de acentuado envelhecimento populacional consistem, entre outros, na escassez de recursos humanos e nas assimetrias regionais na alocação de profissionais (Ordem dos Enfermeiros, 2004). A crise financeira global, que se instalou a partir de 2008, levou a importantes restrições no financiamento do Serviço Nacional de Saúde português, reacendendo debates acerca da distribuição justa dos níveis de saúde e da qualidade dos serviços. Para a enfermagem, fez aumentar o número de enfermeiros emigrantes, principalmente devido aos baixos salários e ao baixo índice de recrutamento (OPSS, 2016). O número de enfermeiros portugueses, registrados na Ordem dos Enfermeiros, em 2015, era de cerca de 67.893 profissionais (Ordem dos Enfermeiros, 2017).

Nesse contexto, a enfermagem portuguesa confronta-se, principalmente, com problemas relacionados com a informação, o acompanhamento em fim de vida, o processo de tomada de decisão, o respeito pela pessoa e o sigilo profissional (Nunes, 2006).

O Brasil é um país de dimensões continentais, cujo território possui 8,5 milhões de quilômetros quadrados e a população ultrapassa os 200 milhões de habitantes. O país se divide em cinco regiões geográficas, nomeadamente, Norte, Nordeste, Centro-Oeste, Sudeste e Sul, com distintas características demográficas, econômicas, sociais, culturais e de saúde, além de amplas desigualdades internas (Paim, Travassos, Almeida, Bahia, \& Macinko, 2011).

No extremo Sul do país, o Rio Grande do Sul possui uma das melhores economias e um dos maiores Índices de Desenvolvimento Humano do país. Segundo dados do Instituto Brasileiro de Geografia e Estatística, a população estimada no Rio Grande do Sul em 2016 era de cerca de 11 milhões de habitantes (IBGE, 2017). Em 2016 estavam registrados no Conselho Regional de Enfermagem do Rio Grande do Sul 22.870 enfermeiros, 79.618 técnicos em enfermagem e 16.224 auxiliares de enfermagem, num total de 118.712 mil profissionais de enfermagem (Cofen, 2017). Os desafios para enfermagem brasileira, bem como para a enfermagem Rio Grandense, estão relacionados com as restrições de financiamento, os problemas de infraestrutura e a carência de efetivação de recursos humanos (Paim, Travassos, Almeida, Bahia, \& Macinko, 2011).

No Brasil, o contexto e a organização do sistema de saúde deixa os profissionais de enfermagem mais expostos a problemas éticos que surgem nas relações com pacientes, 
colegas e com a própria gestão do serviço, principalmente relacionados com os processos de trabalho, comunicação, autonomia, recursos e apoio institucional (Nora, Zoboli, \& Vieira, 2015).

Portugal e Brasil guardam uma estreita relação de diferenças e similaridades históricas no que diz respeito ao desenvolvimento da enfermagem enquanto profissão. A influência das Santas Casas de Misericórdia nos cuidados, o apoio da Fundação Rockefeller na criação das escolas de enfermagem e a influência da teórica Wanda Horta na enfermagem brasileira e portuguesa, marcam o intercâmbio entre os dois países. A institucionalização do ensino da enfermagem, entretanto, ocorreu de forma distinta, o que determinou diferenças no que tange à divisão social do trabalho (Monteiro \& Oguisso, 2007).

O Rio Grande do Sul possui um território três vezes maior em quilômetros quadrados, quando comparado com Portugal, apesar de abrigar um número populacional semelhante. Por outro lado, o número de enfermeiros registrados nos respectivos órgãos de classe difere em grande escala, principalmente quando se leva em consideração os profissionais de enfermagem - técnicos e auxiliares de enfermagem, ativos no Rio Grande do Sul (Ordem dos Enfermeiros, 2017) (Cofen, 2017).

Os sistemas de saúde vigentes nos dois países também guardam estreita relação em suas políticas públicas, enquanto que a organização geral do trabalho é diferenciada. Os enfermeiros influenciam e são influenciados pelas complexas estruturas sociopolíticas, pela organização do contexto de trabalho e pela relação que mantem com as outras personagens do cuidado (Musto, Rodney, \& Vanderheide, 2015) e, é nessa complexidade que os problemas éticos têm lugar (Leuter, Petrucci, Mattei, Tabassi, \& Lancia, 2013). Segundo Lützén, Dahlqvist, Eriksson, \& Norberg (2006), enfermeiros que não estejam preparados para lidar com esse tipo de situação moralmente problemática, tem maior risco de vivenciar o sofrimento moral.

O contexto de trabalho pode, portanto, influenciar a frequência e a intensidade da vivência de situações moralmente problemática e do sofrimento moral. Ambientes de trabalho éticos podem, apesar dos desafios, promover uma prática ética e baseada em valores, considerado requisito fundamental para um cuidado seguro e de qualidade (Lützén et al., 2010). 
PARTE II - ESTUDOS EMPÍRICOS 


\section{DO PROBLEMA AO DESENHO DA INVESTIGAÇÃO}

Este capítulo define o problema de investigação e justifica a pertinência do tema, frente a conjuntura atual do trabalho em enfermagem. Descreve os objetivos do trabalho e o caminho metodológico percorrido no desenvolvimento da tese.

\subsection{DEFINIÇÃO DO PROBLEMA DE INVESTIGAÇÃO}

$\mathrm{Na}$ área da ética da enfermagem, o sofrimento moral é um tema que desperta interesse de investigadores por todo o mundo, principalmente nos últimos anos, como mostra um recente estudo bibliométrico, que analisou estudos publicados entre 1946 e 2014 (Vosner, Zeleznik, Kokol, Vosner, \& Zavrsnik, 2016). Esse aumento no número de publicações acerca do sofrimento moral pode ter relação com os desafios em termos de avanços tecnológicos, restrições de financiamento, falta de recursos humanos e conflitos sociais e culturais, representando barreiras ao compromisso moral do enfermeiro (Austin, 2016).

A enfermagem é uma profissão fundamentada na ética, nos valores e no compromisso do enfermeiro em ajudar aqueles sob seus cuidados. Caracteriza-se pela complexidade do cuidado contínuo e pela proximidade nas relações com pacientes, familiares e outros membros da equipe de saúde. Os desafios da prática profissional acabam por expor o enfermeiro a um significativo número de situações éticas difíceis, exigindo dos profissionais expertise para tomada de decisão e enfrentamento de problemas (Barlem \& Ramos, 2015).

Historicamente atrelada aos conceitos de religiosidade e caridade, a enfermagem mantém ainda nos dias de hoje a imagem de uma profissão de doação e sacrifício (Barlem, Lunardi, Lunardi, Tomaschewski-Barlem, \& Silveira, 2013). Nesse contexto, é desafiador para o profissional falar sobre sofrimento moral, uma vez que pode ser visto como uma fraqueza ou uma incapacidade da pessoa para lidar com o estresse inerente à profissão, condicionando o profissional a manter o silêncio e levando a uma aceitação desse sofrimento como parte da rotina de trabalho (Austin, 2016). 
Para identificar o sofrimento moral, desenvolver intervenções e ajudar a prevenir consequências negativas, perceber o que está na raiz do problema é uma estratégia fundamental (Rathert, May, \& Chung, 2016). Os instrumentos e as escalas podem ser importantes aliados no processo de identificação do sofrimento moral, desde que sejam confiáveis e possam garantir a legitimidade dos resultados (Medeiros, et al., 2015).

Os estudos acerca do sofrimento moral têm sido realizados, sobretudo, em contextos hospitalares, principalmente nas áreas de cuidados intensivos (Borhani, Mohammadi, \& Roshanzadeh, 2015) e de emergência (Trautmann, Epstein, Rovnyak, \& Snyder, 2015). A escala mais utilizada para investigar o sofrimento moral foi construída no contexto dos cuidados intensivos, sendo considerada mais adequada para medir sofrimento moral em enfermeiros que cuidam de pacientes adultos em hospitais (Corley, Elswick, Gorman, \& Clor, 2001).

Os estudos sobre sofrimento moral desenvolvidos em contextos de cuidado extra hospitalares são, usualmente, de abordagem qualitativa (Maluwa, Andre, Ndebele, \& Chilemba, 2012) (Spenceley, Witcher, Hagen, Hall, \& Kardolus-Wilson, 2015). Em contextos do cuidado extra hospitalares, há, entretanto, evidências de possibilidade de utilização de escalas para identificar o sofrimento moral (Eizenberg, Desivilya, \& Hirschfeld, 2009). A escala desenvolvida por Eizenberg, Desivilya \& Hirschfeld (2009) caracteriza-se por sua sensibilidade cultural; foi construída especificamente para o contexto de saúde iraniano, o que pode comprometer a sua utilização em cenários de outras culturas.

A literatura sustenta que, embora possa existir um grau de variação individual relacionado ao sofrimento moral, este é um fenômeno concreto, com restrições identificáveis e características definidoras claras (Weber, 2016). Estudos na área do sofrimento moral podem gerar resultados positivos em aspectos relacionados com a qualidade e os custos dos cuidados de enfermagem (Deady \& McCarthy, 2010), bem como com a retenção e a satisfação profissional (Trautmann, Epstein, Rovnyak, \& Snyder, 2015). O sofrimento moral é considerado um relevante objeto de estudo e investigação na área da enfermagem (McCarthy \& Gastmans, 2015). 


\subsection{OBJETIVO GERAL}

Analisar o fenômeno do sofrimento moral em enfermeiros brasileiros e portugueses.

\subsection{OBJETIVOS ESPECÍFICOS}

- Identificar fatores de risco para sofrimento moral em enfermeiros na literatura científica de enfermagem;

- Construir e buscar evidências de validade da escala de risco de sofrimento moral em uma amostra de enfermeiros assistenciais do Brasil e de Portugal;

- Descrever a frequência de vivência de fatores de risco de sofrimento moral em uma amostra de enfermeiros assistenciais do Brasil e de Portugal;

- Verificar a associação entre o risco de sofrimento moral e as variáveis sociodemográficas, formação, atividade profissional e local de trabalho em uma amostra de enfermeiros assistenciais do Brasil e de Portugal.

\subsection{DESENHO DE INVESTIGAÇÃO}

Esta tese se insere no acordo de dupla titulação do Doutoramento em Enfermagem, firmado entre o Instituto de Ciências da Saúde da Universidade Católica Portuguesa e a Escola de Enfermagem da Universidade de São Paulo. A realização de parte do percurso acadêmico em outro país possibilitou uma investigação luso-brasileira para integração das práticas, dos saberes e da ética da enfermagem dos dois países.

Como parte projeto de investigação 'O dever-ser ético e os problemas cotidianos da prática clínica - D2B', desenvolvido por pesquisadores do Centro de Investigação Interdisciplinar em Saúde da Universidade Católica Portuguesa, sob coordenação da 
professora doutora Margarida M Vieira, essa investigação vincula uma de suas tarefas à Escola de Enfermagem da Universidade de São Paulo, sob coordenação da professora doutora Elma Zoboli.

Para operacionalizar o estudo, foi elaborado um desenho de investigação, que lista todas as etapas percorridas no intuito de responder adequadamente a cada um dos objetivos específicos propostos e, assim, obter os resultados pretendidos (Quadro 1).

\section{Quadro 1 - Relação entre a finalidade do estudo e o plano de investigação}

\begin{tabular}{|c|c|c|c|c|c|}
\hline Fase & Finalidade & Técnica & $\begin{array}{c}\text { Recolha de } \\
\text { dados }\end{array}$ & $\begin{array}{c}\text { Fonte de } \\
\text { dados }\end{array}$ & $\begin{array}{c}\text { Análise de } \\
\text { dados }\end{array}$ \\
\hline I & $\begin{array}{c}\text { Identificar } \\
\text { fatores de risco } \\
\text { para sofrimento } \\
\text { moral em } \\
\text { enfermeiros }\end{array}$ & $\begin{array}{l}\text { Revisão da } \\
\text { literatura }\end{array}$ & $\begin{array}{l}\text { Scoping } \\
\text { review }\end{array}$ & $\begin{array}{c}\text { Bases de } \\
\text { dados online }\end{array}$ & $\begin{array}{l}\text { Análise } \\
\text { numérica e } \\
\text { temática }\end{array}$ \\
\hline \multirow[b]{2}{*}{ II } & $\begin{array}{l}\text { Construir uma } \\
\text { escala }\end{array}$ & $\begin{array}{l}\text { Validação de } \\
\text { conteúdo }\end{array}$ & $\begin{array}{l}\text { Lista de itens } \\
\text { identificados }\end{array}$ & $\begin{array}{c}\text { Grupo de } \\
\text { juízes do } \\
\text { Brasil e de } \\
\text { Portugal }\end{array}$ & $\begin{array}{l}\text { Análise de } \\
\text { juízes }\end{array}$ \\
\hline & $\begin{array}{l}\text { Buscar } \\
\text { evidências de } \\
\text { validade da } \\
\text { escala }\end{array}$ & $\begin{array}{l}\text { Análise } \\
\text { fatorial }\end{array}$ & $\begin{array}{l}\text { Versão pré } \\
\text { final } \\
\text { (53 itens) }\end{array}$ & $\begin{array}{c}\text { Amostra de } \\
\text { enfermeiros do } \\
\text { Brasil e de } \\
\text { Portugal }\end{array}$ & $\begin{array}{c}\text { Alpha de } \\
\text { Cronbach, } \\
\text { KMO, Bartlett }\end{array}$ \\
\hline III & $\begin{array}{c}\text { Descrever a } \\
\text { frequência da } \\
\text { vivência dos } \\
\text { fatores de risco } \\
\text { de sofrimento } \\
\text { moral nas } \\
\text { amostras }\end{array}$ & $\begin{array}{l}\text { Estatística } \\
\text { descritiva }\end{array}$ & ERSM* & $\begin{array}{l}\text { Amostra de } \\
\text { enfermeiros do } \\
\text { Brasil e de } \\
\text { Portugal }\end{array}$ & $\begin{array}{l}\text { Média, desvio } \\
\text { padrão, mínimo } \\
\text { e máximo, } \\
\text { amostra e } \\
\text { frequência } \\
\text { relativa }\end{array}$ \\
\hline IV & $\begin{array}{c}\text { Verificar } \\
\text { associações } \\
\text { entre as } \\
\text { variáveis }\end{array}$ & $\begin{array}{l}\text { Estatística } \\
\text { inferencial }\end{array}$ & ERSM* & $\begin{array}{c}\text { Amostra de } \\
\text { enfermeiros do } \\
\text { Brasil e de } \\
\text { Portugal }\end{array}$ & $\begin{array}{l}\text { Teste t de } \\
\text { Student e } \\
\text { ANOVA }\end{array}$ \\
\hline
\end{tabular}

*ERSM = Escala de Risco de Sofrimento Moral

No Brasil, a operacionalização do estudo deu-se através do contato com representantes do COREN/RS, por e-mail, em março de 2015. A instituição solicitou o resumo do projeto de investigação, o documento de aprovação do Comitê de Ética em Pesquisa e o link para aceder ao questionário (Anexo I), que foram enviados em agosto de 2015, sendo o apoio confirmado em março de 2016 (Anexo II). Em 11 de março de 
2016 foi lançado, no site oficial do COREN-RS, a notícia: "Pesquisa avalia situações da prática de enfermeiros(as) no RS. A Escola de Enfermagem da Universidade de São Paulo (EEUSP) e a Universidade Católica Portuguesa (UCP) realizam uma pesquisa que visa avaliar as situações da prática dos(as) enfermeiros(as) trabalhadores(as) de instituições de saúde do Rio Grande do Sul. Podem participar enfermeiros(as) do Rio Grande do Sul que atuam em qualquer campo assistencial ou serviço da rede de saúde, respondendo o instrumento eletrônico e divulgando em suas redes sociais e profissionais a pesquisa" (Anexo III).

Em Portugal, a operacionalização do estudo deu-se através do apoio do Instituto de Ciências da Saúde da Universidade Católica Portuguesa, para o envio do link de acesso ao instrumento para os ex-alunos de licenciatura e mestrado da própria instituição.

\subsection{MÉTODO}

As considerações metodológicas descrevem e justificam o tipo de estudo, o cenário, a escolha da amostra e os processos que envolveram a recolha e a análise dos dados.

\subsubsection{Tipo de estudo}

Trata-se de um estudo metodológico para desenvolvimento, busca de evidências de validade e refinamento de instrumento de pesquisa (Polit \& Beck, 2011). O processo de construção e análise psicométrica foi baseado no modelo da teoria clássica dos testes, descrito por DeVellis (2017).

\subsubsection{Cenário do estudo}

A investigação foi realizada em dois cenários: no sul do Brasil e em Portugal. A escolha dos cenários considerou critérios de tamanho populacional para a 
comparabilidade dos resultados, bem como critérios de acessibilidade à informação, recursos e suporte.

As populações de Portugal e do Rio Grande do Sul são semelhantes em número, ao passo que a população de enfermeiros difere em grande escala. Em 2015, Portugal somava pouco mais de 10 milhões de habitantes (www.portugal.gov.pt) e o Rio Grande do Sul, cerca de 11 milhões de habitantes (www.ibge.gov.br). Com relação ao número de enfermeiros, Portugal contava com 67.893 profissionais registrados na Ordem dos Enfermeiros, em 2015, enquanto que o Rio Grande do Sul apresentava registros de 22.870 enfermeiros. Entretanto, o Rio Grande do Sul conta ainda com 79.618 técnicos em enfermagem e 16.224 auxiliares de enfermagem registrados, num total de 118.712 profissionais de enfermagem.

A razão é de cerca de 6 enfermeiros para cada mil habitantes em Portugal e de cerca de 2 enfermeiros para cada mil habitantes no Rio Grande do Sul. Quando consideramos os demais profissionais de enfermagem registrados no Rio Grande do Sul, somando técnicos e auxiliares de enfermagem, este coeficiente sobe para uma relação de cerca de 13 profissionais de enfermagem para cada mil habitantes.

\subsubsection{Amostra}

A amostra foi constituída por enfermeiros assistenciais, registrados no Conselho Regional de Enfermagem do Rio Grande do Sul e na Ordem dos Enfermeiros de Portugal, que aceitaram aderir ao estudo de forma livre e voluntária. O instrumento de recolha de dados foi enviado de forma eletrônica, constituindo técnica de amostragem não aleatória por conveniência (Polit \& Beck, 2011).

No Brasil, a estratégia de recolha de dados envolveu: a inserção da escala em uma plataforma online - GoogleDocs (Anexo IV); a publicação de notícia-convite pelo Conselho Regional de Enfermagem do Rio Grande do Sul em seu site oficial (Anexo III); a divulgação da pesquisa em rede social (Anexo V); o envio de convite com link de acesso para ex-alunos e pós-graduandos em enfermagem de duas universidades da região (Anexo VI); e divulgação do tipo 'bola de neve' (Polit \& Beck, 2011). 
Em Portugal, a estratégia de recolha de dados envolveu: a inserção da escala no software de investigação QUALTRICS: Online Survey Software \& Insight Platform, que permite criar, distribuir e controlar as respostas recebidas, além de tratar os dados (Anexo VII); e o envio do link de acesso ao instrumento para ex-alunos do Instituto de Ciências da Saúde da Universidade Católica Portuguesa (Anexo VIII).

Todos os enfermeiros atuantes na prática clínica assistencial foram considerados aptos a participar do estudo. Foram excluídos os enfermeiros cuja atividade principal na enfermagem fosse nas áreas de ensino e pesquisa. $\mathrm{O}$ cálculo do tamanho de amostra considerou o referencial de DeVellis (2017) para a construção de escalas, estabelecido entre cerca de 5 a 10 sujeitos por cada item da escala.

A caracterização da amostra foi realizada através de variáveis sociodemográficas, de formação, de atividade profissional e de local de trabalho. As variáveis são descritas na Tabela 1, juntamente com o método de recolha de dados e o tipo e operacionalização da variável.

Tabela 1 - Caracterização das amostras

\begin{tabular}{|c|c|c|}
\hline Variável & Método de recolha dos dados & $\begin{array}{c}\text { Tipo e operacionalização } \\
\text { da variável }\end{array}$ \\
\hline \multicolumn{3}{|c|}{1 SOCIODEMOGRÁFICAS } \\
\hline 1.1 Sexo & $\begin{array}{l}\text { Referida em 'masculino' e } \\
\text { 'feminino' }\end{array}$ & Categórica dicotômica \\
\hline 1.2 Idade & Referida em anos completos & Numérica discreta \\
\hline 1.3 Estado civil & $\begin{array}{l}\text { Referida em 'casado(a)/em união } \\
\text { estável', 'separado(a)/divorciado(a)', } \\
\text { 'solteiro', 'viúvo(a)' e 'outro' }\end{array}$ & $\begin{array}{c}\text { Categórica politômica } \\
\text { nominal }\end{array}$ \\
\hline
\end{tabular}

\section{FORMAÇÃO}

2.1 Especialização, Mestrado, Doutorado

2.2 Formação em ética ou bioética

2.2.1 Se sim, onde
Referida em quantidade, tipo e ano de conclusão
Numéricas discretas

Referida em 'sim' ou 'não'

Categórica dicotômica

Referida em 'local de trabalho', 'instituição de ensino', 'evento científico' ou 'outro'

Categórica politômica nominal

\section{ATIVIDADE PROFISSIONAL}

3.1 Tempo como enfermeiro
Referida em anos completos

Numérica discreta 
3.2 Tipo de vínculo empregatício

\subsection{Horas de} contrato

\subsection{Costuma}

ultrapassar as horas de contrato

3.4.1 Se sim, as horas extras são pagas

3.5 Local de trabalho

3.6 Tempo de trabalho no serviço atual

\subsection{Mantem quantos} vínculos empregatícios

3.8 Cidade onde trabalha

3.9 Rendimento mensal em relação ao salário mínimo brasileiro $(R \$ 788,00)$
Referida em 'estatutário', 'contrato CLT', ou 'outro'

Referida em 'até $35 \mathrm{~h}$ ', '36h a 40h' ou 'mais de 40h'

Referida em 'sim' ou 'não'

Referida em 'sim' ou 'não'

Referida em 'atenção básica', 'atenção hospitalar' ou 'outro'

Referida em anos completos

Referida em ' 1 ', ' 2 ' ou '3 ou mais'

Aberta

Referida em 'de 1 até 3', 'mais de 3 até 5 ', 'mais de 5 até 7 ', 'mais de 7 até 10 ' ou 'mais de 10 '
Categórica politômica nominal

Categórica politômica nominal

Categórica dicotômica

Categórica dicotômica

Categórica politômica nominal

Numérica discreta

Categórica politômica ordinal

Nominal

Categórica politômica ordinal

\section{LOCAL DE TRABALHO}

4.1 Satisfação geral, qualidade, colaboração, comunicação, envolvimento em decisões clínicas e éticas, autonomia

Referidas em 'muito insatisfeito', 'insatisfeito', 'pouco satisfeito', 'satisfeito' ou 'muito satisfeito'

Referida em 'nunca', 'raramente', 'frequentemente' ou 'sempre'

Categórica politômica ordinal

Múltipla escolha: 'mal estar', 'raiva', 'cansaço', 'tristeza', 'desconforto',

\subsection{Vivenciar essas situações lhe provoca}

Categórica politômica ordinal

$$
\text { nominal }
$$

'angústia', 'inapetência',

'frustração', insónia', 'impotência',

'dor', 'insatisfação', dor de cabeça', 'sofrimento', desesperança' ou 'outros' 
As variáveis para caracterização da amostra foram adaptadas para o contexto português. Considerou-se necessária a adequação das variáveis: 'tipo de contrato de trabalho', 'unidade/local de trabalho', 'região ou distrito/cidade onde trabalha' e 'rendimento mensal'. Os detalhes estão descritos na Tabela 2.

Tabela 2 - Adaptação cultural das variáveis de caracterização da amostra para Portugal

\begin{tabular}{|c|c|c|}
\hline Variável & Método de recolha & $\begin{array}{c}\text { Tipo e operacionalização } \\
\text { da variável }\end{array}$ \\
\hline \multicolumn{3}{|c|}{3 ATIVIDADE PROFISSIONAL } \\
\hline $\begin{array}{l}\text { 3.2 Tipo de contrato } \\
\text { de trabalho }\end{array}$ & $\begin{array}{c}\text { Referida em 'sem contrato', 'liberal', } \\
\text { 'a termo', 'sem termo', } \\
\text { 'reformado(a)' ou 'outro' }\end{array}$ & $\begin{array}{c}\text { Categórica politômica } \\
\text { nominal }\end{array}$ \\
\hline $\begin{array}{l}\text { 3.5 Unidade ou local } \\
\text { de trabalho }\end{array}$ & $\begin{array}{c}\text { Referida em 'UCSP', 'UCC', 'USF', } \\
\text { 'USP', 'ECCI', 'hospital ou } \\
\text { equivalente' ou 'outro local' }\end{array}$ & $\begin{array}{c}\text { Categórica politômica } \\
\text { nominal }\end{array}$ \\
\hline $\begin{array}{l}\text { 3.8 Região ou } \\
\text { distrito onde } \\
\text { trabalha }\end{array}$ & $\begin{array}{c}\text { Referida em 'Aveiro', 'Beja', } \\
\text { 'Braga', 'Bragança', 'Castelo } \\
\text { Branco', 'Coimbra', 'Évora', 'Faro', } \\
\text { 'Guarda', 'Leiria', 'Lisboa', } \\
\text { 'Portalegre', 'Porto', 'Santarém', } \\
\text { 'Setúbal', 'Viana do Castelo', 'Vila } \\
\text { Real', 'Viseu', 'Região Autónoma } \\
\text { dos Açores' ou 'Região Autónoma } \\
\text { da Madeira' }\end{array}$ & $\begin{array}{c}\text { Categórica politômica } \\
\text { nominal }\end{array}$ \\
\hline $\begin{array}{l}3.9 \text { Rendimento } \\
\text { mensal em relação } \\
\text { ao salário base da } \\
\text { enfermagem em } \\
\text { Portugal }(€ 1.020,06)\end{array}$ & $\begin{array}{l}\text { Referida em 'inferior', 'igual' ou } \\
\text { 'superior' }\end{array}$ & $\begin{array}{c}\text { Categórica politômica } \\
\text { ordinal }\end{array}$ \\
\hline
\end{tabular}

Para caracterizar os participantes quanto a situação relativa ao sofrimento moral vivenciado, foram acrescidas algumas variáveis, descritas na Tabela 3, juntamente com o método de recolha dos dados, o seu tipo e operacionalização.

Tabela 3 - Variáveis de caracterização do sofrimento moral

\begin{tabular}{ccc}
\hline Variável & Método de recolha dos dados & $\begin{array}{c}\text { Tipo e operacionalização } \\
\text { da variável }\end{array}$ \\
\hline 5 SOFRIMENTO MORAL \\
\hline
\end{tabular}




\begin{tabular}{|c|c|c|}
\hline $\begin{array}{l}5.1 \text { Os fatores de } \\
\text { risco assinalados lhe } \\
\text { provocam sofrimento } \\
\text { moral }\end{array}$ & $\begin{array}{l}\text { Referida em 'nunca', 'raramente', } \\
\text { 'frequentemente' ou 'sempre' }\end{array}$ & $\begin{array}{c}\text { Categórica politômica } \\
\text { ordinal }\end{array}$ \\
\hline $\begin{array}{l}5.2 \text { Considera que } \\
\text { está em sofrimento } \\
\text { moral }\end{array}$ & Referida em 'sim' ou 'não' & Categórica dicotômica \\
\hline $\begin{array}{l}5.3 \text { Considera que já } \\
\text { vivenciou sofrimento } \\
\text { moral anteriormente }\end{array}$ & $\begin{array}{l}\text { Referida em 'nunca', 'uma vez' ou } \\
\text { 'mais de uma vez' }\end{array}$ & $\begin{array}{c}\text { Categórica politômica } \\
\text { ordinal }\end{array}$ \\
\hline $\begin{array}{l}\text { 5.4 Tem liberdade } \\
\text { para falar sobre } \\
\text { sofrimento moral } \\
\text { com a chefia/colegas }\end{array}$ & $\begin{array}{l}\text { Referida em 'nunca', 'raramente', } \\
\text { 'frequentemente' ou 'sempre' }\end{array}$ & $\begin{array}{c}\text { Categórica politômica } \\
\text { ordinal }\end{array}$ \\
\hline $\begin{array}{c}5.5 \text { Se pudesse, } \\
\text { deixaria o trabalho } \\
\text { atual por sofrimento } \\
\text { moral }\end{array}$ & Referida em 'sim' ou 'não' & Categórica dicotômica \\
\hline $\begin{array}{l}\text { 5.5.1 Se sim, que tipo } \\
\text { de trabalho } \\
\text { procuraria }\end{array}$ & $\begin{array}{l}\text { Referida em 'serviço semelhante', } \\
\text { 'outro tipo de serviço' ou 'trabalho } \\
\text { não relacionado com a enfermagem' }\end{array}$ & $\begin{array}{c}\text { Categórica politômica } \\
\text { nominal }\end{array}$ \\
\hline $\begin{array}{l}\text { 5.6 Já alguma vez } \\
\text { deixou um trabalho } \\
\text { por sofrimento moral }\end{array}$ & Referida em 'sim' ou 'não' & Categórica dicotômica \\
\hline
\end{tabular}

\subsubsection{Recolha e análise dos dados}

Para responder aos objetivos da investigação e efetivar o plano proposto, o processo de recolha de dados envolveu uma revisão da literatura e uma análise de juízes, além da recolha de dados de uma amostra de enfermeiros do sul do Brasil e de Portugal para a busca de evidências de validade. Os procedimentos de recolha e análise dos dados são detalhadamente descritos a seguir. 


\subsubsection{Revisão da literatura}

Para realizar a busca e a análise da literatura, com vistas a identificar fatores de risco para sofrimento moral em enfermeiros, foi utilizado o método de Scoping Review, descrito pela primeira vez por Arksey e O’Malley (2005) e, posteriormente, aprimorado por Levac et al. (2010). A Scoping Review é um tipo de revisão da literatura utilizada para mapear produções relevantes no campo de interesse. Pode ser o método de escolha para pesquisadores que estão a investigar temas amplos, onde diferentes desenhos de estudo são úteis. Diferencia-se dos estudos de revisão sistemática da literatura por não partir de uma pergunta de investigação muito específica e por não se preocupar com a avaliação da qualidade dos estudos incluídos (Arksey \& O’Malley, 2005).

O objetivo principal deste tipo de revisão da literatura é, portanto, realizar um rápido mapeamento dos conceitos fundamentais sob investigação, com foco voltado para a identificação da literatura relevante, em termos de amplitude e de profundidade, independentemente do desenho do estudo. Foi o método de escolha, principalmente, porque pode se mostrar eficaz para resumir e identificar resultados de uma ampla gama de estudos na área sob investigação, auxiliando na formulação de políticas e programas ou, no caso, na construção de instrumentos de avaliação (Arksey \& O’Malley, 2005). O objetivo desse estudo foi identificar, mapear e reinterpretar analiticamente os achados acerca de fatores de risco para sofrimento moral em enfermeiros (Levac, Colquhoun, \& O’Brien, 2010).

A fim de sistematizar o método e auxiliar os autores no processo de investigação, Arksey e O’Malley (2005) fornecem um quadro metodológico que compreende a descrição dos cinco estágios necessários para o desenvolvimento de uma Scoping Review, mais um sexto estágio considerado opcional, nomeadamente: (1) a identificação da questão de pesquisa; (2) a identificação dos estudos pertinentes; (3) a seleção dos estudos; (4) o mapeamento dos dados; (5) e o agrupamento, resumo e relato dos dados; e (6) a consulta com peritos para validar os resultados da revisão.

\section{Identificação da questão de pesquisa}

A questão de pesquisa deve ser de tal modo aberta, que possibilite uma grande amplitude nos resultados das buscas. Aliar um propósito claro com uma pergunta bem 
definida pode auxiliar na identificação e na seleção dos estudos mais pertinentes (Arksey \& O’Malley, 2005). Nesse estudo, a questão de investigação foi: 'O que se sabe sobre fatores de risco para sofrimento moral na enfermagem?'.

\section{Identificação dos estudos pertinentes}

Para a identificação dos estudos pertinentes, é importante definir a abrangência dos resultados em termos de período de tempo e linguagem, considerando o orçamento e o tempo de que o pesquisador dispõe. É preciso considerar quais as bases de dados que serão incluídas e quais os termos e os conceitos-chave mais apropriados para favorecer a busca, além de considerar a busca por listas de referência, principalmente de outras revisões da literatura, se houver, para garantir que todos os estudos relevantes foram incluídos. Um ponto de saturação dos achados pode ser identificado quando não for mais possível encontrar referências novas (Arksey \& O’Malley, 2005).

Para ser o mais inclusivo possível, a estratégia de busca desse estudo considerou trabalhos originais e teóricos, incluindo teses, dissertações, editoriais e literatura cinzenta. O período de tempo foi estabelecido entre os anos de 1984 e 2014, incluindo, portanto, o ano em que o termo 'sofrimento moral' foi descrito pela primeira vez na literatura de enfermagem. Os idiomas foram limitados a inglês, espanhol e português, considerando os conhecimentos do investigador.

Múltiplas fontes de dados foram verificadas, incluindo bases de dados eletrônicas e listas de referências. As bases de dados verificadas foram: US National Library of Medicine (PubMed), Literatura Latino-Americana e do Caribe em Ciências da Saúde [Latin American and Caribbean Health Sciences] (LILACS), Índice Bibliográfico Espanhol de Ciências da Saúde [Bibliographical Index Spanish Health Sciences] (IBECS), Medical Literature Analysis and Retrieval System Online (MEDLINE), Scientific Electronic Library Online (SciELO); e o Repositório Científico de Acesso Aberto de Portugal (RCAAP). O Google Scholar foi utilizado, estrategicamente, para identificar estudos não indexados em bases de dados de saúde.

O conceito chave utilizado nas buscas foi o termo 'sofrimento moral' que, apesar de não ser um Descritor em Ciências da Saúde (Decs) ou um Medical Subject Headings (Mesh), é o principal termo sob investigação e foi considerado fundamental para identificar todos os estudos que utilizaram esse termo no seu título e/ou resumo, associado com os Decs/Mesh 'fator de risco/risk factor' e 'enferm*/nurs *' - através do operador 
booleano 'AND'. Essa estratégia foi capaz de identificar 81 estudos a partir das pesquisas nas bases de dados de saúde e cerca de 5.730 resultados do Google Scholar. Para otimizar a análise dos estudos identificados pelo Google Scholar, estes foram ordenados por relevância e os 200 primeiros foram analisados. A busca pelas listas de referência incorporou mais 18 estudos ao processo.

\section{Seleção dos estudos}

Como o número de estudos identificados costuma ser extenso, estabelecer critérios de inclusão e exclusão é fundamental, mas, diferentemente das revisões sistemáticas, esses critérios são definidos post hoc, com base no aumento da familiaridade do investigador com a literatura (Arksey \& O’Malley, 2005). A estratégia adotada consistiu na seleção dos estudos cujo tema central descrevesse o sofrimento moral no contexto do cuidado, ou seja, na prática. Foram excluídos os estudos que abordavam o sofrimento moral nas áreas do ensino e da investigação.

No processo de seleção, primeiramente foram excluídos os estudos duplicados. Depois, com base nos critérios de inclusão e exclusão estabelecidos, os estudos foram sendo selecionados ou excluídos após a leitura dos títulos, após a leitura dos resumos e, finalmente, após a leitura dos textos completos. Assim, estudos que não abordavam possíveis fatores de risco/fatores relacionados/causas de sofrimento moral, estudos cujos sujeitos de investigação fossem estudantes ou outros profissionais de saúde que não enfermeiros e estudos realizados em outro contexto que não a prática de cuidados, foram excluídos. A amostra final é composta por 38 estudos e o processo pode ser visualizado na Figura 1. 
Figura 1 - Processo de busca e seleção de estudos

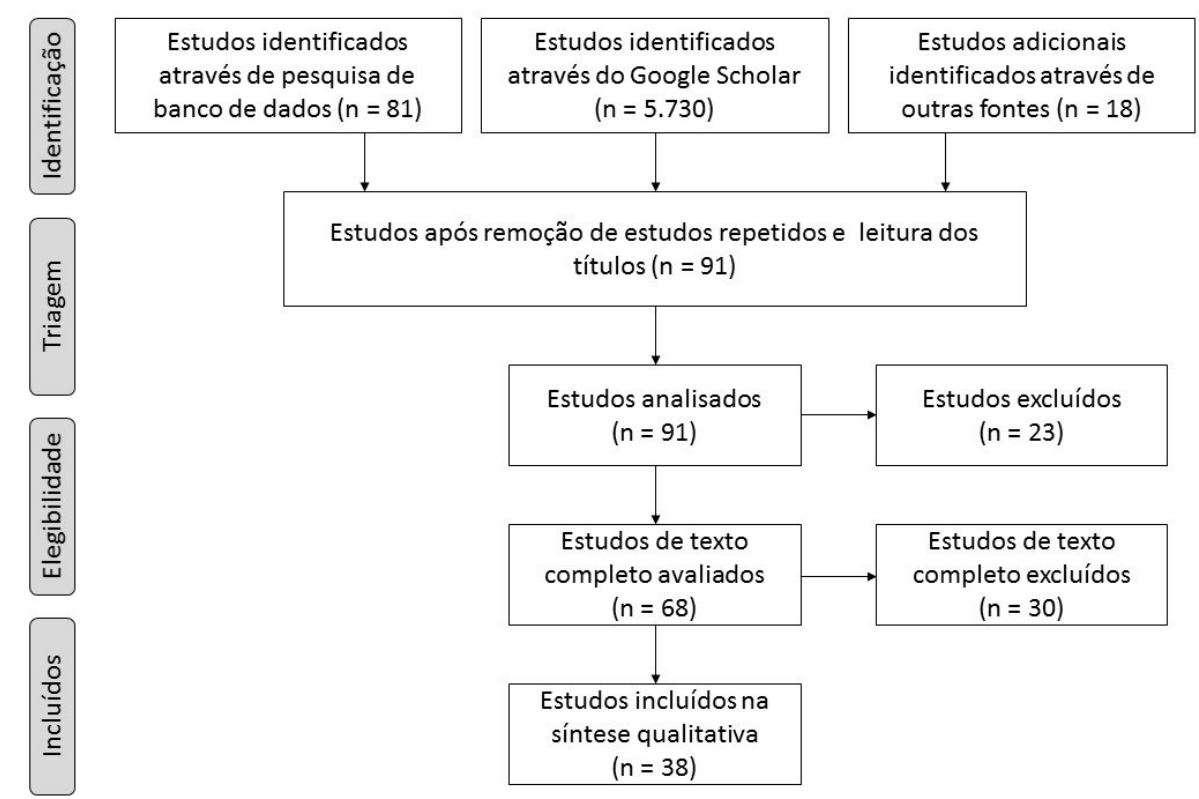

Mapeamento dos dados

Após a seleção dos estudos pertinentes ao foco de investigação, foi preciso sintetizar e interpretar suas informações. Esse processo tem o objetivo de mapear dados relevantes acerca da extensão, da natureza e da distribuição dos estudos selecionados e pode ser realizado a partir da criação de gráficos, planilhas, tabelas ou bancos de dados com as informações relevantes (Arksey \& O’Malley, 2005). A literatura sugere como potenciais categorias de recolha de informações: autores, ano de publicação, local do estudo, tipo de estudo, população, objetivo, método e resultados do estudo. As categorias de coleta de dados escolhidas vão depender do foco da investigação (Armstrong, Hall, Doyle, \& Waters, 2011).

\section{Agrupar, resumir e relatar os resultados}

O quinto passo desse tipo de revisão consiste em compilar e comunicar os resultados, fornecendo uma visão geral do material analisado (Arksey \& O’Malley, 2005). A análise numérica contribui na visualização da natureza e da extensão dos estudos selecionados, ao passo que a análise temática auxilia na apresentação de uma narrativa dos resultados encontrados, de forma clara e coerente, sem determinar uma síntese forçada dos achados ou níveis de evidência (Levac, Colquhoun, \& O’Brien, 2010). Os 
fatores de risco para sofrimento moral em enfermeiros foram a principal unidade de análise, compondo os resultados dessa revisão.

\section{Consulta com peritos}

O sexto passo desse tipo de revisão é considerado um elemento opcional, com o potencial de engrandecer os resultados do trabalho, a partir da sua partilha com outros investigadores (Arksey \& O’Malley, 2005). É também a primeira evidência de validade psicométrica, denominada de validade aparente. É um processo simples e subjetivo, com o intuito de indicar se, aparentemente, a escala avalia o que sugere (DeVellis, 2016).

A lista de fatores de risco identificados nos estudos analisados foi partilhada com quatro enfermeiras do Centro de Investigação Interdisciplinar em Saúde (CIIS) da Universidade Católica Portuguesa - Porto, no intuito de perceber se os fatores identificados faziam sentido a esses investigadores.

\subsubsection{Análise de juízes}

A análise de juízes foi utilizada para verificar a validade de conteúdo da escala, com base na avaliação e julgamento do material em estudo por um grupo de profissionais com experiência na área investigada. É comumente utilizada nos processos que envolvem a construção e a validação de instrumentos, uma vez que pode auxiliar na avaliação da pertinência e adequação do seu conteúdo (Medeiros, et al., 2015). É esperado que o grupo de juízes avalie o grau em que a escala evidencia o conteúdo do que pretende medir, ou seja, o quanto os itens representam o conceito em estudo (DeVellis, 2016)

Um profissional, para poder ser considerado um juiz, deve ser especialista na área investigada, dotado de amplo conhecimento teórico e prático. Os critérios para selecionar juízes incluem o nível de escolaridade, o desenvolvimento de pesquisas e o número de publicações na área investigada, bem como o mínimo conhecimento metodológico sobre construção e validação de escalas e instrumentos, entre outros (Alexandre \& Coluci, 2011). Descrever claramente e detalhadamente quais foram os critérios adotados na seleção dos juízes, garante que o estudo possa ser replicado por outros pesquisadores (Galdeano \& Rossi, 2006). 
Os critérios de seleção adotados nessa pesquisa foram: possuir grau de mestre ou superior; possuir experiência profissional ou acadêmica de, no mínimo, 5 anos; e ter publicado, pelo menos, 5 artigos científicos. Todos os requisitos anteriores devem ser, de preferência, na área da enfermagem ou em outras áreas relacionadas com a temática da investigação - saúde/ética/bioética/filosofia.

A literatura sugere que o processo envolva no mínimo cinco e no máximo dez juízes (Alexandre \& Coluci, 2011). Após contato com pesquisadores que integram os grupos de pesquisa dos quais a autora participa, nomeadamente os grupos 'Bioética e Saúde Coletiva' do Programa de Pós-Graduação em Saúde Coletiva da Universidade do Vale do Rio dos Sinos e o grupo 'Ética na Enfermagem', do Centro de Investigação Interdisciplinar em Saúde da Universidade Católica Portuguesa, alguns integrantes dos grupos foram convidados a participar, bem como a indicar outros profissionais. Os profissionais foram convidados a participar dessa etapa da investigação através de uma carta (Apêndice A), enviada por e-mail, juntamente com o link para aceder à lista de itens identificados na análise da literatura em dezembro de 2014 em Portugal e em junho de 2015 no Brasil. No total, 15 juízes portugueses e 8 juízes brasileiros receberam essa cartaconvite.

Aos juízes foi perguntado se consideravam cada item da lista como um fator de risco para sofrimento moral, analisando sua relevância e clareza para medir o fenômeno. Havia, ainda, um espaço para sugestões acerca de outros itens ou aspectos relacionados com o sofrimento moral que poderiam estar em falta, além da possibilidade de comentários acerca do tema (DeVellis, 2016). Para a decisão final sobre os itens, foi considerado a percentagem de concordância dos juízes acerca de cada item (Hulley, Cummings, Browner, \& Grady, 2015). A literatura sugere que a concordância e, portanto, a aceitação ou a exclusão de itens deveria ser considerada com percentuais acima de $80 \%$ (Pasquali, 2009). Também, que sejam adicionadas algumas perguntas para uma breve caracterização dos juízes (Alexandre \& Coluci, 2011), pelo que foi aos participantes perguntado: sexo, idade e formação acadêmica. 


\subsubsection{Amostra de enfermeiros assistenciais}

Aos itens resultantes das etapas anteriores foi associada uma escala do tipo Likert de 4 pontos, sendo $1=$ nunca, $2=$ raramente, $3=$ frequentemente e $4=$ sempre, para determinar sua frequência. A Escala de Likert foi criada em 1932, por Rensis Likert e é, atualmente, o tipo de escala mais utilizada em pesquisas psicométricas. Originalmente criada para avaliar o nível de concordância do sujeito para com uma afirmação, pode também ser utilizada para avaliar frequência, intensidade ou outro. É composta por opções de resposta bipolares, ou seja, a resposta à afirmação pode ser positiva ou negativa, incluindo, normalmente, uma opção de resposta neutra. Podem ser usados mais níveis de resposta, como sete ou mesmo nove níveis. Pode-se também, estrategicamente, utilizar apenas quatro níveis de resposta, o que força o sujeito pesquisado a se posicionar positiva ou negativamente em relação ao tema investigado, excluindo-se a opção de ser 'indiferente' (DeVellis, 2016).

Para testar as propriedades psicométricas da então criada escala de risco de sofrimento moral, foi realizada uma análise fatorial exploratória, com avaliação de componentes principais e rotação varimax. Essa técnica é utilizada para definir a estrutura inerente entre as variáveis, ou seja, definir conjuntos de itens que são fortemente interrelacionados e, também, como método para redução dos dados. A análise fatorial exploratória é constituída por diferentes estágios, quais sejam, definição de objetivos, planejamento, proposta de suposições, determinação de fatores, interpretação dos fatores e validação da análise fatorial (DeVellis, 2016).

Primeiro, os objetivos da análise fatorial exploratória foram definidos como: analisar os itens identificados na literatura e reduzir o seu número, a fim de evitar fatigar o respondente e aumentar a confiabilidade das respostas. Depois, o planejamento considerou o tamanho da amostra entre 5 e 10 participantes por item (DeVellis, 2016). Responderam ao estudo 268 enfermeiros do sul do Brasil e 278 enfermeiros de Portugal.

A seguir, é necessário apresentar uma fundamentação conceitual capaz de demonstrar evidência de que existe uma estrutura nos dados, antes de realizar a análise (DeVellis, 2016). A existência de ferramentas de avaliação, com evidências de validade, acerca do sofrimento moral em enfermeiros, mesmo que de diferentes contextos de aplicação, sugere essa evidência (Corley, Elswick, Gorman, \& Clor, 2001) (Wocial \& 
Weaver, 2013) (Eizenberg, Desivilya, \& Hirschfeld, 2009). Depois, é preciso verificar se os dados são fatoráveis, o que é realizado pelo teste de esfericidade de Bartlett e pelo índice Kaiser-Meyer-Olkin (KMO). É esperado que o teste de Bartlett resulte me valores inferiores a 0,5 , o que indicaria correlações suficientes entre as variáveis para realizar a análise fatorial exploratória. Depois, é esperado que o índice KMO resulte em valores iguais ou superiores a 0,5 , o que indicaria a adequação do conjunto de dados para ser submetido a análise fatorial exploratória (DeVellis, 2016).

O método de extração dos fatores foi a análise de componentes principais, com o intuito de resumir a maior parte da informação original a um número mínimo de fatores. A decisão acerca do número de fatores a serem extraídos da análise considerou autovalor maior ou igual a 1 e análise da variância. Para a interpretação dos fatores, no quinto estágio da análise fatorial exploratória, foram consideradas as cargas fatorais dos itens, a fim de verificar o papel de cada variável na definição do fator, onde valores entre $0,30 \mathrm{e}$ 0,40 são consideradas minimamente aceitáveis, preferindo-se cargas fatorais maiores ou iguais a 0,50. Neste estudo, itens com cargas fatorais inferiores a 0,50 foram excluídos. E, por último, a avaliação do grau de generalidade dos resultados para a população, a fim de validar a análise fatorial, onde podem ser realizadas análise fatorial confirmatória ou avaliação da estabilidade estrutural (DeVellis, 2016).

O coeficiente Alpha de Cronbach foi utilizado para avaliar a confiabilidade da escala, também denominada de consistência interna, indicando a proporção da variância nos escores da escala atribuíveis ao verdadeiro escore. Pode variar entre 0 e 1 , considerando resultados de 0,7 a 0,8 como razoáveis, 0,8 a 0,9 como muito bons e resultados acima de 0,9 como redundantes, quando seria adequado reduzir o número de itens da escala (DeVellis, 2016).

As análises descritiva e inferencial dos resultados foram realizadas através da ferramenta Statistical Package for the Social Sciences - SPSS, versão 21.0. As variáveis contínuas foram descritas pela média, desvio padrão, mínimo e máximo. As variáveis categóricas foram descritas pela amostra (n) e pela frequência relativa. $O$ teste $t$ de Student, para amostra independentes, foi utilizado para análise e comparação de médias das variáveis dicotômicas. Para comparação de médias das variáveis politômicas foi utilizada a análise de variância, ou teste de ANOVA, seguido do teste de comparação múltipla de Bonferroni. A homogeneidade da variância foi avaliada pelo teste de Levene. 
Os testes estatísticos foram realizados bilateralmente considerando um nível de significância de 5\% (Pestana \& Gageiro, 2014).

A recolha de dados aconteceu entre os meses de março a junho de 2016 no sul do Brasil e entre os meses de abril a maio de 2017 em Portugal. A média de risco de sofrimento moral foi categorizada por divisão numérica simples, considerando resultados de $1=$ sem risco, $2=$ risco baixo, 2,5 = risco moderado, $3=$ risco alto e $4=$ risco grave.

\subsubsection{Considerações éticas}

Os juízes convidados para participar da etapa de validação de conteúdo receberam, via e-mail, uma carta convite com uma solicitação para que, com base em sua reconhecida experiência no tema, colaborassem no processo de obtenção de consenso e validação de conteúdo dos itens identificados na literatura como fatores de risco para sofrimento moral (Apêndice A).

Para a aplicação da escala de risco de sofrimento moral aos enfermeiros do Rio Grande do Sul, obteve-se aprovação do Comitê de Ética em Pesquisa da Escola de

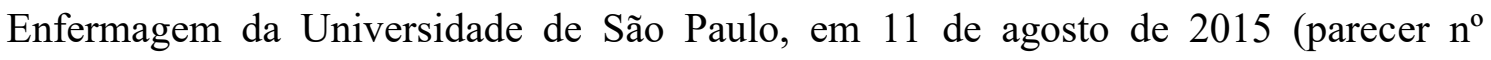
1.180.518 - Anexo X). O Termo de Consentimento Livre e Esclarecido é composto por uma breve identificação da investigadora e da investigação: o título do estudo, os objetivos, o tipo de estudo, a contribuição do participante no estudo, as garantias para a preservação do seu anonimato e da sua liberdade de participação e retirada da pesquisa, informações para contato e a aprovação do comitê de ética (Apêndice B).

Em Portugal, o estudo teve parecer do Ethics Lab da Universidade Católica Portuguesa (Anexo XI). No Termo de Consentimento Livre e Esclarecido constam uma breve descrição da investigação e da investigadora (Apêndice C).

A pesquisa pode fazer recordar sentimentos e experiências naqueles profissionais que vivenciaram ou vivenciam o sofrimento moral, gerando algum grau de angústia. Os contatos da pesquisadora ficam disponíveis para casos de dúvidas ou para conhecimento posterior dos resultados. Os dados serão utilizados apenas para fins investigativos e as diretrizes e normas regulamentadoras para pesquisa em saúde serão observadas. 


\section{ESTUDO I - IDENTIFICAÇÃO DE FATORES DE RISCO PARA SOFRIMENTO MORAL}

Este capítulo responde ao primeiro objetivo específico da tese: 'Identificar fatores de risco para sofrimento moral em enfermeiros na literatura científica de enfermagem'. Estudo publicado na Revista Nursing Inquiry, v.23, n.4, p.346-357, 2016 (Schaefer, Zoboli, \& Vieira, 2016).

\subsection{RESULTADOS}

Os estudos selecionados foram analisados segundo informações acerca dos autores, do ano de publicação, do país em que o estudo foi realizado, do método utilizado, da população em estudo e dos potenciais fatores de risco para sofrimento moral. As informações recolhidas estão descritas na Tabela 4. 
Tabela 4 - Mapeamento da literatura

\begin{tabular}{|c|c|c|c|c|}
\hline Autor(es) & País & Método & População & Resultados: possíveis fatores de risco para sofrimento moral \\
\hline (Olson, 1995) & $\begin{array}{l}\text { Estados } \\
\text { Unidos }\end{array}$ & $\begin{array}{l}\text { Análise } \\
\text { conceitual e } \\
\text { revisão de } \\
\text { literatura }\end{array}$ & $x_{2}$ & $\begin{array}{l}\text { - Clima ético (diálogo, suporte organizacional, colaboração, abordar e } \\
\text { resolver questões éticas, enfermeiro está incluído no desenvolvimento e } \\
\text { implementação de políticas institucionais, possibilidade de consulta ética, } \\
\text { educação continuada em ética, comitê de ética, biblioteca com recursos, } \\
\text { modelos de prática profissional) }\end{array}$ \\
\hline (Kelly, 1998) & $\begin{array}{l}\text { Estados } \\
\text { Unidos }\end{array}$ & $\begin{array}{l}\text { Qualitativo, } \\
\text { teoria } \\
\text { fundamentada }\end{array}$ & $\begin{array}{l}22 \text { enfermeiros } \\
\text { recém-formados }\end{array}$ & $\begin{array}{l}\text { - Falta de pessoal - Condições de trabalho difíceis - Terminar o trabalho a } \\
\text { tempo - Excessivo número de pacientes para cuidar - Falta de suporte dos } \\
\text { colegas e chefia - Medo de não ser aceito pela equipe - Falta de confiança - } \\
\text { Medo de errar - Não saber o que fazer - Negligenciar o paciente e o cuidado } \\
\text { por falta de tempo - Recursos limitados - Medo de punição ao reportar erros } \\
\text { - Sentir-se impotente para mudar o contexto }\end{array}$ \\
\hline $\begin{array}{l}\text { (Corley, Elswick, } \\
\text { Gorman, \& Clor, } \\
\text { 2001) }\end{array}$ & $\begin{array}{l}\text { Estados } \\
\text { Unidos }\end{array}$ & $\begin{array}{l}\text { Pesquisa } \\
\text { metodológica }\end{array}$ & $\begin{array}{l}214 \text { enfermeiros } \\
\text { de diferentes } \\
\text { hospitais }\end{array}$ & $\begin{array}{l}\text { - Cuidado inadequado por número insuficiente de enfermeiros - Executar } \\
\text { ordens para testes e tratamento que considero desnecessários - Trabalhar } \\
\text { com níveis de pessoal que considero 'inseguro' - Tratamento agressivo que } \\
\text { só prolonga a morte }\end{array}$ \\
\hline $\begin{array}{l}\text { (Fry, Harvey, } \\
\text { Hurley, \& Foley, } \\
\text { 2002) }\end{array}$ & $\begin{array}{l}\text { Estados } \\
\text { Unidos }\end{array}$ & $\begin{array}{l}\text { Qualitativo e } \\
\text { descritivo }\end{array}$ & $\begin{array}{l}13 \text { enfermeiros } \\
\text { oficiais das } \\
\text { Forças Armadas } \\
\quad \text { dos EUA }\end{array}$ & $\begin{array}{l}\text { - Conflito de valores sobre o que seria do melhor interesse do paciente - } \\
\text { Falta de apoio da chefia - Executar as ordens de comando }\end{array}$ \\
\hline $\begin{array}{l}\text { (Kälvemark, } \\
\text { Höglund, } \\
\text { Hansson, } \\
\text { Westerholm, \& } \\
\text { Arnetz, 2004) }\end{array}$ & Suécia & $\begin{array}{l}\text { Qualitativo e } \\
\text { descritivo }\end{array}$ & $\begin{array}{l}5 \text { a } 7 \text { membros: } \\
\text { departamentos de } \\
\text { cardiologia, } \\
\text { hematologia e } \\
\text { farmácia }\end{array}$ & $\begin{array}{l}\text { - Falta de recursos - Falta de tempo - Falta de pessoal - Falta de camas - } \\
\text { Preocupações econômicas - Políticas institucionais - Quebrar as regras - Ser } \\
\text { forçado a agir de acordo com os regulamentos - Integridade do paciente - } \\
\text { Sigilo - Conflitos de valores - Hierarquia - Falta de estruturas de apoio }\end{array}$ \\
\hline $\begin{array}{c}\text { (Meltzer \& } \\
\text { Huckabay, 2004) }\end{array}$ & $\begin{array}{l}\text { Estados } \\
\text { Unidos }\end{array}$ & $\begin{array}{l}\text { Quantitativo, } \\
\text { transversal e } \\
\text { descritivo }\end{array}$ & $\begin{array}{l}60 \text { enfermeiras de } \\
\text { cuidados } \\
\text { intensivos de dois } \\
\text { hospitais }\end{array}$ & - Cuidado fútil \\
\hline $\begin{array}{l}\text { (Peter \& } \\
\text { Liaschenko, 2004) }\end{array}$ & $\begin{array}{l}\text { Estados } \\
\text { Unidos }\end{array}$ & Teórico & - & $\begin{array}{l}\text { - Empresarialização dos cuidados de saúde - Sistema institucional } \\
\text { burocrático - Pessoal insuficiente - Recursos indisponíveis }\end{array}$ \\
\hline
\end{tabular}


(Austin,

Lemermeyer,

Goldberg,

Bergum, \&

Johnson, 2005)

\begin{tabular}{|c|c|c|c|}
\hline $\begin{array}{c}\text { (Corley, Minick, } \\
\text { Elswick, \& } \\
\text { Jacobs, 2005) }\end{array}$ & $\begin{array}{l}\text { Estados } \\
\text { Unidos }\end{array}$ & $\begin{array}{l}\text { Quantitativo, } \\
\text { transversal e } \\
\text { correlacional }\end{array}$ & $\begin{array}{l}106 \text { enfermeiros } \\
\text { de dois grandes } \\
\text { centros médicos, } \\
\text { uma unidade de } \\
\text { saúde federal e } \\
\text { um centro médico } \\
\text { universitário }\end{array}$ \\
\hline (Gutierrez, 2005) & $\begin{array}{l}\text { Estados } \\
\text { Unidos }\end{array}$ & $\begin{array}{l}\text { Qualitativo e } \\
\text { descritivo, teoria } \\
\text { fundamentada }\end{array}$ & $\begin{array}{c}12 \text { enfermeiros de } \\
\text { cuidados } \\
\text { intensivos }\end{array}$ \\
\hline (Hanna, 2005) & $\begin{array}{l}\text { Estados } \\
\text { Unidos }\end{array}$ & $\begin{array}{c}\text { Qualitativo e } \\
\text { fenomenológico }\end{array}$ & $\begin{array}{c}10 \text { enfermeiros } \\
\text { que participaram } \\
\text { no procedimento } \\
\text { de abortos } \\
\text { eletivos }\end{array}$ \\
\hline (Laabs, 2005) & $\begin{array}{l}\text { Estados } \\
\text { Unidos }\end{array}$ & $\begin{array}{l}\text { Quantitativo, } \\
\text { transversal e } \\
\text { descritivo }\end{array}$ & $\begin{array}{l}101 \text { enfermeiros } \\
\text { dos cuidados de } \\
\text { saúde primários }\end{array}$ \\
\hline
\end{tabular}

- Medo ou dúvida - Falta de pessoal - Política institucional - Não participar na tomada de decisão - Aceitar autoridade médica - Gênero (estereótipo de poder associado ao feminino da enfermagem e masculino da medicina) Sensibilidade moral - Conflitos de valores - Gerentes de enfermagem atuando como barreiras ao cuidado - Medo de perder o emprego Insegurança - Falta de coragem - Falta de recursos - Falta de tempo

- Trabalhar com níveis de pessoal que considero 'inseguro' - Pobre ambiente ético de trabalho

- Tratamento médico agressivo - Uso inadequado dos recursos - Médico dá informações incompletas ou imprecisas - Quando os desejos do paciente são ignorados - Conflitos quanto ao tratamento - Falta de acompanhamento médico - Expectativas quanto ao trabalho do enfermeiro - Comunicação ineficaz - Falta de enfermeiros - Medo - Estrutura hierárquica

- Participar em procedimentos que considero inadequados

- Decisões clínicas feitas por outros - Pacientes que não podiam pagar pelo tratamento - Pressão para atender um número excessivo de pacientes Desentendimentos - Barreiras linguísticas e culturais - Pouco tempo para atender às necessidades do paciente - Avaliação de desempenho com base em número de pacientes atendidos, não por complexidade ou qualidade Falta de compreensão do médico sobre a prática da enfermagem - Medo de ser demitido por queixar-se ou não cumprir a meta de atendimento Restrições legais 


\begin{tabular}{|c|c|c|c|}
\hline (Ferrell, 2006) & $\begin{array}{l}\text { Estados } \\
\text { Unidos }\end{array}$ & $\begin{array}{c}\text { Bibliográfico e } \\
\text { qualitativo } \\
\text { descritivo }\end{array}$ & $\begin{array}{c}108 \text { enfermeiros } \\
\text { em dois cursos de } \\
\text { educação }\end{array}$ \\
\hline $\begin{array}{c}\text { (Sporrong, } \\
\text { Höglund, \& } \\
\text { Arnetz, 2006) }\end{array}$ & Suécia & $\begin{array}{c}\text { Quantitativo, } \\
\text { correlacional e } \\
\text { qualitativo }\end{array}$ & $\begin{array}{l}259 \text { funcionários } \\
\text { de quatro } \\
\text { departamentos } \\
\text { médicos e três } \\
\text { farmácias dos } \\
\text { quais } 117 \\
\text { enfermeiros }\end{array}$ \\
\hline $\begin{array}{l}\text { (Janvier, Nadeau, } \\
\text { Deschênes, } \\
\text { Couture, \& } \\
\text { Barrington, 2007) }\end{array}$ & Canadá & $\begin{array}{c}\text { Quantitativo e } \\
\text { transversal }\end{array}$ & $\begin{array}{l}279 \text { profissionais, } \\
\text { incluindo } 115 \\
\text { enfermeiros e } 164 \\
\text { residentes }\end{array}$ \\
\hline $\begin{array}{l}\text { (Mobley, Rady, } \\
\text { Verheijde, Patel, } \\
\text { \& Larson, 2007) }\end{array}$ & $\begin{array}{l}\text { Estados } \\
\text { Unidos }\end{array}$ & $\begin{array}{l}\text { Quantitativo, } \\
\text { prospectivo }\end{array}$ & $\begin{array}{l}44 \text { enfermeiros de } \\
\text { cuidados } \\
\text { intensivos }\end{array}$ \\
\hline (Zuzelo, 2007) & $\begin{array}{l}\text { Estados } \\
\text { Unidos }\end{array}$ & $\begin{array}{c}\text { Quantitativo e } \\
\text { descritivo }\end{array}$ & $\begin{array}{c}100 \text { enfermeiros } \\
\text { de emergência e } \\
\text { serviços de } \\
\text { perioperatórios }\end{array}$ \\
\hline
\end{tabular}

- Cuidado fútil em fim de vida - Barreiras religiosas ou espirituais - Alta tecnologia de prolongamento de vida - Cuidado agressivo negando cuidado paliativo - Conflitos entre família, paciente e equipe de saúde 59 funcionários e quatro médicos e três

- Cuidado deficiente por falta de tempo - Quando há demora no atendimento quais 117

enfermeiros

9 profissionais

\section{Couture, \& \\ Barrington, 2007)}

(Mobley, Rady, Verheijde, Patel, \& Larson, 2007)

Estados

Quantitativo, cuidados

- Cuidado agressivo

- Cuidado fútil - Realizar cuidado não no melhor interesse do paciente Perguntar à família sobre doação de órgãos quando a morte é inevitável Seguir vontade da família - Executar ordem para testes e tratamentos desnecessários - Iniciar ressuscitação quando acho que só prolongará a morte - Seguir prescrição para dor quando a medicação já não faz mais efeito - Aumentar a dose de morfina de paciente inconsciente quando acredita que isso irá apressar sua morte

- Trabalhar com nível de pessoal que considero ‘inseguro' - Falta de pessoal - Trabalhar com profissionais que considero não ser tão competentes quanto o atendimento ao paciente requer - Seguir tratamento que não considero efetivo - Seguir tratamento não no melhor interesse no paciente - Realizar ordem para testes e tratamentos desnecessários - Cuidado fútil - Médicos dão aos pacientes falsas esperanças - A vontade do paciente é desrespeitada - Sentir-se subordinado ao médico - Estruturo hierárquica - Falta de poder ou autonomia para interferir e contestar decisões - Habilidades e diagnósticos do enfermeiro são ignorados - Decisões clínicas que desconsideram qualidade de vida - Procedimentos dolorosos sem benefícios - Decisão da família de insistir em manter o paciente vivo 


\begin{tabular}{|c|c|c|c|}
\hline $\begin{array}{c}\text { (Morris \& } \\
\text { Dracup, 2008) }\end{array}$ & $\begin{array}{l}\text { Estados } \\
\text { Unidos }\end{array}$ & Editorial. & - \\
\hline $\begin{array}{c}\text { (Oberle \& } \\
\text { Hughes, 2008) }\end{array}$ & Canadá & $\begin{array}{l}\text { Qualitativo, } \\
\text { teoria } \\
\text { fundamentada }\end{array}$ & $\begin{array}{l}14 \text { enfermeiros } \\
\text { nas áreas médico- } \\
\text { cirúrgicas de } \\
\text { adultos, incluindo } \\
\text { cuidados } \\
\text { intensivos }\end{array}$ \\
\hline
\end{tabular}

\section{(Rice, Rady, \\ Hamrick,}

Verheijde, \&

Pendergast, 2008)

\section{Estados \\ Unidos}

\section{Quantitativo e}

transversal

284 enfermeiros

de um hospital de

cuidados

intensivos

- Conflito com a família acerca do tratamento - Incapacidade de controlar a dor do paciente - Gastar recursos com pacientes que não vão sobreviver - Questões de fim de vida - Mal-entendidos e conflitos com médicos Incapacidade de influenciar decisões e tomada de decisão - Quando o sofrimento do paciente é intensificado porque o médico não pode ou não quer escrever ordens apropriadas - Posição inferior na estrutura hierárquica - Não ser ouvido pelo médico - Esperar que o enfermeiro permaneça em silencio mesmo quando testemunha escolhas erradas - Incapacidade de reduzir o sofrimento do paciente

- Prover cuidado que não atende as necessidades do doente - Trabalhar com profissionais não tão competentes quanto o cuidado ao paciente requer Executar um cuidado para o qual não me sinto profissionalmente competente - Trabalhar com níveis de profissionais que considero 'inseguro' - Ser obrigada a seguir os desejos da família - Seguir tratamento não no melhor interesse do paciente - Realizar ordem para exame ou teste desnecessário - Seguir desejo da família para não falar de morte quando o paciente questiona sobre - Seguir ordens de medicação para dor quanto já não faz mais efeito

- Ambiente organizacional - Falta de recursos materiais e humanos -

2 enfermeiros, 2 técnicos em

(Dalmolin, Lunardi, \& Filho, 2009)

Brasil

Qualitativo, etnográfico enfermagem e 2 auxiliares de enfermagem de internação clínica e cirúrgica

\section{(Eizenberg,}

Desivilya, \& Hirschfeld, 2009)
Israel Método misto

179 enfermeiros

de diferentes

locais de trabalho
Excesso de trabalho - Relações interpessoais no trabalho - Conflitos com outros profissionais - Conflitos nas relações de poder - Incapacidade de opinar por mudanças - Estresse físico, mental e emocional - Elevado número de pacientes - Estresse - Falta de apoio social - Medo de punição Falta de diálogo - Desrespeito dos direitos dos pacientes - $\mathrm{O}$ abandono da família - Não é esclarecer o paciente sobre sua situação - Cuidados inadequados - Profissionais não preparados para lidar com a morte - Falta de apoio institucional

- Falta de tempo - Paciente não tem recursos para pagar pelo tratamento Falta de estrutura física - Demora no atendimento - Ver cuidados inadequados ou erros de outros profissionais - Ser forçado a ignorar questões do paciente e da família - Ser forçado a colocar o paciente em local inadequado por falta de estrutura 


\begin{tabular}{|c|c|c|c|}
\hline $\begin{array}{c}\text { (Epstein \& } \\
\text { Hamric, 2009) }\end{array}$ & $\begin{array}{l}\text { Estados } \\
\text { Unidos }\end{array}$ & Teórico & - \\
\hline $\begin{array}{c}\text { (Lunardi, et al., } \\
\text { 2009) }\end{array}$ & Brasil & Reflexão teórica & - \\
\hline $\begin{array}{c}\text { (Pauly, Varcoe, } \\
\text { Storch, \& Newton, } \\
\text { 2009) }\end{array}$ & Canadá & $\begin{array}{l}\text { Quantitativo e } \\
\text { transversal }\end{array}$ & $\begin{array}{c}374 \text { enfermeiros } \\
\text { em hospitais de } \\
\text { cuidados } \\
\text { intensivos }\end{array}$ \\
\hline $\begin{array}{l}\text { (Harrowing } \& \\
\text { Mill, 2010) }\end{array}$ & Uganda & $\begin{array}{l}\text { Qualitativo, } \\
\text { etnográfico }\end{array}$ & $\begin{array}{c}24 \text { enfermeiros } \\
\text { dos cuidados } \\
\text { críticos e da saúde } \\
\text { pública }\end{array}$ \\
\hline $\begin{array}{c}\text { (Ohnishi, et al., } \\
\text { 2010) }\end{array}$ & Japão & $\begin{array}{l}\text { Quantitativo e } \\
\text { transversal }\end{array}$ & $\begin{array}{c}289 \text { enfermeiros } \\
\text { psiquiátricos de } 6 \\
\text { hospitais }\end{array}$ \\
\hline (Lawrence, 2011) & $\begin{array}{l}\text { Estados } \\
\text { Unidos }\end{array}$ & $\begin{array}{l}\text { Quantitativo, } \\
\text { descritivo e } \\
\text { correlacional }\end{array}$ & $\begin{array}{l}28 \text { enfermeiros } \\
\text { dos cuidados } \\
\text { intensivos }\end{array}$ \\
\hline $\begin{array}{c}\text { (Pavlish, Brown- } \\
\text { Saltzman, Hersh, } \\
\text { Shirk, \& Rounkle, } \\
\text { 2011) }\end{array}$ & $\begin{array}{l}\text { Estados } \\
\text { Unidos }\end{array}$ & $\begin{array}{l}\text { Qualitativo e } \\
\text { descritivo }\end{array}$ & $\begin{array}{l}91 \text { enfermeiros } \\
\text { registrados em } \\
\text { uma conferência }\end{array}$ \\
\hline
\end{tabular}

- Tratamento agressivo e prolongado para pacientes terminais - Pouca comunicação entre equipe médica e de enfermagem - Falta de liderança eficaz - Política institucional incerta ou ausente - Repetição de situações moralmente problemáticas ao longo do tempo

- Extensão da vida - Cuidado fútil - Exames desnecessários - Despreparo para o cuidado no processo de morrer - Falta de consentimento - Falta de apoio para lidar com conflitos - Aceitar autoridade médica sem participar no processo de tomada de decisões - Conflitos com os pacientes - Falta de possibilidade de exercer algum poder na instituição - Comunicação ineficaz - Organização hospitalar

- Clima ético

- Ser incapaz de mudar o sistema - Falta de financiamento - Falta de pessoal - Falta de materiais e equipamentos - Não ser capaz de oferecer qualidade nos cuidados - Má compreensão do trabalho do enfermeiro - Ser culpado pelo mau atendimento

- Trabalhar com nível de pessoal que considero ‘inseguro’ - Observar, sem tomar medidas, quando o doente continua a ser hospitalizado embora sua condição seja estável - Tratar pacientes de forma inadequada por falta de pessoal - Trabalhar em um local onde os enfermeiros são tratados como máquinas

- Cuidado fútil - Família agarrada à esperança quando não há nenhuma Enfermeiros pouco preparados para lidar com a morte - Cuidado não é no melhor interesse do paciente

- Tratamento agressivo em situações de fim de vida - Vontade do paciente não é levada em consideração - Prestar cuidados de baixa qualidade Equipe de saúde não adere aos padrões estabelecidos de cuidado - Conflito com equipe sobre opções de tratamento - Família que impede o cuidado Fornecer diagnóstico e prognóstico honestos - Abordar expectativas irrealistas da família - Falta de comunicação - Falta de apoio da gestão - 


\section{(Barlem, Lunardi, \\ Lunardi, \\ Dalmolin, \& \\ Tomaschewski, \\ 2012)}

\section{(Maluwa, Andre, \\ Ndebele, \&}

Chilemba, 2012)

Malavi

Qualitativo e

descritivo

\section{Quantitativo e \\ transversal}

124 enfermeiros hospitalares

20 enfermeiros de diferentes contextos

\section{2 enfermeiros}

de 20 asilos e 3

$\begin{array}{ccc}\text { (Piers, et al., 2012) Bélgica } & \begin{array}{c}\text { Quantitativo e } \\ \text { transversal }\end{array} & \begin{array}{c}\text { enfermarias } \\ \text { geriátricas de } \\ \text { cuidados } \\ \text { intensivos }\end{array}\end{array}$

\section{(Varcoe, Pauly, \\ Webster, \& \\ Storch, 2012)}

(Winters \&

Neville, 2012)

Canadá

Teórico

(Papathanassoglo

u, et al., 2012)

Nova Zelândia

Qualitativo e

descritivo

Quantitativo,

Europa

(Veer, Francke, Struijs, \&

Willemsv, 2013)
Holanda
5 enfermeiros hospitalares

255 enfermeiros numa conferência de cuidados intensivos

\section{5 enfermeiros}

Quantitativo, de asilos, home transversal e
Manter a confidencialidade - Tomar decisões para pacientes vulneráveis com família ausente

- Não relatar a ocorrência de erros - Realização de procedimentos inadequados ou desnecessários - Falta de competência dos membros da equipe - Observar desrespeito da privacidade - Não dizer a verdade ao paciente - Prolongamento persistente da vida

- Número reduzido de profissionais - Violar regras, regulamentos e políticas da instituição para proteger o paciente - Conflitos entre jovens médicos e enfermeiros experientes - Sentir-se desvalorizado ou maltratado - Falta de recursos - Colegas não cumprem deveres - Falta geral de compreensão Favorecimento de alguns profissionais pela gestão

- Cuidado fútil - Trabalhar com colegas que considero incompetentes Ignorar suspeita de abuso por um cuidador - Falta de discussão sobre questões éticas em serviço - Exaustão emocional - Realização pessoal reduzida

- Economia política atual - Contexto sócio político e econômico Organização do sistema de saúde - Preconceito de gênero - Resultados do paciente - Desigualdades na saúde - Condições dos pacientes: pobreza, falta de moradia, racismo correlacional
- Cuidado fútil - Assistir um médico que está prestando cuidado incompetente - Prover cuidado de menor qualidade para reduzir custos Número de pacientes - Status percebido do trabalho

- Discrepância entre a vontade do paciente, família, médico e enfermeiros Erros de colegas - Nível inadequado de funcionários - Não ter conhecimento de acordos feitos sobre o cuidado - Paciente pergunta informações médicas à enfermeira e ela não pode responder - Discrepância entre cuidado indicado e cuidado necessário - Menor satisfação com o care e hospitais de cuidados intensivos 
trabalho - Estresse - Baixa qualidade percebida de atendimento - Satisfação com possibilidade de crescimento profissional - Satisfação com colegas Falta de autonomia - Não ter tempo suficiente para atender os pacientes -

Menor possibilidade de consultar os colegas

- Falta de recursos humanos - Sobrecarga de trabalho - Problemas de comunicação e de relacionamento - Rotinas rígidas - Conflitos com colegas

Qualitativo, exploratório e descritivo
14 enfermeiros

hospitalares 
A análise numérica mostra que os estudos analisados foram publicados entre os anos de 1995 e 2014, com maior número de publicações nos anos de 2005 ( $\mathrm{n}=5 ; 13,2 \%$ ), $2009(\mathrm{n}=5 ; 13,2 \%)$ e $2012(\mathrm{n}=5 ; 13,2 \%)$. A metade dos estudos foi realizada nos Estados Unidos $(\mathrm{n}=19 ; 50 \%)$. Depois os países com mais publicações são Canadá $(\mathrm{n}=$ $4 ; 10,5 \%)$ e Brasil $(\mathrm{n}=4 ; 10,5 \%)$. Quanto ao tipo de estudo, há um equilíbrio quanto ao número de trabalhos quantitativos e qualitativos, com 14 estudos quantitativos $(36,8 \%)$ e 13 estudos qualitativos (34,2\%). Ainda foram analisados 8 estudos teóricos $(21,0 \%), 2$ que utilizaram método misto $(5,3 \%)$ e 1 estudo metodológico (2.6\%). A maioria dos estudos quantitativos eram transversais e utilizaram escalas para a coleta de dados $(\mathrm{n}=$ $10 ; 71,4 \%$ ), já nos estudos qualitativos, a maioria utilizou as entrevistas como principal ferramenta de coleta de dados $(n=10 ; 76,9 \%)$. Considerando todos os enfermeiros que participaram dos estudos analisados, os resultados encontrados refletem as respostas de cerca de 3.497 enfermeiros dos mais variados serviços de saúde (Tabela 4).

Os estudos foram cuidadosamente lidos para identificar e listar o maior número possível de fatores de risco para sofrimento moral. A partir das informações retiradas dos estudos (Tabela 4), criou-se uma lista de potenciais fatores de risco para sofrimento moral (Tabela 5).

Tabela 5 - Lista de potenciais fatores de risco para sofrimento moral em enfermeiros $(n=53)$

\footnotetext{
Potenciais fatores de risco para sofrimento moral em enfermeiros

Conflitos entre paciente, família, profissionais

Conflitos religiosos / espirituais

Demora no atendimento

Desorganização do sistema de saúde

Despreparo para lidar com a morte

Desrespeito à vontade do paciente

Desvalorização profissional

Esgotamento físico / mental / emocional

Estresse

Estrutura hierárquica que determina a impotência e a subordinação do enfermeiro ao médico

Expectativas de outros em relação à atuação do enfermeiro

Falsas esperanças para pacientes e familiares

Falta de apoio da instituição

Falta de apoio dos colegas

Falta de competência de outros profissionais

Falta de competência pessoal

Falta de consideração pelos seus conhecimentos

Falta de diálogo / comunicação entre profissionais

Falta de discussão sobre questões éticas no serviço
} 
Falta de enfermeiros

Falta de financiamento, recursos, equipamentos

Falta de liderança eficaz no serviço

Falta de tempo por excesso de trabalho

Impossibilidade de crescimento profissional

Impotência para contestar decisões de outros profissionais

Inexistência de comissões de ética

Insatisfação com o trabalho

Medo de atuar profissionalmente

Medo de não ser aceito pela equipe

Medo de não terminar o trabalho a tempo

Medo de notificar erros que você cometeu

Medo de perder o emprego

Mercantilização dos cuidados de saúde

Não ser incluído na tomada de decisões

Normas institucionais que dificultam o cuidado

Número excessivo de pacientes atribuídos a cada enfermeiro

Observar cuidado inadequado ou desnecessário feito por outros profissionais

Obstáculos linguísticos e culturais

Paciente sem condições de pagar pelo tratamento

Pouca autonomia no trabalho

Presenciar comportamento inadequado de familiares

Problemas na estrutura física da instituição

Questões de gênero pelo estereótipo de poder que associa o masculino à medicina e o

feminino à enfermagem

Realização pessoal reduzida

Sentir-se impotente para mudar o contexto

Ser forçado a não contar a verdade ao paciente

Ser forçado a quebrar confidencialidade e sigilo

Ser forçado a transgredir as regras

Ser obrigado a prestar cuidado inadequado ou desnecessário

Ser questionado sobre informações que são sigilosas

Ter que decidir pelo paciente

Uso abusivo da alta tecnologia no prolongamento da vida

Uso inadequado dos recursos disponíveis

Utilizando o sexto passo do método de revisão da literatura, essa lista foi partilhada com quatro colegas do Centro de Investigação Interdisciplinar da Universidade Católica Portuguesa - Porto, sendo considerada pertinente, confirmando sua validade aparente.

\subsection{DISCUSSÃO}

O sofrimento moral tem sido frequente alvo de investigação na área da enfermagem desde que foi pela primeira vez conceituado como o fenômeno resultante da 
dificuldade em levar adiante uma ação considerada moralmente adequada devido a restrições ou obstáculos, sobretudo institucionais (Jameton, 1984). Mesmo fazendo parte das agendas investigativas de outras profissões, como a medicina e a psicologia, é na enfermagem que se encontra o maior número de estudos sobre o tema (McCarthy \& Gastmans, 2015).

Um aumento considerável no número de publicações sobre sofrimento moral nos últimos anos, principalmente a partir de 2009 (Vosner, Zeleznik, Kokol, Vosner, \& Zavrsnik, 2016), chama atenção para os desafios impostos pelas crescentes desigualdades sociais e de saúde. A tendência é de que, cada vez mais, os enfermeiros sejam menos capazes de fornecer cuidados com a qualidade considerada necessária para cumprir com a percebida obrigação moral profissional, aumentando, inevitavelmente, a ocorrência do sofrimento moral (McCarthy \& Gastmans, 2015).

Essa realidade pode determinar uma maior resignação da resistência do enfermeiro aos fatores relacionados com o sofrimento moral e uma aceitação das barreiras impostas ao exercício ético, tornando estes profissionais mais passivos e menos reativos (Barlem \& Ramos, 2015). Nesse contexto, uma das questões mais preocupantes é a possibilidade do sofrimento moral passar a ser considerado como uma característica aceitável do papel profissional (McCarthy \& Gastmans, 2015).

A literatura reforça a necessidade de insistir nas investigações acerca do sofrimento moral (Barlem \& Ramos, 2015), principalmente, para que as organizações não hesitem em levantar questões, como quais são as fontes mais comuns de sofrimento moral em seus serviços e, assim, evitem o silenciamento e a incorporação do sofrimento como parte da rotina profissional. Os instrumentos e as escalas podem auxiliar nesse processo, principalmente para avaliar a situação do sofrimento moral e a eficácia das intervenções (Austin, 2016).

Com o intuito de construir uma escala, esse estudo buscou na literatura a fundamentação empírica, através do método de Scoping Review. O método utilizado objetivou garantir um mapeamento rápido do conceito sob investigação, permitindo ao pesquisador construir um resumo detalhado do estado da arte, de acordo com um amplo número de pesquisas no campo científico da enfermagem. Este é um tipo de método de revisão da literatura cientificamente reconhecido (Armstrong, Hall, Doyle, \& Waters, 
2011) e também utilizado com sucesso por outros pesquisadores (Coombs, 2015) (Knight, et al., 2014).

A proposta de construir uma escala por meio de uma revisão da literatura permitiu que fossem analisados os resultados de estudos quantitativos, qualitativos, teóricos e metodológicos, que utilizaram diferentes métodos de recolha e análise de dados, com diferentes populações, nos mais variados serviços de saúde. Os dados representam a experiência e a vivência de mais de três mil enfermeiros assistenciais, atuantes em serviços de cirurgia, cardiologia, hematologia, cuidados intensivos, emergência, assistência geriátrica, forças armadas, saúde pública e unidades de cuidados da atenção primária à saúde ao redor do mundo. A heterogeneidade e a representatividade dos fatores de risco identificados nessa conjuntura são fundamentais para potenciar a validade da escala (DeVellis, 2016).

A primeira definição de sofrimento moral considerava as barreiras institucionais como a principal causa para o impedimento da ação moral (Jameton, 1984). Essas barreiras, usualmente, incluíam: impedimentos gerados pela supervisão, hegemonia do poder médico, estrutura e política institucional, considerações legais, excesso de normas e manuais a serem seguidos, estruturas de comunicação institucional, estilo de liderança, entre outros (Corley, Elswick, Gorman, \& Clor, 2001) (Veer, Francke, Struijs, \& Willemsv, 2013). Em estudos subsequentes, os investigadores passaram a considerar, também, outros tipos de barreiras como fontes de sofrimento moral, quais sejam, os fatores internos (Corley, 2002) e as situações clínicas (Hamric, Borchers, \& Epstein, 2012).

Atualmente, há um consenso geral na literatura de que as fontes para sofrimento moral podem ser agrupadas em: situações clínicas, condições de trabalho difíceis e recursos limitados, condições estruturais e fontes morais. No grupo das situações clínicas aparecem situações que podem envolver danos ao paciente, como por exemplo, o tratamento agressivo em fim de vida, a realização de testes desnecessários, a falta de tratamento, a má gestão da dor, o cuidado incompetente ou inadequado, entre outros. Referente às condições de trabalho e recursos tem-se a crescente mercantilização da saúde, as políticas de gestão e organização, a mudança de foco do paciente e família para a organização, a falta de profissionais, os cortes de financiamento, o aumento da carga de trabalho, entre outros. As condições estruturais revelam aspectos relacionados com os 
desequilíbrios de poder, a falta de reconhecimento e desvalorização da enfermagem, a falta de oportunidade para expressar preocupações e os conflitos interprofissionais. Já as fontes ditas morais estariam ligadas com a sensibilidade moral, com os conflitos de valores e com aspectos do clima ético institucional, entre outros (McCarthy \& Gastmans, 2015).

Verifica-se que os fatores de risco identificados nesse estudo são representativos de todas as fontes para sofrimento moral que constam na literatura, indicando um potencial de abrangência e de sensibilidade para a fundamentação de uma escala de avaliação de risco de sofrimento moral. Esse estudo foi capaz de compilar e analisar os resultados de um grande número de publicações sobre o sofrimento moral na área da enfermagem.

Considerando que o sofrimento moral pode levar os enfermeiros a vivenciar consequências negativas, interferir na qualidade do cuidado e determinar a satisfação e a retenção de profissionais, considera-se que estudos que busquem contribuir para a melhoria de aspectos relacionados com a vivência do sofrimento moral devem ser incentivados (McCarthy \& Gastmans, 2015). 


\section{ESTUDO II - CONSTRUIR E BUSCAR EVIDÊNCIAS DE VALIDADE DA ESCALA DE RISCO DE SOFRIMENTO MORAL}

Esse capítulo responde ao segundo objetivo específico da tese: 'Construir e buscar evidências de validade da escala de risco de sofrimento moral em uma amostra de enfermeiros assistenciais do sul do Brasil e de Portugal'. Primeiro, é descrito o processo de validação de conteúdo, conduzido através da análise de juízes. Depois, o processo de validação de constructo, realizado através da análise fatorial, para ambos os países.

A busca de evidências de validade por análise fatorial no sul do Brasil foi publicada na revista Nursing Ethics, [Epub ahead of print], 2017 (Schaefer, Zoboli, \& Vieira, 2017).

\subsection{RESULTADOS}

Dos 15 juízes portugueses contatados para participar do estudo, 5 enviaram respostas completas e 1 enviou a listagem de fatores de risco com a grande maioria das respostas em branco, sendo excluído da análise de dados. Entre os juízes portugueses, 4 eram mulheres e 1 era homem, com uma média de idade de cerca de 47 anos. Quanto à titulação acadêmica, 1 participante tinha concluído o mestrado na área da enfermagem e os demais tinham concluído doutoramento na área da enfermagem. Dos 8 peritos brasileiros que receberam a carta convite, 7 retornaram respostas completas, dos quais 5 eram mulheres e 2 eram homens, com uma média de idade de cerca de 50 anos. Com relação à titulação acadêmica, 2 tinham concluído mestrado na área da enfermagem, 3 tinham concluído doutorado na área da enfermagem e 1 tinha concluído pós-doutorado na área da filosofia. Todos os participantes tinham considerável experiência na área da ética na enfermagem, lecionavam e realizavam investigação há mais de 5 anos.

Quanto ao grau em que a escala evidencia o conteúdo do que pretende medir, os itens 'mercantilização dos cuidados de saúde', 'barreiras linguísticas e culturais', 'inexistência de comissões de ética', 'problemas na estrutura física da instituição' e 'questões de gênero' foram os que suscitaram maiores dúvidas, sendo considerados menos relevantes para medir a variável latente, ou seja, o sofrimento moral (Tabela 6). 
Tabela 6 - Fatores de risco e percentuais de relevância dos itens

\begin{tabular}{|c|c|c|c|c|}
\hline \multirow[t]{3}{*}{ Fatores de risco } & \multicolumn{4}{|c|}{$\begin{array}{l}\text { Considera o item um fator de risco } \\
\text { para sofrimento moral? }\end{array}$} \\
\hline & \multicolumn{2}{|c|}{ Portugal } & \multicolumn{2}{|c|}{ Brasil } \\
\hline & Sim & Não & Sim & Não \\
\hline Conflitos entre paciente, família, profissionais & $100 \%$ & & $100 \%$ & \\
\hline Conflitos religiosos / espirituais & $100 \%$ & & $100 \%$ & \\
\hline Demora no atendimento & $80 \%$ & $30 \%$ & $90 \%$ & $10 \%$ \\
\hline Desorganização do sistema de saúde & $80 \%$ & $20 \%$ & $60 \%$ & $40 \%$ \\
\hline Despreparo para lidar com a morte & $100 \%$ & & $90 \%$ & $10 \%$ \\
\hline Desrespeito à vontade do paciente & $100 \%$ & & $100 \%$ & \\
\hline Desvalorização profissional & $100 \%$ & & $100 \%$ & \\
\hline Esgotamento físico / mental / emocional & $100 \%$ & & $90 \%$ & $10 \%$ \\
\hline Estresse & $60 \%$ & $40 \%$ & $70 \%$ & $30 \%$ \\
\hline $\begin{array}{l}\text { Estrutura hierárquica que determina a impotência e a } \\
\text { subordinação do enfermeiro ao médico }\end{array}$ & $80 \%$ & & $90 \%$ & $10 \%$ \\
\hline $\begin{array}{l}\text { Expectativas de outros em relação à atuação do } \\
\text { enfermeiro }\end{array}$ & $80 \%$ & $20 \%$ & $70 \%$ & $30 \%$ \\
\hline Falsas esperanças para pacientes e familiares & $80 \%$ & & $70 \%$ & $30 \%$ \\
\hline Falta de apoio da instituição & $100 \%$ & & $100 \%$ & \\
\hline Falta de apoio dos colegas & $100 \%$ & & $100 \%$ & \\
\hline Falta de competência de outros profissionais & $100 \%$ & & $90 \%$ & $10 \%$ \\
\hline Falta de competência pessoal & $60 \%$ & $40 \%$ & $90 \%$ & $10 \%$ \\
\hline Falta de consideração pelos seus conhecimentos & $80 \%$ & $20 \%$ & $100 \%$ & \\
\hline Falta de diálogo / comunicação entre profissionais & $100 \%$ & & $100 \%$ & \\
\hline Falta de discussão sobre questões éticas no serviço & $100 \%$ & & $80 \%$ & $20 \%$ \\
\hline Falta de enfermeiros & $100 \%$ & & $100 \%$ & \\
\hline Falta de financiamento, recursos, equipamentos & $80 \%$ & $20 \%$ & $100 \%$ & \\
\hline Falta de liderança eficaz no serviço & $100 \%$ & & $100 \%$ & \\
\hline Falta de tempo por excesso de trabalho & $80 \%$ & $20 \%$ & $100 \%$ & \\
\hline Impossibilidade de crescimento profissional & $80 \%$ & $20 \%$ & $70 \%$ & $30 \%$ \\
\hline $\begin{array}{l}\text { Impotência para contestar decisões de outros } \\
\text { profissionais }\end{array}$ & $80 \%$ & $20 \%$ & $100 \%$ & \\
\hline Inexistência de comissões de ética & $40 \%$ & $60 \%$ & $70 \%$ & $30 \%$ \\
\hline Insatisfação com o trabalho & $100 \%$ & & $60 \%$ & $40 \%$ \\
\hline Medo de atuar profissionalmente & $100 \%$ & & $70 \%$ & $30 \%$ \\
\hline Medo de não ser aceito pela equipe & $100 \%$ & & $90 \%$ & $10 \%$ \\
\hline Medo de não terminar o trabalho a tempo & $80 \%$ & $20 \%$ & $90 \%$ & $10 \%$ \\
\hline Medo de notificar erros que você cometeu & $100 \%$ & & $100 \%$ & \\
\hline Medo de perder o emprego & $100 \%$ & & $90 \%$ & $10 \%$ \\
\hline Mercantilização dos cuidados de saúde & $40 \%$ & $60 \%$ & $80 \%$ & $20 \%$ \\
\hline Não ser incluído na tomada de decisões & $100 \%$ & & $100 \%$ & \\
\hline Normas institucionais que dificultam o cuidado & $100 \%$ & & $100 \%$ & \\
\hline $\begin{array}{l}\text { Número excessivo de pacientes atribuídos a cada } \\
\text { enfermeiro }\end{array}$ & $100 \%$ & & $100 \%$ & \\
\hline $\begin{array}{l}\text { Observar cuidado inadequado ou desnecessário feito } \\
\text { por outros profissionais }\end{array}$ & $100 \%$ & & $100 \%$ & \\
\hline Obstáculos linguísticos e culturais & $40 \%$ & $60 \%$ & $60 \%$ & $40 \%$ \\
\hline Paciente sem condições de pagar pelo tratamento & $80 \%$ & $30 \%$ & $90 \%$ & $10 \%$ \\
\hline Pouca autonomia no trabalho & $100 \%$ & & $100 \%$ & \\
\hline Presenciar comportamento inadequado de familiares & $80 \%$ & $20 \%$ & $70 \%$ & $30 \%$ \\
\hline Problemas na estrutura física da instituição & $40 \%$ & $60 \%$ & $90 \%$ & $10 \%$ \\
\hline
\end{tabular}


Questões de gênero pelo estereótipo de poder que associa o masculino à medicina e o feminino à enfermagem

Realização pessoal reduzida

Sentir-se impotente para mudar o contexto

Ser forçado a não contar a verdade ao paciente

Ser forçado a quebrar confidencialidade e sigilo

Ser forçado a transgredir as regras

Ser obrigado a prestar cuidado inadequado ou

desnecessário

Ser questionado sobre informações que são sigilosas

Ter que decidir pelo paciente

Uso abusivo da alta tecnologia no prolongamento da vida

\begin{tabular}{cccc}
$40 \%$ & $\mathbf{6 0 \%}$ & $40 \%$ & $\mathbf{6 0} \%$ \\
$100 \%$ & & $60 \%$ & $40 \%$ \\
$100 \%$ & & $80 \%$ & $20 \%$ \\
$100 \%$ & & $100 \%$ & \\
$80 \%$ & $20 \%$ & $100 \%$ & \\
$80 \%$ & $20 \%$ & $100 \%$ & \\
$80 \%$ & $20 \%$ & $100 \%$ & \\
$60 \%$ & $40 \%$ & $90 \%$ & $10 \%$ \\
$80 \%$ & $20 \%$ & $90 \%$ & $10 \%$ \\
$80 \%$ & $20 \%$ & $60 \%$ & $40 \%$ \\
$100 \%$ & & $90 \%$ & $10 \%$ \\
\hline
\end{tabular}

A decisão final sobre os itens da escala cabe ao autor, por isso, e considerando a fundamentação metodológica adotada nessa investigação, onde somente itens com percentuais de discordância acima de $80 \%$ seriam passíveis de eliminação, nenhum dos itens foi excluído nessa etapa (DeVellis, 2016). Aos 53 itens foi associada uma escala do tipo Likert de 4 pontos, conforme Quadro 2.

Quadro 2 -Escala de Risco de Sofrimento Moral (versão pré final)

\begin{tabular}{|l|c|c|c|c|}
\hline $\begin{array}{l}\text { Com que frequência você vivencia as seguintes } \\
\text { situações no seu dia a dia de trabalho? }\end{array}$ & nunca & raramente & frequentemente & sempre \\
\hline Falta de liderança eficaz no serviço & 1 & 2 & 3 & 4 \\
\hline $\begin{array}{l}\text { Falta de diálogo / comunicação entre } \\
\text { profissionais }\end{array}$ & 1 & 2 & 3 & 4 \\
\hline Realização pessoal reduzida & 1 & 2 & 3 & 4 \\
\hline Desorganização do sistema de saúde & 1 & 2 & 3 & 4 \\
\hline Falta de apoio dos colegas & 1 & 2 & 3 & 4 \\
\hline Medo de atuar profissionalmente & 1 & 2 & 3 & 4 \\
\hline Desvalorização profissional & 1 & 2 & 3 & 4 \\
\hline Falta de enfermeiros & 1 & 2 & 3 & 4 \\
\hline Mercantilização dos cuidados de saúde & 1 & 2 & 3 & 4 \\
\hline Falta de competência pessoal & 1 & 2 & 3 & 4 \\
\hline $\begin{array}{l}\text { Ser obrigado a prestar cuidado inadequado ou } \\
\text { desnecessário }\end{array}$ & 1 & 2 & 3 & 4 \\
\hline Obstáculos linguísticos e culturais & 1 & 2 & 3 & 4 \\
\hline $\begin{array}{l}\text { Falta de discussão sobre questões éticas no } \\
\text { serviço }\end{array}$ & 1 & 2 & 3 & 4 \\
\hline $\begin{array}{l}\text { Expectativas de outros em relação à atuação do } \\
\text { enfermeiro }\end{array}$ & 1 & 2 & 3 & 4 \\
\hline Inexistência de comissões de ética & 1 & 2 & 3 & 4 \\
\hline Falta de tempo por excesso de trabalho & 1 & 2 & 3 & 4 \\
\hline Falta de financiamento, recursos, equipamentos & 1 & 2 & 3 & 4 \\
\hline
\end{tabular}




\begin{tabular}{|c|c|c|c|c|}
\hline Falta de consideração pelos seus conhecimentos & 1 & 2 & 3 & 4 \\
\hline Despreparo para lidar com a morte & 1 & 2 & 3 & 4 \\
\hline Desrespeito à vontade do paciente & 1 & 2 & 3 & 4 \\
\hline Falsas esperanças para pacientes e familiares & 1 & 2 & 3 & 4 \\
\hline Estresse & 1 & 2 & 3 & 4 \\
\hline Problemas na estrutura física da instituição & 1 & 2 & 3 & 4 \\
\hline Medo de perder o emprego & 1 & 2 & 3 & 4 \\
\hline $\begin{array}{l}\text { Presenciar comportamento inadequado de } \\
\text { familiares }\end{array}$ & 1 & 2 & 3 & 4 \\
\hline Falta de competência de outros profissionais & 1 & 2 & 3 & 4 \\
\hline $\begin{array}{l}\text { Uso abusivo da alta tecnologia no } \\
\text { prolongamento da vida }\end{array}$ & 1 & 2 & 3 & 4 \\
\hline Impossibilidade de crescimento profissional & 1 & 2 & 3 & 4 \\
\hline Esgotamento físico / mental / emocional & 1 & 2 & 3 & 4 \\
\hline Normas institucionais que dificultam o cuidado & 1 & 2 & 3 & 4 \\
\hline Uso inadequado dos recursos disponíveis & 1 & 2 & 3 & 4 \\
\hline Medo de não ser aceito pela equipe & 1 & 2 & 3 & 4 \\
\hline Medo de notificar erros que você cometeu & 1 & 2 & 3 & 4 \\
\hline $\begin{array}{l}\text { Ser questionado sobre informações que são } \\
\text { sigilosas }\end{array}$ & 1 & 2 & 3 & 4 \\
\hline Sentir-se impotente para mudar o contexto & 1 & 2 & 3 & 4 \\
\hline $\begin{array}{l}\text { Estrutura hierárquica que determina a } \\
\text { impotência e a subordinação do enfermeiro ao } \\
\text { médico }\end{array}$ & 1 & 2 & 3 & 4 \\
\hline $\begin{array}{l}\text { Número excessivo de pacientes atribuídos a cada } \\
\text { enfermeiro }\end{array}$ & 1 & 2 & 3 & 4 \\
\hline $\begin{array}{l}\text { Observar cuidado inadequado ou desnecessário } \\
\text { feito por outros profissionais }\end{array}$ & 1 & 2 & 3 & 4 \\
\hline Conflitos entre paciente, família, profissionais & 1 & 2 & 3 & 4 \\
\hline Questões de gênero & 1 & 2 & 3 & 4 \\
\hline Ser forçado a não contar a verdade ao paciente & 1 & 2 & 3 & 4 \\
\hline Não ser incluído na tomada de decisões & 1 & 2 & 3 & 4 \\
\hline Demora no atendimento & 1 & 2 & 3 & 4 \\
\hline $\begin{array}{l}\text { Paciente sem condições de pagar pelo } \\
\text { tratamento }\end{array}$ & 1 & 2 & 3 & 4 \\
\hline Falta de apoio da instituição & 1 & 2 & 3 & 4 \\
\hline $\begin{array}{l}\text { Impotência para contestar decisões de outros } \\
\text { profissionais }\end{array}$ & 1 & 2 & 3 & 4 \\
\hline Realização pessoal reduzida & 1 & 2 & 3 & 4 \\
\hline Ser forçado a transgredir as regras & 1 & 2 & 3 & 4 \\
\hline Ser forçado a quebrar confidencialidade e sigilo & 1 & 2 & 3 & 4 \\
\hline Medo de não terminar o trabalho a tempo & 1 & 2 & 3 & 4 \\
\hline Pouca autonomia no trabalho & 1 & 2 & 3 & 4 \\
\hline Ter que decidir pelo paciente & 1 & 2 & 3 & 4 \\
\hline Conflitos religiosos / espirituais & 1 & 2 & 3 & 4 \\
\hline
\end{tabular}

A escala foi enviada para uma amostra de enfermeiros assistenciais do sul do Brasil e para uma amostra de enfermeiros assistenciais de Portugal. Os resultados foram submetidos à análise fatorial exploratória e são descritos a seguir. 


\subsubsection{Brasil}

No Brasil, a validação de constructo resultou da análise das respostas de 268 participantes. Os participantes eram, em sua maioria, mulheres $(n=239 ; 89,2 \%)$, com média de idade de cerca de 36 anos $(\mathrm{DP}=8,6)$ e média de anos na profissão de cerca de $10 \operatorname{anos}(\mathrm{DP}=8,1)$.

$\mathrm{Na}$ análise fatorial exploratória, todos os itens com carga fatorial menor do que 0,5 foram excluídos. Além disso, todos os itens foram cuidadosamente analisados durante o processo para assegurar que a análise mantinha consistência teórica. A melhor explicação fatorial foi a análise que compunha a escala com 7 fatores, 30 itens, 59,8\% da variância explicada, Alpha de Cronbach $=0,913$, teste de Kaiser-Meyer Olkin $(\mathrm{KMO})=$ 0,869 e índice de Bartlett significativo com $\mathrm{p}<0,001$.

Os fatores identificados foram nomeados como: Questões institucionais e de gestão: desafios no local de trabalho; Cuidado em fim de vida: dificuldade para prestar cuidados em fim de vida; Autonomia: autonomia profissional reduzida; Carga de trabalho: excessiva carga de trabalho; Segurança: falta de segurança profissional; Recursos: falta de recursos; Conflitos: conflitos no cuidado.

O primeiro fator é formado por 7 itens, nomeadamente: esgotamento físico, mental e emocional; estresse; problemas na estrutura física da instituição; realização pessoal reduzida; desvalorização profissional; desorganização do sistema de saúde; e normas institucionais que dificultam o cuidado. Foi nomeado de 'questões institucionais e de gestão', apresenta uma média de 2,89, um Alpha de Cronbach de 0,939 e explica $13 \%$ da variância. O segundo fator é formado por 6 itens: falsas esperanças para pacientes e familiares; uso abusivo da alta tecnologia no prolongamento da vida; desrespeito à vontade do paciente; despreparo para lidar com a morte; uso inadequado dos recursos disponíveis; obstáculos linguísticos e culturais, sendo denominada de 'cuidado em fim de vida'. A média desse fator é de 2,19, o Alpha de Cronbach é 0,772 e explica $10 \%$ da variância.

Depois, o terceiro fator, formado por 4 itens: pouca autonomia no trabalho; não ser incluído na tomada de decisões; estrutura hierárquica que determina a impotência e a subordinação do enfermeiro ao médico; e impotente para contestar decisões de outros 
profissionais. A esse fator, com média de 2,44, Alpha de Cronbach de 0,830 e 9,4\% de explicação da variância, deu-se o nome 'Autonomia'. O quarto fator denomina-se 'Carga de trabalho' e também é formado por 4 itens: falta de enfermeiros; mercantilização dos cuidados de saúde; número excessivo de pacientes atribuídos a cada enfermeiro; e falta de tempo por excesso de trabalho. A média desse fator foi 2,80, o Alpha de Cronbach 0,761 e a variância explicada de $8 \%$.

O quinto fator inclui 4 itens: medo de notificar erros que você cometeu; ser questionado sobre informações que são confidenciais; medo de não ser aceito pela equipe; e medo de perder o emprego. O fator apresentou média de 2,00, Alpha de Cronbach de 0,657 e explica $7,4 \%$ da variância, recebendo o nome de 'Segurança'. O sexto fator é composto por 3 itens: demora no atendimento; paciente sem condições de pagar pelo tratamento; e falta de financiamento, recursos e equipamentos. A esse fator que explica 6,2\% da variância, tem média de 2,62 e Alpha de Cronbach de 0,572, deu-se o nome de 'Recursos'. O último fator foi formado por 2 itens: presenciar comportamento inadequado de familiares; e conflito entre paciente, família e profissional, deu-se o nome de 'Conflitos'. Esse fator explica 5,8\% da variância, tem média de 2,57 e Alpha de Cronbach de 0,669 .

Todos os fatores e seus respectivos itens e valores estão descritos na Tabela 7. 
Tabela 7 - Fatores e cargas fatorais dos itens da Escala de Risco de Sofrimento Moral, Rio Grande do Sul, Brasil (n = 268)

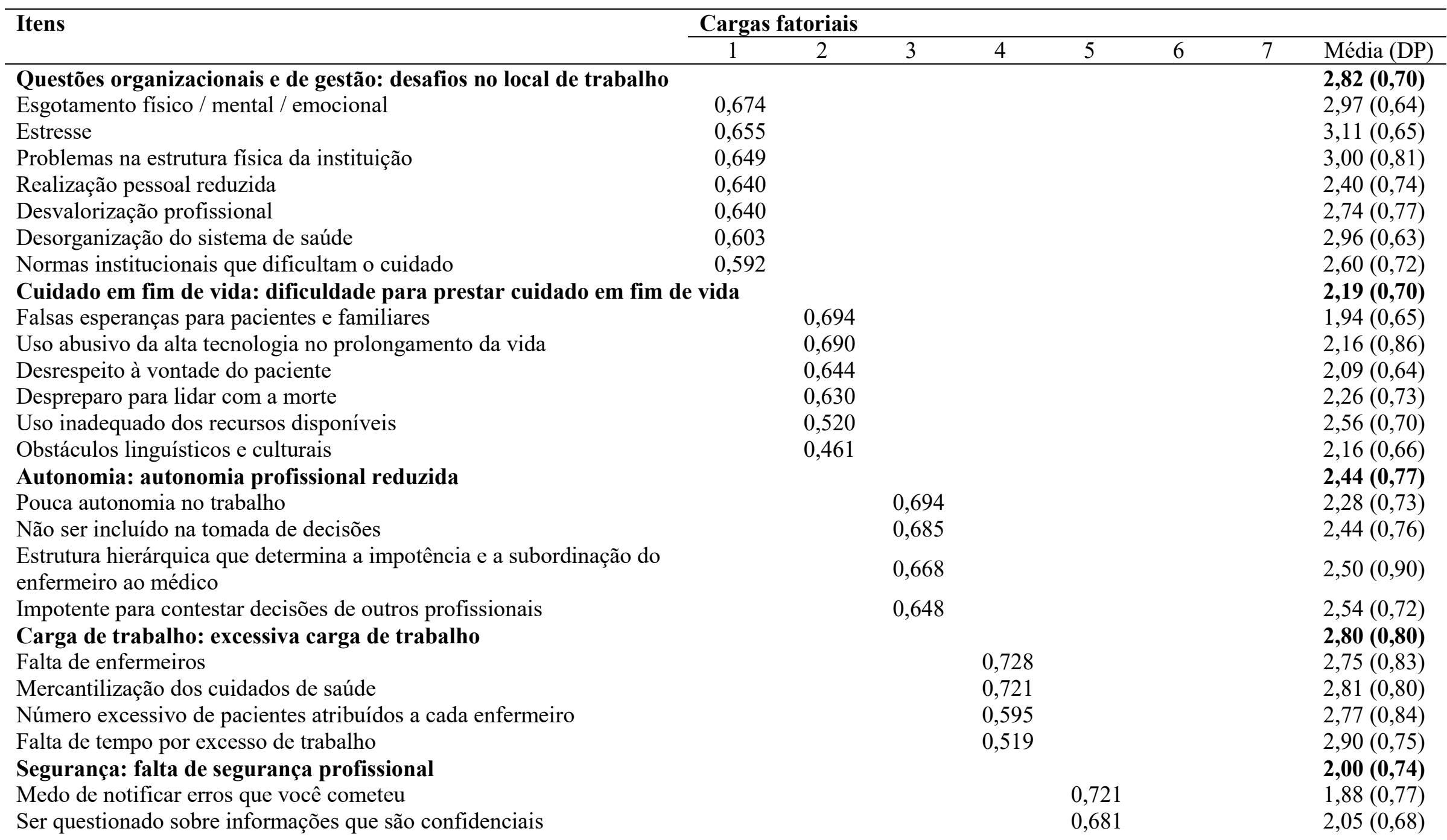


Medo de não ser aceito pela equipe

Medo de perder o emprego

Recursos: falta de recursos

Demora no atendimento

0,687

0,654

Paciente sem condições de pagar pelo tratamento

Falta de financiamento / recursos / equipamentos

Orientação interpessoal: conflitos no cuidado

$2,84(0,77)$

$\mathbf{2 , 5 7}(\mathbf{0 , 6 4 )}$

Presenciar comportamento inadequado de familiares

Conflitos entre paciente, família e profissionais

\begin{tabular}{rrrrrrrrrc} 
Alpha de Cronbach & 0,839 & 0,772 & 0,830 & 0,761 & 0,657 & 0,572 & 0,669 & 2,44 & $(0,63)$ \\
Variância & $13 \%$ & $10 \%$ & $9,4 \%$ & $8 \%$ & $7,4 \%$ & $6,2 \%$ & $5,8 \%$ & - \\
Variância cumulativa & $13 \%$ & $23 \%$ & $32,4 \%$ & $40,4 \%$ & $47,8 \%$ & $54 \%$ & $\mathbf{5 9 , 8 \%}$ & - \\
\hline
\end{tabular}


A média dos itens foi de 2,50, variando de 1,88 a 3,11, o que indica moderado risco para sofrimento moral na amostra investigada. A escala, com forte evidência de validade para a população de enfermeiros do sul do Brasil, foi nomeada de Escala de Risco de Sofrimento Moral (ERSM) e é apresentada no Quadro 3.

\section{Quadro 3 - Escala de Risco de Sofrimento Moral (versão brasileira)}

\begin{tabular}{|c|c|c|c|c|}
\hline $\begin{array}{l}\text { Com que frequência você vivencia as seguintes } \\
\text { situações no seu dia a dia de trabalho? }\end{array}$ & nunca & raramente & frequentemente & sempre \\
\hline Desorganização do sistema de saúde & 1 & 2 & 3 & 4 \\
\hline Desvalorização profissional & 1 & 2 & 3 & 4 \\
\hline Falta de enfermeiros & 1 & 2 & 3 & 4 \\
\hline Mercantilização dos cuidados de saúde & 1 & 2 & 3 & 4 \\
\hline Obstáculos linguísticos e culturais & 1 & 2 & 3 & 4 \\
\hline Falta de tempo por excesso de trabalho & 1 & 2 & 3 & 4 \\
\hline Falta de financiamento/ recursos/ equipamentos & 1 & 2 & 3 & 4 \\
\hline Despreparo para lidar com a morte & 1 & 2 & 3 & 4 \\
\hline Desrespeito à vontade do paciente & 1 & 2 & 3 & 4 \\
\hline Falsas esperanças para pacientes e familiares & 1 & 2 & 3 & 4 \\
\hline Estresse & 1 & 2 & 3 & 4 \\
\hline Problemas na estrutura física da instituição & 1 & 2 & 3 & 4 \\
\hline Medo de perder o emprego & 1 & 2 & 3 & 4 \\
\hline $\begin{array}{l}\text { Presenciar comportamento inadequado de } \\
\text { familiares }\end{array}$ & 1 & 2 & 3 & 4 \\
\hline $\begin{array}{l}\text { Uso abusivo da alta tecnologia no } \\
\text { prolongamento da vida }\end{array}$ & 1 & 2 & 3 & 4 \\
\hline Esgotamento físico / mental / emocional & 1 & 2 & 3 & 4 \\
\hline Normas institucionais que dificultam o cuidado & 1 & 2 & 3 & 4 \\
\hline Uso inadequado dos recursos disponíveis & 1 & 2 & 3 & 4 \\
\hline Medo de não ser aceito pela equipe & 1 & 2 & 3 & 4 \\
\hline Medo de notificar erros que você cometeu & 1 & 2 & 3 & 4 \\
\hline $\begin{array}{l}\text { Ser questionado sobre informações que são } \\
\text { sigilosas }\end{array}$ & 1 & 2 & 3 & 4 \\
\hline $\begin{array}{l}\text { Estrutura hierárquica que determina a } \\
\text { impotência e a subordinação do enfermeiro ao } \\
\text { médico }\end{array}$ & 1 & 2 & 3 & 4 \\
\hline $\begin{array}{l}\text { Número excessivo de pacientes atribuídos a } \\
\text { cada enfermeiro }\end{array}$ & 1 & 2 & 3 & 4 \\
\hline Conflitos entre paciente, família, profissionais & 1 & 2 & 3 & 4 \\
\hline Não ser incluído na tomada de decisões & 1 & 2 & 3 & 4 \\
\hline Demora no atendimento & 1 & 2 & 3 & 4 \\
\hline $\begin{array}{l}\text { Paciente sem condições de pagar pelo } \\
\text { tratamento }\end{array}$ & 1 & 2 & 3 & 4 \\
\hline $\begin{array}{l}\text { Impotência para contestar decisões de outros } \\
\text { profissionais }\end{array}$ & 1 & 2 & 3 & 4 \\
\hline Insatisfação com o trabalho & 1 & 2 & 3 & 4 \\
\hline Pouca autonomia no trabalho & 1 & 2 & 3 & 4 \\
\hline
\end{tabular}




\subsubsection{Portugal}

Em Portugal, a validação de constructo resultou da análise das respostas de 278 participantes que eram, em sua maioria mulheres $(n=229 ; 83,0 \%)$, com média de idade de cerca de 33,7 anos (DP =6,7) e média de anos na profissão de cerca de 6 anos (DP = $5,1)$.

$\mathrm{Na}$ análise fatorial exploratória, todos os itens com carga fatorial menor do que 0,5 foram excluídos. Além disso, todos os itens foram cuidadosamente analisados durante o processo para assegurar que a análise mantinha consistência teórica. A melhor explicação fatorial foi a análise que compunha a escala com 4 fatores, 20 itens, 53,9\% da variância explicada, Alpha de Cronbach $=0,790$, teste de Kaiser-Meyer Olkin $(\mathrm{KMO})=$ 0,914 índice de Bartlett significativo com $\mathrm{p}<0,001$.

Os fatores foram nomeados como: Carga de trabalho: excessiva carga de trabalho; Cuidado: dificuldade para prestar cuidado; Questões organizacionais e de gestão: desafios no local de trabalho; e Segurança: falta de segurança profissional.

O primeiro fator, carga de trabalho, é formado por 6 itens, nomeadamente: falta de enfermeiros, mercantilização dos cuidados de saúde, falta de tempo por excesso de trabalho, stress, esgotamento físico / mental / emocional e número excessivo de utentes atribuídos a cada enfermeiro. Apresenta uma média de 2,97 (DP =0,55), um Alpha de Cronbach de 0,835 e explica $35,5 \%$ da variância.

O segundo fator, cuidado, é formado por 7 itens, quais sejam: ser obrigado a prestar cuidado inadequado ou desnecessário, vontade do utente não é respeitada, uso inadequado dos recursos disponíveis, observar cuidado inadequado ou desnecessário, não ser incluído na tomada de decisões, demora no atendimento e ser forçado a transgredir as regras. Esse fator teve média de 2,24 ( $\mathrm{DP}=0,47)$, Alpha de Cronbach de 0,836 e 7,0\% de explicação da variância.

O terceiro fator, questões organizacionais e de gestão, é formado por quatro itens: falta de liderança eficaz no serviço, realização pessoal reduzida, desvalorização profissional e baixa satisfação em relação ao trabalho. A média foi de 2,57 ( $\mathrm{DP}=0,62)$, Alpha de Cronbach de 0,815 e 6,0\% de explicação da variância. O último fator, segurança, é constituído por três itens: medo de não ser aceito pela equipe, medo de notificar erros 
que você cometeu e questões de gênero. A média foi de 1,93 (DP =0,59), Alpha de Cronbach de 0,674 e 5,4\% de explicação da variância.

Todos os fatores, seus respectivos itens e cargas fatorais estão descritos na Tabela 8. 
Tabela 8 - Fatores e cargas fatorais dos itens da Escala de Risco de Sofrimento Moral, Portugal $(\mathbf{n}=\mathbf{2 7 8})$

\begin{tabular}{|c|c|c|c|c|c|}
\hline \multirow[t]{2}{*}{ Itens } & \multicolumn{4}{|c|}{ Cargas fatorais } & \multirow[b]{2}{*}{ Média (DP) } \\
\hline & 1 & 2 & 3 & 4 & \\
\hline Carga de trabalho: excessiva carga de trabalho & & & & & $2,97(0,55)$ \\
\hline Falta de enfermeiros & 0,693 & & & & $3,12(0,77)$ \\
\hline Mercantilização dos cuidados de saúde & 0,692 & & & & $2,93(0,75)$ \\
\hline Falta de tempo por excesso de trabalho & 0,701 & & & & $3,01(0,67)$ \\
\hline Stress & 0,695 & & & & $3,03(0,62)$ \\
\hline Esgotamento físico / mental / emocional & 0,635 & & & & $2,76(0,70)$ \\
\hline Número excessivo de utentes atribuídos a cada enfermeiro & 0,633 & & & & $2,91(0,82)$ \\
\hline Cuidado: dificuldade para prestar cuidado & & & & & $2,24(0,47)$ \\
\hline Ser obrigado a prestar cuidado inadequado ou desnecessário & & 0,593 & & & $2,11(0,70)$ \\
\hline Vontade do utente não é respeitada & & 0,781 & & & $2,05(0,59)$ \\
\hline Uso inadequado dos recursos disponíveis & & 0,511 & & & $2,47(0,67)$ \\
\hline Observar cuidado inadequado ou desnecessário & & 0,601 & & & $2,36(0,63)$ \\
\hline Não ser incluído na tomada de decisões & & 0,594 & & & $2,43(0,74)$ \\
\hline Demora no atendimento & & 0,645 & & & $2,46(0,60)$ \\
\hline Ser forçado a transgredir as regras & & 0,541 & & & $1,79(0,69)$ \\
\hline Questões organizacionais e de gestão: desafios no local de trabalho & & & & & $2,57(0,62)$ \\
\hline Falta de liderança eficaz no serviço & & & 0,713 & & $2,60(0,71)$ \\
\hline Realização pessoal reduzida & & & 0,765 & & $2,48(0,78)$ \\
\hline Desvalorização profissional & & & 0,635 & & $2,72(0,81)$ \\
\hline Insatisfação com o trabalho & & & 0,619 & & $2,47(0,79)$ \\
\hline Segurança: falta de segurança profissional & & & & & $1,93(0,59)$ \\
\hline Medo de não ser aceito pela equipe & & & & 0,775 & $1,92(0,71)$ \\
\hline Medo de notificar erros que você cometeu & & & & 0,750 & $1,95(0,80)$ \\
\hline Questões de gênero & & & & 0,550 & $1,90(0,76)$ \\
\hline Alpha de Cronbach & 0.835 & 0.836 & 0.815 & 0.674 & - \\
\hline Variância & 35.5 & 7.0 & 6.0 & 5.4 & - \\
\hline Variância cumulativa & 35.5 & 42.5 & 48.5 & 53.9 & - \\
\hline
\end{tabular}


A média dos itens foi de 2,43, variando de 1,79 a 3,12, o que indica risco baixo para sofrimento moral na amostra investigada. A escala é apresentada no Quadro 4.

Quadro 4 - Escala de Risco de Sofrimento Moral (versão portuguesa)

\begin{tabular}{|l|c|c|c|c|}
\hline $\begin{array}{l}\text { Com que frequência você vivencia as seguintes } \\
\text { situações no seu dia a dia de trabalho? }\end{array}$ & nunca & raramente & frequentemente & sempre \\
\hline Falta de enfermeiros & 1 & 2 & 3 & 4 \\
\hline Mercantilização dos cuidados de saúde & 1 & 2 & 3 & 4 \\
\hline Falta de tempo por excesso de trabalho & 1 & 2 & 3 & 4 \\
\hline Stress & 1 & 2 & 3 & 4 \\
\hline Esgotamento físico / mental / emocional & 1 & 2 & 3 & 4 \\
\hline $\begin{array}{l}\text { Número excessivo de utentes atribuídos a cada } \\
\text { enfermeiro }\end{array}$ & 1 & 2 & 3 & 4 \\
\hline $\begin{array}{l}\text { Ser obrigado a prestar cuidado inadequado ou } \\
\text { desnecessário }\end{array}$ & 1 & 2 & 3 & 4 \\
\hline Vontade do utente não é respeitada & 1 & 2 & 3 & 4 \\
\hline Uso inadequado dos recursos disponíveis & 1 & 2 & 3 & 4 \\
\hline Observar cuidado inadequado ou desnecessário & 1 & 2 & 3 & 4 \\
\hline Não ser incluído na tomada de decisões & 1 & 2 & 3 & 4 \\
\hline Demora no atendimento & 1 & 2 & 3 & 4 \\
\hline Ser forçado a transgredir as regras & 1 & 2 & 3 & 4 \\
\hline Falta de liderança eficaz no serviço & 1 & 2 & 3 & 4 \\
\hline Realização pessoal reduzida & 1 & 2 & 3 & 4 \\
\hline Desvalorização profissional & 1 & 2 & 3 & 4 \\
\hline Insatisfação com o trabalho & 1 & 2 & 3 & 4 \\
\hline Medo de não ser aceito pela equipe & 1 & 2 & 3 & 4 \\
\hline Medo de notificar erros que você cometeu & 1 & 2 & 3 & 4 \\
\hline Questões de gênero & 1 & 2 & 3 & 4 \\
\hline
\end{tabular}

\subsection{DISCUSSÃO}

As escalas são ferramentas quantitativas muito utilizadas na enfermagem, inclusivamente, para estudar o sofrimento moral (Corley, Elswick, Gorman, \& Clor, 2001) (Eizenberg, Desivilya, \& Hirschfeld, 2009) (Wocial \& Weaver, 2013). De fato, medir ou quantificar fenômenos sociais ou comportamentais é uma atividade fundamental na ciência, que auxilia na aquisição de conhecimento acerca de pessoas, eventos ou processos. A análise de juízes busca evidências de validade de conteúdo, com o intuito de assegurar a relevância de cada item na escala. A concordância dos peritos demonstra que a escala tem boas chances de alcançar bons resultados nos próximos níveis de validação (DeVellis, 2016). 
É fundamental garantir que a ferramenta utilizada seja capaz de avaliar o que pretende, caso contrário, a validade das conclusões pode ser posta em causa. A construção de uma escala confiável e com evidências de validade pressupõe, primeiro, um amplo conhecimento acerca do fenômeno de interesse e acerca das ferramentas quantitativas já disponíveis. Depois, é preciso garantir que os testes psicométricos sejam os mais fidedignos possíveis (DeVellis, 2016).

Considerando que o item que se deseja medir, no caso, o sofrimento moral, não é uma variável diretamente observável e que pressupõe pensamento por parte do respondente, ou seja, será preciso que, durante o preenchimento, o entrevistado reconstrua, interprete, julgue, compare ou avalie informações menos acessíveis, uma escala pode ser a ferramenta de avaliação mais apropriada. Nesses casos, itens múltiplos podem capturar a essência da variável com um grau de precisão que um único item não poderia alcançar (DeVellis, 2016).

As escalas podem ser desenvolvidas a partir de fontes teóricas, empíricas ou mesmo através da combinação de diferentes estratégias. Na área do sofrimento moral, por exemplo, entrevistas com enfermeiros, consultas com peritos (Corley, Elswick, Gorman, \& Clor, 2001), estudos de caso e adaptação de ferramentas já existentes (Eizenberg, Desivilya, \& Hirschfeld, 2009) são das estratégias mais utilizadas. Seja qual for o caminho, o ponto crucial, segundo DeVellis (2016) é garantir que a escala seja desenvolvida com cuidado e não represente apenas um agregado de itens, mas antes, que esses itens façam sentido entre si e compartilhem uma causa comum.

Para que uma escala alcance um nível de sensibilidade capaz de captar os detalhes dos diferentes contextos da prática profissional, a heterogeneidade de seu conteúdo é uma característica primordial (DeVellis, 2016). O método utilizado para identificar os fatores de risco nesse estudo, através de extensa revisão de dados empíricos provenientes de pesquisas com enfermeiros dos mais variados serviços de saúde ao redor do mundo, foi importante para alcançar esse objetivo (Arksey \& O’Malley, 2005).

Depois, foi preciso verificar se os dados eram fatoráveis, o que foi determinado pelo teste de esfericidade de Bartlett e pelo índice KMO. OS resultados mostraram que existiam correlações suficientes entre as variáveis, bem como o conjunto de dados era adequado para realizar a análise fatorial exploratória (DeVellis, 2016). 
Uma vez desenvolvida a escala, é preciso assegurar sua confiabilidade e sua sensibilidade, sendo a análise fatorial um dos testes psicométricos mais utilizados nesse processo. Esse tipo de análise busca identificar categorias com afirmações semelhantes e quantas dessas categorias serão suficientes para capturar a maior parte das informações contidas no conjunto original. No fundo, busca-se extrair do conjunto de dados, no caso, da lista de fatores de risco para sofrimento moral, as categorias necessárias para explicar o fenômeno em estudo. Nesse processo, os itens individuais, que não se encaixam em nenhuma das categorias identificadas, podem ser considerados para eliminação (DeVellis, 2016).

A confiabilidade de uma escala é, comumente, medida através do coeficiente Alpha de Cronbach, que representa o grau de consistência interna da escala, ou seja, a homogeneidade dos seus itens. Uma escala é internamente consistente quanto mais os seus itens forem correlacionados uns com os outros, o que sugere que estão todos medindo a mesma coisa (DeVellis, 2016). Os valores de Alpha de Cronbach alcançados neste estudo foram considerados adequados.

A amostra utilizada para submeter a escala aos testes psicométricos foi considerada adequada, uma vez que obedece aos critérios exigidos com relação ao número de participantes por item para a realização de uma análise fatorial. Não é raro ver análises fatoriais utilizando amostras pequenas, mas há que se considerar que amostras maiores aumentam o grau de generalização das conclusões obtidas (DeVellis, 2016). A amostra é comparável com amostras de outros estudos válidos na área do sofrimento moral, tanto em relação às características dos participantes, quanto à experiência na área da enfermagem (Borhani, Mohammadi, \& Roshanzadeh, 2015) (Trautmann, Epstein, Rovnyak, \& Snyder, 2015) (Dyo, Kalowes, \& Devries, 2016).

Cada um dos fatores identificados através da análise fatorial precisou ser analisado quanto aos itens que mais fortemente o exemplificam, isto é, que tem as maiores cargas fatorais, porque são eles que mais se correlacionam com o fenômeno em estudo e, portanto, são os mais adequados para determinar a natureza do fator em questão. $\mathrm{O}$ processo é facilitado quando há vários itens que claramente carregam um significado comum. Embora possa parecer simples nomear cada um dos fatores, a coerência pode determinar sua validade (DeVellis, 2016). 
Os fatores de risco relacionados com as questões organizacionais e de gestão representam desafios substanciais para os enfermeiros nos locais de trabalho. Outros estudos na literatura de enfermagem, principalmente relacionados com o sofrimento moral, também identificaram esse tipo de desafio em seus resultados (Harrowing \& Mill, 2010) (Maluwa, Andre, Ndebele, \& Chilemba, 2012). Varcoe, Pauly, Webster \& Storch (2012), já chamavam atenção para a necessidade de desenvolver instrumentos mais amplos, que considerem questões políticas, sociais e econômicas em relação ao sofrimento moral, para além das questões individuais.

De fato, a literatura destaca que, ultimamente, o sofrimento moral tem sido mais investigado a partir de uma perspectiva psicológica e individual, e menos a partir das características organizacionais que o afetam (Wall, Austin, \& Garros, 2016). Consequentemente, surge a ideia de que o enfrentamento para o sofrimento moral está em uma maior coragem moral por parte do indivíduo, o que é potencialmente problemático, já que deposita no indivíduo solitário toda a responsabilidade, diminuindo a participação da organização (Austin, 2016).

As dificuldades no cuidado em fim de vida envolvem, principalmente, questões relacionadas com a falta de limites na manutenção da vida de pacientes terminais (McAndrew, Leske, \& Schroeter, 2016) e com a resistência aos cuidados paliativos (Wall, Austin, \& Garros, 2016). Segundo Borhani, Mohammadi \& Roshanzadeh (2015), o cuidado fútil está fortemente associado à vivência do sofrimento moral pelo enfermeiro, quando o profissional sabe que o cuidado não é eficaz, mas é obrigado a fornecê-lo. A resistência aos cuidados paliativos pode despertar, para além da preocupação com o cuidado fútil, uma preocupação social acerca da quantidade de recursos empregada no tratamento dos extremos da população, enquanto os recursos de saúde estão cada vez mais limitados. O estudo de Wall, Austin \& Garros (2006) questiona o gasto excessivo com pacientes sabidamente terminais e o pouco investimento em iniciativas mais amplas de saúde da população. Nesse contexto, o sofrimento moral advém do sentimento de não estar fazendo o que é melhor para a sociedade como um todo.

A autonomia profissional chama atenção para um fato já destacado por Corley, Elswick, Gorman \& Clor (2001): o enfermeiro, frequentemente, possui mais responsabilidade do que autoridade no seu contexto de trabalho. Ele executa, mas dificilmente é considerado no processo de tomada de decisão. Esse problema pode ser 
ainda mais sério em contextos onde as regras são determinadas pela chefia, sem participação das partes interessadas, com estruturas hierárquicas burocráticas e atitudes inflexíveis por parte da instituição (Atabay, Cangarli, \& Penbek, 2015).

A carga de trabalho do enfermeiro é um dos fatores mais presentes em estudos ao redor de mundo, principalmente relacionado com a falta de enfermeiros. A falta de pessoal compromete a qualidade do atendimento e a segurança do paciente, originando uma percepção de incapacidade para cumprir com a responsabilidade profissional, caracterizando fonte de sofrimento moral (Wolf, et al., 2016). A excessiva carga de trabalho leva ao desgaste a à alienação profissional, tanto porque priva o profissional de dar atenção e ouvir o seu paciente, quanto porque rouba dos enfermeiros o tempo para que reflitam sobre o seu próprio sofrimento (Maluwa, Andre, Ndebele, \& Chilemba, 2012).

A falta de segurança profissional agrega fatores de risco que parecem estar mais relacionados com o início da carreira profissional. De fato, alguns estudos mostram que o sofrimento moral costuma ser maior nos enfermeiros mais jovens, quando comparado com profissionais mais experientes (Woods, Rodgers, Towers, \& Grow, 2015). A literatura sugere que a explicação para essa associação pode estar tanto na aquisição de experiência e desenvolvimento de mecanismos de defesa, com o aumento da idade e dos anos de serviço (Borhani, Mohammadi, \& Roshanzadeh, 2015), quanto com o fato de que um maior conhecimento dos enfermeiros mais jovens acerca do conteúdo moral das ações diárias possa os deixar mais suscetíveis a vivenciar o sofrimento moral (Woods, Rodgers, Towers, \& Grow, 2015).

A falta de recursos é um elemento que põe em risco o cumprimento do compromisso moral profissional do enfermeiro, qual seja, prestar o melhor cuidado de enfermagem. Quando o enfermeiro percebe que a falta de recursos acarreta prejuízo para os resultados do paciente, o sofrimento moral é inevitável (Wolf, et al., 2016). Também, os conflitos no cuidado, que derivam do desentendimento entre profissionais, familiares e pacientes. Segundo Johnstone \& Hutchison (2015), nessas situações, a máxima atenção deve ser direcionada para evitar o risco da imposição moral, quando o enfermeiro, ou outro profissional da equipe de saúde, impõe o seu ponto de vista sobre a decisão do paciente. 
De uma forma geral, os fatores guardam muitas similaridades entre si e com algumas das ferramentas já utilizadas para investigar sofrimento moral, principalmente em relação aos temas de cuidado em fim de vida, carga de trabalho, conflitos e autonomia, o que pode estar relacionado com o considerável número de estudos que usaram a mesma ferramenta para recolha de dados (Corley, Elswick, Gorman, \& Clor, 2001). Entretanto, é possível notar algumas diferenças entre as versões brasileira e portuguesa da escala, nomeadamente a ausência dos fatores relacionados com o cuidado em fim de vida e com a falta de recursos na versão portuguesa, além de um maior enfoque sobre as preocupações financeiras na versão brasileira.

O tema dos cuidados em fim de vida está fortemente atrelado ao tema dos cuidados paliativos. Em Portugal, o número de serviços e também de formação pós-graduada na área dos cuidados paliativos tem vindo a aumentar. Há um interesse especial do enfermeiro pela temática, apesar das equipes serem sempre de abordagem interdisciplinar (Ferreira, Pereira, Martins, \& Barbieri-Figueiredo, 2016). Essa pode ser uma das razões pelas quais os itens relacionados com as dificuldades no cuidado em fim de vida acabaram por não integrar a versão final da escala para Portugal, traduzindo uma menor vivência de falta de limites para o tratamento fútil para os enfermeiros desse contexto (McAndrew, Leske, \& Schroeter, 2016).

Em relação à falta de recursos, a maior preocupação dos enfermeiros brasileiros com essa temática ficou clara não só por esse fator não constar na versão portuguesa, mas também pelos itens em si, nos quais a preocupação com a falta de financiamento, com a falta de estrutura, com o uso inadequado dos recursos disponíveis e com a demora no atendimento ficou mais evidente. A literatura corrobora esse achado nos resultados de outros estudos sobre sofrimento moral realizados em países em desenvolvimento, onde as dificuldades financeiras foram encontradas como uma das principais fontes de sofrimento moral nos enfermeiros (Harrowing \& Mill, 2010) (Maluwa, Andre, Ndebele, \& Chilemba, 2012).

O nível moderado de sofrimento moral encontrado na amostra sul Brasileira é consistente com outros estudos (Lusignani, Gianni, Re, \& Buffon, 2016) (Borhani, Abbaszadeh, Nakhaee, \& Roshanzadeh, 2014), embora todos tenham sido realizados exclusivamente em ambiente hospitalar. Também o baixo nível de sofrimento moral, como o encontrado para a amostra de enfermeiros portugueses, já foi descrito em estudos 
anteriores (Xiaoyan, Yufang, Lifeng, \& Congcong, 2016). A literatura afirma que o sofrimento moral costuma ser maior em contextos hospitalares, quando comparado com outros serviços, como os de atenção primária à saúde (Eizenberg, Desivilya, \& Hirschfeld, 2009), assim, o nível moderado e baixo de sofrimento moral deste estudo pode resultar dessa diferença de médias entre serviços.

No geral, os resultados alinham-se com os de outros estudos, reforçando uma preocupação partilhada acerca do sofrimento moral em enfermeiros e contribuindo para o desenvolvimento de um conjunto coeso de conhecimento (Wall, Austin, \& Garros, 2016). Os resultados psicométricos aceitáveis revelam que a Escala de Risco de Sofrimento Moral é adequada para identificar o risco de sofrimento moral em enfermeiros trabalhadores de diferentes contextos de atenção à saúde, seja em serviços hospitalares ou de atenção primária, em ambos os países. 


\section{ESTUDO III - DESCREVER A FREQUÊNCIA DE VIVÊNCIA DE FATORES DE RISCO DE SOFRIMENTO MORAL}

O quarto capítulo da tese dedica-se à descrição da frequência de vivência de fatores de risco para sofrimento moral em uma amostra de enfermeiros assistenciais do sul do Brasil e de Portugal, com o intuito de responder ao terceiro objetivo específico da tese, qual seja, 'Descrever a frequência de vivência de fatores de risco de sofrimento moral em uma amostra de enfermeiros assistenciais do sul do Brasil e de Portugal'.

\subsection{RESULTADOS BRASIL}

Dos 268 profissionais cujas respostas foram analisadas, 89,2\% eram mulheres (n $=239)$ e $10,8 \%$ eram homens $(n=29)$. A idade variou entre os 23 e os 62 anos, sendo a média de 36,6 anos (DP 8,6). A maioria, 61,6\% $(\mathrm{n}=165)$ declara estar casado ou em união estável, 32,1\% $(\mathrm{n}=86)$ disseram estar solteiros, $6 \%(\mathrm{n}=16)$ estavam separados ou divorciados e 1 pessoa $(0,4 \%)$ disse ser viúva.

Nas questões relativas à formação, 75\% $(\mathrm{n}=201)$ dos profissionais possuía alguma pós-graduação, sendo 2,3\% $(\mathrm{n}=5)$ na área da ética; 32,5\% $(\mathrm{n}=87)$ haviam concluído um mestrado, sendo 3\% $(\mathrm{n}=4)$ destes na área da ética; 7,1\% $(\mathrm{n}=19)$ dos enfermeiros que haviam concluído um doutorado, dos quais $2(9,5 \%)$ na área da ética; e ainda 2 participantes com pós-doutorado concluído $(0,7 \%)$, nenhum na área da ética. A maioria dos participantes relata não ter realizado nenhuma formação na área da ética ou da bioética no último ano $(83,6 \% ; n=224)$. Cerca de $61,2 \%(n=164)$ dos participantes afirma que já precisou de aconselhamento para problemas éticos na prática profissional.

Das características da atividade profissional, os participantes atuam como enfermeiros, em média, há 10,1 anos (DP 8,1), 81\% $(\mathrm{n}=213)$ dos enfermeiros mantem um vínculo empregatício, $17,9 \%(\mathrm{n}=47)$ mantem jornadas duplas e uma parcela mínima dos participantes mantem, ao mesmo tempo, 3 ou mais empregos $(1,1 \% ; n=3)$. Referente à carga horária semanal de trabalho, a maioria dos enfermeiros trabalha entre $36 \mathrm{~h}$ e $40 \mathrm{~h}$ $(74,8 \% ; n=199)$, outros $15,4 \%(n=41)$ trabalham mais de $40 h$ por semana, $7,5 \%(n=$ 20) trabalham até $35 \mathrm{~h}$ por semana e $2,3 \%(\mathrm{n}=6)$ afirmaram não se enquadrar nas 
alternativas de resposta anteriores. Cerca de 60,4\% $(n=162)$ dos enfermeiros ultrapassa o número de horas do seu contrato de trabalho e, destes, $71,6 \%(\mathrm{n}=116)$ não recebe estas horas pagas. Tendo por base um salário mínimo de 788,00 reais, 7,2\% $(\mathrm{n}=19)$ recebe de 1 a 3 salários, 24,9\% $(\mathrm{n}=66)$ recebe mais de 3 a 5 salários, 31,3\% $(\mathrm{n}=83)$ recebe mais de 5 a 7 salários, $23,8 \%(n=63)$ recebe mais de 7 a 10 salários e $12,8 \%(n=34)$ recebe mais de 10 salários.

Em relação ao contexto de trabalho, $64,8 \%(n=171)$ trabalham em instituições hospitalares e 35,2\% $(\mathrm{n}=97)$ trabalham na atenção básica/primária. Nas instituições hospitalares, $22 \%(\mathrm{n}=58)$ dos enfermeiros estão nas unidades de internação (médica, cirúrgica, obstétrica, pediátrica, outras especialidades $), 10,6 \%(\mathrm{n}=28)$ nas unidades de urgência, emergência e serviços de atendimento móvel, 7,2\% $(\mathrm{n}=19)$ nas unidades de terapia intensiva (neonatal, infantil, adulto ou outras), 6,1\% $(n=16)$ nos serviços de apoio (incluindo centro de materiais e esterilização, controle de infecção hospitalar e outros), $5,3 \%(n=14)$ estão, igualmente, nos serviços/ unidades de atendimento especializados (reabilitação, oncologia, nefrologia, hemodinâmica, outros) e no centro cirúrgico, 3,0\% $(\mathrm{n}=8)$ em centro obstétrico e ambulatório/ policlínica, 1,9\% $(\mathrm{n}=5)$ em serviços de diagnóstico e $0,4 \%(\mathrm{n}=1)$ em unidade de internação psiquiátrica. No contexto da atenção básica/primária, 34,1\% $(\mathrm{n}=90)$ estão em Unidade Básica de Saúde, Centro de Saúde, Posto de Saúde, Unidade de ESF/NASF e 1,1\% $(\mathrm{n}=3)$ estão em CAPS e outras instituições de Saúde Mental (sem internação). Cerca de 84,6\% $(\mathrm{n}=225)$ trabalha nesses locais há mais de 1 ano, sendo a média de anos no emprego atual de 6,7 anos (DP 8,1).

Os respondentes estavam atuando em diferentes cidades do Rio Grande do Sul, sendo o maior número de participantes de Porto Alegre $(44,8 \% ; n=115)$. As características sociodemográficas, de formação e de atividade profissional estão descritas, detalhadamente, na Tabela 9.

Tabela 9 - Características sociodemográficas, de formação e de atividade profissional dos enfermeiros, Rio Grande do Sul, Brasil $(n=268)$

\begin{tabular}{lllc}
\hline Características & Categorias & $\mathbf{n}(\mathbf{\%})^{\mathbf{a}}$ & Média $\pm \mathbf{D P}$ \\
\hline Gênero & Feminino & $\mathbf{2 3 9}(\mathbf{8 9 , 2})$ & \\
& Masculino & $29(10,8)$ & \\
Idade & & & $36,6 \pm 8,6$ \\
Estado civil & Casado(a)/união estável & $\mathbf{1 6 5 ( 6 1 , 6 )}$ &
\end{tabular}




\begin{tabular}{|c|c|c|c|}
\hline & Solteiro(a) & $86(32,1)$ & \\
\hline & Separado(a)/divorciado(a) & $16(6)$ & \\
\hline & Viúvo(a) & $1(0,4)$ & \\
\hline \multirow[t]{2}{*}{ Formação } & Graduação & $268(100)$ & \\
\hline & Especialização & $201(75)$ & \\
\hline \multirow{3}{*}{ Na área da ética } & Sim & $5(2,3)$ & \\
\hline & Não & $196(97,7)$ & \\
\hline & Mestrado & $87(32,5)$ & \\
\hline \multirow{3}{*}{ Na área da ética } & Sim & $4(3)$ & \\
\hline & Não & $83(97)$ & \\
\hline & Doutorado & $19(7,1)$ & \\
\hline \multirow{3}{*}{ Na área da ética } & Sim & $2(9,5)$ & \\
\hline & Não & $17(90,5)$ & \\
\hline & Pós-doutorado & $2(0,7)$ & \\
\hline \multirow{2}{*}{$\mathrm{Na}$ área da ética } & Sim & $0(0)$ & \\
\hline & Não & $2(0,7)$ & \\
\hline \multirow{2}{*}{$\begin{array}{l}\text { Formação em ética no } \\
\text { último ano }\end{array}$} & Sim & $44(16,4)$ & \\
\hline & Não & $224(83,6)$ & \\
\hline \multirow{2}{*}{$\begin{array}{l}\text { Precisou de aconselhamento } \\
\text { para problemas éticos }\end{array}$} & Sim & $164(61,2)$ & \\
\hline & Não & $104(38,8)$ & \\
\hline \multirow[t]{2}{*}{$\begin{array}{l}\text { Tempo de trabalho como } \\
\text { enfermeiro }\end{array}$} & & & $\begin{array}{l}10,1 \pm 8,1 \\
(1-40)\end{array}$ \\
\hline & 1 & $213(81)$ & \\
\hline \multirow[t]{3}{*}{ Vínculos empregatícios ${ }^{\mathrm{b}}$} & 2 & $47(17,9)$ & \\
\hline & 3 ou mais & $3(1,1)$ & \\
\hline & Até $35 \mathrm{~h}$ & $20(7,5)$ & \\
\hline \multirow{3}{*}{ Carga horária semanal $^{\mathrm{c}}$} & $36 h-40 h$ & $199(74,8)$ & \\
\hline & Mais de $40 \mathrm{~h}$ & $41(15,4)$ & \\
\hline & Outro & $6(2,3)$ & \\
\hline Ultrapassa $\mathrm{o}$ número $\mathrm{de}$ & Sim & $162(60,4)$ & \\
\hline horas do contrato & Não & $106(39,6)$ & \\
\hline Se sim, as horas extras são & Sim & $46(28,4)$ & \\
\hline \multirow[t]{3}{*}{ pagas } & Não & $116(71,6)$ & \\
\hline & De 1 a 3 salários & $19(7,2)$ & \\
\hline & Mais de 3 a 5 salários & $66(24,9)$ & \\
\hline \multirow[t]{3}{*}{ Rendimento mensal $^{\mathrm{d}}$} & Mais de 5 a 7 salários & $83(31,3)$ & \\
\hline & Mais de 7 a 10 salários & $63(23,8)$ & \\
\hline & Mais de 10 salários & $34(12,8)$ & \\
\hline \multirow{6}{*}{ Nível de atenção à saúde } & Básica/primária & $97(35,2)$ & \\
\hline & Hospitalar & $171(64,8)$ & \\
\hline & Unidades de internação & $58(22,0)$ & \\
\hline & $\begin{array}{l}\text { Unidades de urgência, emergência } \\
\text { e serviço móvel }\end{array}$ & $28(10,6)$ & \\
\hline & Unidades de terapia intensiva & $19(7,2)$ & \\
\hline & Serviços de apoio & $16(6,1)$ & \\
\hline \multirow[t]{6}{*}{ Hospitalar } & $\begin{array}{l}\text { Unidades de atendimento } \\
\text { especializado }\end{array}$ & $14(5,3)$ & \\
\hline & Centro cirúrgico & $14(5,3)$ & \\
\hline & Centro obstétrico & $8(3,0)$ & \\
\hline & Ambulatório/policlínica & $8(3,0)$ & \\
\hline & Serviço diagnóstico & $5(1,9)$ & \\
\hline & Internação psiquiátrica & $1(0,4)$ & \\
\hline Atenção básica/primária ${ }^{\mathrm{e}}$ & $\begin{array}{l}\text { Unidade Básica de Saúde, Centro } \\
\text { de Saúde, Posto de Saúde, } \\
\text { Unidade de ESF/NASF }\end{array}$ & $90(34,1)$ & \\
\hline
\end{tabular}




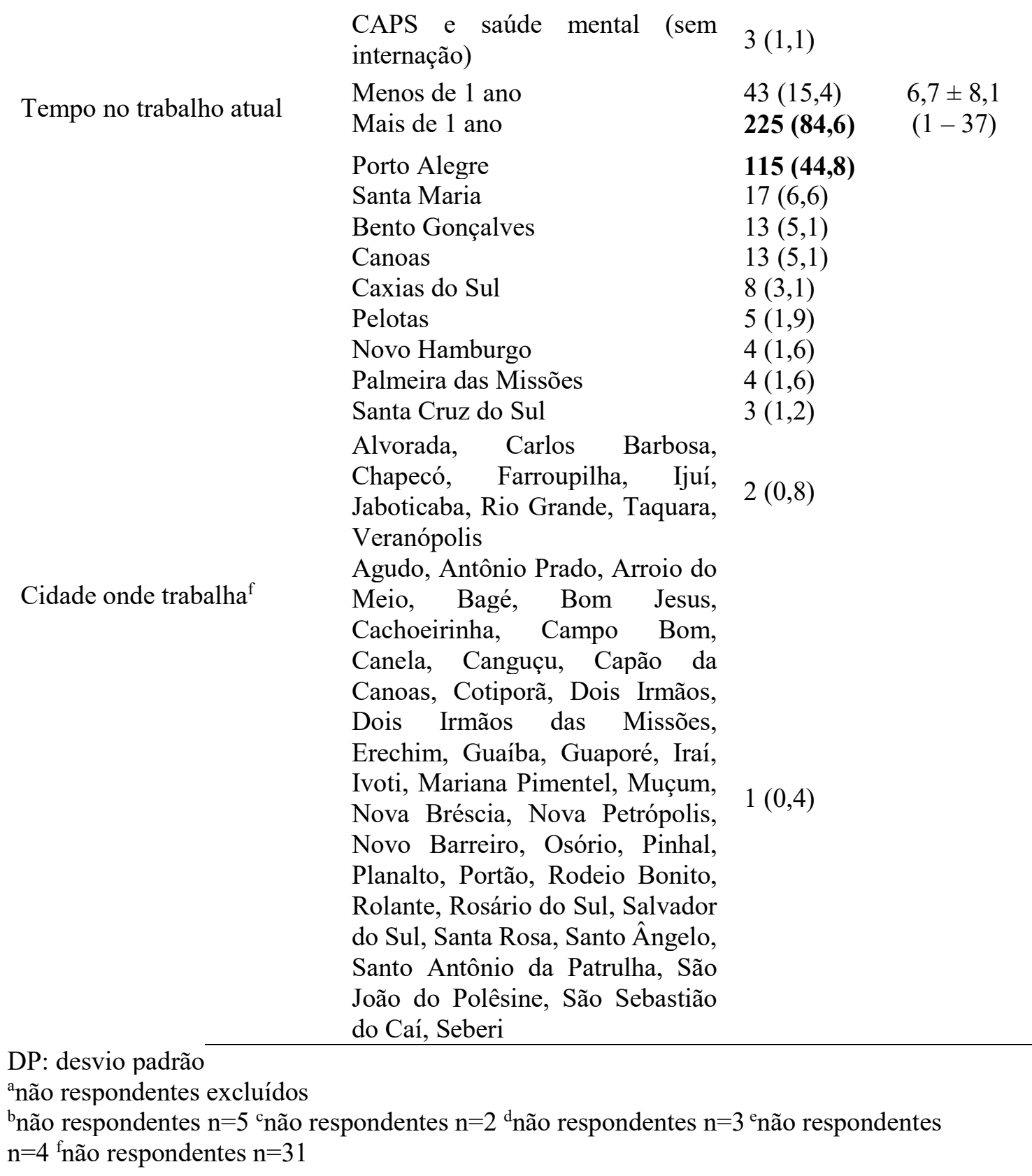

Com relação às variáveis do local de trabalho, os enfermeiros demonstraram estar insatisfeitos com o trabalho $(44 \% ; \mathrm{n}=118)$, com a qualidade dos cuidados $(48,1 \% ; \mathrm{n}=$ 129), com a colaboração entre profissionais $(44,4 \% ; n=119)$, com a comunicação entre profissionais $(42,7 \% ; \mathrm{n}=114)$, com o envolvimento nas decisões clínicas do cuidado $(44,2 \% ; n=117)$, com o envolvimento nas decisões éticas do cuidado $(46,1 \% ; n=123)$ e com a autonomia no trabalho $(43,4 \% ; \mathrm{n}=116)$.

Quando questionado aos enfermeiros se presenciam ou realizam ações contra seus valores, 59,6\% $(\mathrm{n}=159)$ refere raramente vivenciar esse tipo de situação no dia a dia de trabalho, enquanto que $29,6 \%(n=79)$ refere vivenciar esse tipo de situação de modo 
frequente. Presenciar ou realizar ações contra seus valores no dia a dia de trabalho gera desconforto para $69 \%(n=180)$, impotência para $66,7 \%(n=174)$, frustração para $63,2 \%$ $(\mathrm{n}=165)$, angústia para 59,8\% $(\mathrm{n}=156)$, insatisfação para 57,9\% $(151)$ e tristeza para $41,8 \%(n=109)$ dos enfermeiros, entre outros. Os resultados relativos às variáveis do local de trabalho são descritos na Tabela 10.

Tabela 10 - Variáveis relativas ao local de trabalho dos enfermeiros, Rio Grande do Sul, Brasil $(n=268)$

\begin{tabular}{|c|c|c|}
\hline Características & Categorias & n $(\%)^{a}$ \\
\hline \multirow{4}{*}{ Satisfação geral com o trabalho } & Muito satisfeito & $21(7,8)$ \\
\hline & Satisfeito & $55(20,5)$ \\
\hline & Insatisfeito & $118(44,0)$ \\
\hline & Muito insatisfeito & $74(27,6)$ \\
\hline \multirow{4}{*}{$\begin{array}{l}\text { Satisfação com a qualidade dos } \\
\text { cuidados }\end{array}$} & Muito satisfeito & $14(5,2)$ \\
\hline & Satisfeito & $57(21,3)$ \\
\hline & Insatisfeito & $129(48,1)$ \\
\hline & Muito insatisfeito & $68(25,4)$ \\
\hline \multirow{4}{*}{$\begin{array}{l}\text { Satisfação com a colaboração } \\
\text { entre profissionais }\end{array}$} & Muito satisfeito & $25(9,3)$ \\
\hline & Satisfeito & $81(30,2)$ \\
\hline & Insatisfeito & $119(44,4)$ \\
\hline & Muito insatisfeito & $43(16,0)$ \\
\hline \multirow{4}{*}{$\begin{array}{l}\text { Satisfação com a comunicação } \\
\text { entre profissionais }{ }^{\mathrm{b}}\end{array}$} & Muito satisfeito & $33(12,4)$ \\
\hline & Satisfeito & $89(33,3)$ \\
\hline & Insatisfeito & $114(42,7)$ \\
\hline & Muito insatisfeito & $31(11,6)$ \\
\hline \multirow{4}{*}{$\begin{array}{l}\text { Satisfação com o envolvimento } \\
\text { em decisões clínicas do cuidado }\end{array}$} & Muito satisfeito & $27(10,2)$ \\
\hline & Satisfeito & $67(25,3)$ \\
\hline & Insatisfeito & $117(44,2)$ \\
\hline & Muito insatisfeito & $54(20,4)$ \\
\hline \multirow{4}{*}{$\begin{array}{l}\text { Satisfação com o envolvimento } \\
\text { em decisões éticas do cuidado }\end{array}$} & Muito satisfeito & $29(10,9)$ \\
\hline & Satisfeito & $60(22,5)$ \\
\hline & Insatisfeito & $123(46,1)$ \\
\hline & Muito insatisfeito & $55(20,6)$ \\
\hline \multirow{4}{*}{$\begin{array}{l}\text { Satisfação com a autonomia no } \\
\text { trabalho }^{\mathrm{b}}\end{array}$} & Muito satisfeito & $26(9,7)$ \\
\hline & Satisfeito & $46(17,2)$ \\
\hline & Insatisfeito & $116(43,4)$ \\
\hline & Muito insatisfeito & $79(29,6)$ \\
\hline \multirow{3}{*}{$\begin{array}{l}\text { No seu trabalho presencia ou } \\
\text { realiza ações contra seus valores }\end{array}$} & Nunca & $25(9,4)$ \\
\hline & Raramente & $159(59,6)$ \\
\hline & Frequentemente/Sempre & $83(31,1)$ \\
\hline \multirow{8}{*}{$\begin{array}{l}\text { Presenciar ou realizar esse tipo de } \\
\text { ações lhe provoca }\end{array}$} & Desconforto & $180(69)$ \\
\hline & Impotência & $174(66,7)$ \\
\hline & Frustração & $165(63,2)$ \\
\hline & Angústia & $156(59,8)$ \\
\hline & Insatisfação & $151(57,9)$ \\
\hline & Tristeza & $109(41,8)$ \\
\hline & Raiva & $82(31,4)$ \\
\hline & Sofrimento & $81(31)$ \\
\hline
\end{tabular}


Desesperança

Dor

anão respondentes excluídos

Inapetência

${ }^{b}$ não respondentes $\mathrm{n}=1{ }^{\mathrm{c}}$ não respondentes $\mathrm{n}=3$

Os fatores de risco com maiores médias de frequência são: estresse $(M=3,11)$, problemas na estrutura física da instituição $(\mathrm{M}=3,00)$, esgotamento físico / mental / emocional $(M=2,97)$, desorganização do sistema de saúde $(M=2,96)$, falta de tempo por excesso de trabalho $(M=2,90)$, falta de financiamento / recursos / equipamentos $(M$ $=2,84)$, mercantilização dos cuidados de saúde $(\mathrm{M}=2,81)$, número excessivo de pacientes atribuídos a cada enfermeiro $(M=2,77)$, falta de enfermeiros $(M=2,75)$, desvalorização profissional $(\mathrm{M}=2,74)$, presenciar comportamento inadequado de familiares $(M=2,71)$, normas institucionais que dificultam o cuidado $(M=2,60)$, uso inadequado dos recursos disponíveis $(\mathrm{M}=2,56)$, demora o atendimento $(\mathrm{M}=2,55)$, impotência para contestar decisões de outros profissionais $(\mathrm{M}=2,54)$ e estrutura hierárquica $(\mathrm{M}=2,50)$.

Os escores médios dos itens variaram entre 1,47 e 3,11. A média foi de 2,50 (DP 0,73), o que indica risco moderado para sofrimento moral. Os fatores de risco, os percentuais e as médias de frequência são descritos na Tabela 11.

Tabela 11 - Fatores de risco para sofrimento moral em enfermeiros: percentuais e médias de frequência, Rio Grande do Sul, Brasil $(n=268)$

\begin{tabular}{|c|c|c|c|c|c|c|c|}
\hline \multirow{2}{*}{ Fator de risco } & \multicolumn{2}{|c|}{ Nunca } & \multicolumn{2}{|c|}{ Raramente } & \multicolumn{2}{|c|}{$\begin{array}{l}\text { Frequentemente/ } \\
\text { Sempre }\end{array}$} & \multirow{2}{*}{ Média } \\
\hline & $\mathbf{n}$ & $(\%)$ & $\mathbf{n}$ & $(\%)$ & $\mathbf{n}$ & $(\%)$ & \\
\hline Estresse & 3 & 1,1 & 35 & 13,1 & 230 & 85,8 & 3,11 \\
\hline $\begin{array}{l}\text { Problemas na estrutura física } \\
\text { da instituição }\end{array}$ & 9 & 3,4 & 60 & 22,4 & 199 & 74,3 & 3,00 \\
\hline $\begin{array}{l}\text { Esgotamento físico / mental / } \\
\text { emocional }\end{array}$ & 2 & 0,7 & 52 & 19,4 & 214 & 79,9 & 2,97 \\
\hline $\begin{array}{l}\text { Desorganização do sistema de } \\
\text { saúde }\end{array}$ & 2 & 0,7 & 54 & 20,1 & 212 & 79,1 & 2,96 \\
\hline $\begin{array}{l}\text { Falta de tempo por excesso de } \\
\text { trabalho }\end{array}$ & 13 & 4,9 & 51 & 19,0 & 204 & 76,1 & 2,90 \\
\hline $\begin{array}{l}\text { Falta de financiamento, } \\
\text { recursos, equipamentos }\end{array}$ & 11 & 4,1 & 71 & 26,5 & 186 & 69,4 & 2,84 \\
\hline
\end{tabular}




\begin{tabular}{|c|c|c|c|c|c|c|c|}
\hline $\begin{array}{l}\text { Mercantilização dos cuidados } \\
\text { de saúde }\end{array}$ & 14 & 5,2 & 75 & 28,0 & 179 & 66,8 & 2,81 \\
\hline $\begin{array}{l}\text { Número excessivo de } \\
\text { pacientes atribuídos a cada } \\
\text { enfermeiro }\end{array}$ & 20 & 7,5 & 72 & 26,9 & 176 & 65,7 & 2,77 \\
\hline Falta de enfermeiros & 18 & 6,7 & 80 & 29,9 & 170 & 63,4 & 2,75 \\
\hline Desvalorização profissional & 19 & 7,1 & 67 & 25,0 & 182 & 67,9 & 2,74 \\
\hline $\begin{array}{l}\text { Presenciar comportamento } \\
\text { inadequado de familiares }\end{array}$ & 5 & 1,9 & 92 & 34,3 & 171 & 63,8 & 2,71 \\
\hline $\begin{array}{l}\text { Normas institucionais que } \\
\text { dificultam o cuidado }\end{array}$ & 14 & 5,2 & 103 & 38,4 & 151 & 56,3 & 2,60 \\
\hline $\begin{array}{l}\text { Uso inadequado dos recursos } \\
\text { disponíveis }\end{array}$ & 13 & 4,9 & 112 & 41,8 & 143 & 53,4 & 2,56 \\
\hline Demora no atendimento & 13 & 4,9 & 114 & 42,5 & 141 & 52,6 & 2,55 \\
\hline $\begin{array}{l}\text { Impotência para contestar } \\
\text { decisões de outros } \\
\text { profissionais }\end{array}$ & 14 & 5,2 & 117 & 43,7 & 137 & 51,1 & 2,54 \\
\hline $\begin{array}{l}\text { Estrutura hierárquica que } \\
\text { determina a impotência e a } \\
\text { subordinação do enfermeiro ao } \\
\text { médico }\end{array}$ & 39 & 14,6 & 91 & 34,0 & 138 & 51,5 & 2,50 \\
\hline $\begin{array}{l}\text { Paciente sem condições de } \\
\text { pagar pelo tratamento }\end{array}$ & 60 & 22,4 & 54 & 20,1 & 154 & 57,5 & 2,49 \\
\hline $\begin{array}{l}\text { Conflitos entre paciente, } \\
\text { família, profissionais }\end{array}$ & 11 & 4,1 & 138 & 51,5 & 119 & 44,4 & 2,44 \\
\hline $\begin{array}{l}\text { Não ser incluído na tomada de } \\
\text { decisões }\end{array}$ & 27 & 10,1 & 112 & 41,8 & 129 & 48,1 & 2,44 \\
\hline Insatisfação com o trabalho & 25 & 9,3 & 126 & 47,0 & 117 & 43,7 & 2,40 \\
\hline Pouca autonomia no trabalho & 33 & 12,3 & 139 & 51,9 & 96 & 35,8 & 2,28 \\
\hline $\begin{array}{l}\text { Despreparo para lidar com a } \\
\text { morte }\end{array}$ & 34 & 12,7 & 142 & 53,0 & 92 & 34,3 & 2,26 \\
\hline $\begin{array}{l}\text { Obstáculos linguísticos e } \\
\text { culturais }\end{array}$ & 32 & 11,9 & 167 & 62,3 & 69 & 25,7 & 2,16 \\
\hline $\begin{array}{l}\text { Uso abusivo da alta tecnologia } \\
\text { no prolongamento da vida }\end{array}$ & 66 & 24,6 & 106 & 39,6 & 96 & 35,8 & 2,16 \\
\hline $\begin{array}{l}\text { Desrespeito à vontade do } \\
\text { paciente }\end{array}$ & 40 & 14,9 & 169 & 63,1 & 59 & 22,0 & 2,09 \\
\hline $\begin{array}{l}\text { Medo de não ser aceito pela } \\
\text { equipe }\end{array}$ & 46 & 17,2 & 162 & 60,4 & 60 & 22,4 & 2,06 \\
\hline $\begin{array}{l}\text { Ser questionado sobre } \\
\text { informações que são sigilosas }\end{array}$ & 51 & 19,0 & 158 & 59,0 & 59 & 22,0 & 2,05 \\
\hline Medo de perder o emprego & 77 & 28,7 & 126 & 47,0 & 65 & 24,3 & 2,03 \\
\hline $\begin{array}{l}\text { Falsas esperanças para } \\
\text { pacientes e familiares }\end{array}$ & 60 & 22,4 & 167 & 62,3 & 41 & 15,3 & 1,94 \\
\hline $\begin{array}{l}\text { Medo de notificar erros que } \\
\text { você cometeu }\end{array}$ & 87 & 32,5 & 137 & 51,1 & 44 & 16,4 & 1,88 \\
\hline
\end{tabular}

Com relação às variáveis de sofrimento moral, $43 \%(\mathrm{n}=114)$ dos enfermeiros diz que os fatores de risco da Escala de Risco de Sofrimento Moral são, para eles, fonte frequente de sofrimento moral. Muito semelhante resultado para a opção raramente, escolhida por $42,6 \%(n=113)$ dos enfermeiros. Cerca de $32,7 \%(n=87)$ dos enfermeiros 
diz estar em sofrimento moral no momento do preenchimento da escala, enquanto os outros $67,3 \%(\mathrm{n}=179)$ diz não estar. Entretanto, a grande maioria dos enfermeiros diz já ter vivenciado o sofrimento moral em outra altura da vida profissional, seja uma vez $(23,8 \% ; \mathrm{n}=63)$ ou mais do que uma vez $(49,8 \% ; \mathrm{n}=132)$.

Os enfermeiros raramente sentem liberdade para falar com a chefia sobre sofrimento moral $(43 \% ; n=114)$ e frequentemente falam sobre o assunto com os colegas $(44,5 \% ; n=118)$. Cerca de 36,9\% $(n=99)$ dos enfermeiros deixaria seu local de trabalho atual devido ao sofrimento moral e, destes, 37,5\% $(\mathrm{n}=36)$ procuraria emprego em outro tipo de serviço, $35,4 \%(n=34)$ procuraria emprego em serviço semelhante e $21,9 \%(n=$ 21) procuraria um trabalho não relacionado com a enfermagem. Ainda, 33,1\% $(n=88)$ dos participantes afirma já ter deixado algum trabalho anteriormente por sofrimento moral. As variáveis de sofrimento moral são descritas na Tabela 12.

Tabela 12 - Variáveis de sofrimento moral, Rio Grande do Sul, Brasil (n = 268)

\begin{tabular}{|c|c|c|}
\hline Perguntas & Categorias de resposta & n $(\%)^{\mathrm{a}}$ \\
\hline \multirow{5}{*}{$\begin{array}{l}\text { Diria que os fatores de risco da } \\
\text { escala são fontes de sofrimento } \\
\text { moral }^{\mathrm{b}} \\
\text { Diria que está em sofrimento moral } \\
\text { agora }^{\mathrm{c}}\end{array}$} & Nunca & $29(10,9)$ \\
\hline & Raramente & $113(42,6)$ \\
\hline & Frequentemente/Sempre & $123(46,4)$ \\
\hline & Sim & $87(32,7)$ \\
\hline & Não & $179(67,3)$ \\
\hline \multirow{4}{*}{$\begin{array}{l}\text { Já vivenciou sofrimento moral em } \\
\text { outra altura da vida profissional }^{\mathrm{b}}\end{array}$} & Nunca & $70(26,4)$ \\
\hline & Uma vez & $63(23,8)$ \\
\hline & Mais de uma vez & $132(49,8)$ \\
\hline & Nunca & $33(12,5)$ \\
\hline \multirow{4}{*}{$\begin{array}{l}\text { Sentiria liberdade para falar sobre } \\
\text { sofrimento moral com a chefia }{ }^{b}\end{array}$} & Raramente & $114(43)$ \\
\hline & Frequentemente & $58(21,9)$ \\
\hline & Sempre & $60(22,6)$ \\
\hline & Nunca & $9(3,4)$ \\
\hline \multirow{3}{*}{$\begin{array}{l}\text { Sentiria liberdade para falar sobre } \\
\text { sofrimento moral com os colegas }\end{array}$} & Raramente & $79(29,8)$ \\
\hline & Frequentemente & $118(44,5)$ \\
\hline & Sempre & $59(22,3)$ \\
\hline \multirow{5}{*}{$\begin{array}{l}\text { Se pudesse, deixaria seu local de } \\
\text { trabalho por sofrimento moral } \\
\text { Se sim, que tipo de trabalho iria } \\
\text { procurar }^{\mathrm{d}}\end{array}$} & Sim & $99(36,9)$ \\
\hline & Não & $169(63,1)$ \\
\hline & Em serviço semelhante & $34(35,4)$ \\
\hline & Em outro tipo de serviço & $36(37,5)$ \\
\hline & $\begin{array}{l}\text { Trabalho não relacionado com a } \\
\text { enfermagem }\end{array}$ & $21(21,9)$ \\
\hline \multirow{2}{*}{$\begin{array}{l}\text { Já deixou um local de trabalho } \\
\text { por sofrimento moral }{ }^{\mathrm{c}}\end{array}$} & Sim & $88(33,1)$ \\
\hline & Não & $178(66,9)$ \\
\hline
\end{tabular}




\subsection{RESULTADOS PORTUGAL}

Dos 278 profissionais cujas respostas foram analisadas, 83,0\% eram mulheres (n $=229)$ e $17,0 \%$ eram homens $(\mathrm{n}=47)$. A média de idade foi de 33,7 anos $(\mathrm{DP}=6,7)$. A maioria, 58,2\% $(\mathrm{n}=162)$, declarou estar casado ou em união estável, 37,1\% $(\mathrm{n}=103)$ disseram estar solteiros, $4,3 \%(n=12)$ estavam separados ou divorciados e 1 pessoa $(0,4 \%)$ disse ser viúva.

Nas questões relativas à formação, 49,6\% $(\mathrm{n}=138)$ dos profissionais possuía alguma pós-graduação, 55,0\% $(\mathrm{n}=153)$ haviam concluído um mestrado e 1,4\% $(\mathrm{n}=4)$ dos enfermeiros que haviam concluído um doutoramento. A maioria dos participantes relata não ter realizado nenhuma formação na área da ética ou da bioética no último ano $(91,0 \% ; n=253)$.

Das características da atividade profissional, os participantes atuam como enfermeiros, em média, há 6 anos (DP 5,1), com tipo de contrato de trabalho majoritariamente sem termo $(75,8 \% ; \mathrm{n}=210)$. Referente à carga horária semanal de trabalho, é similar o número de enfermeiros que atuam até $35 \mathrm{~h}$ semanais $(43,2 \% ; \mathrm{n}=120)$ e de enfermeiros que atuam de $36 \mathrm{~h}$ a $40 \mathrm{~h}$ semanais $(40,3 \% ; n=112)$. Cerca de $81,1 \%(n$ $=223$ ) dos enfermeiros costuma ultrapassar o número de horas do seu contrato de trabalho e, destes, $65,0 \%(n=143)$ não recebe estas horas pagas. O rendimento mensal da maioria dos participantes é superior em relação ao salário base da enfermagem em Portugal de $€ 1.020,06(57,8 \% ; n=160)$.

Em relação ao contexto de trabalho, $69,2 \%(n=189)$ trabalham em instituições hospitalares ou equivalentes, $16,5 \%(\mathrm{n}=45)$ trabalham em cuidados de saúde primários e $14,3 \%(n=39)$ atuam em outros tipos de serviços assistenciais.

Os respondentes estavam atuando em diferentes regiões do país, principalmente no Porto $(59,4 \% ; n=164)$, em Lisboa $(14,5 \% ; n=40)$ e em Braga $(10,5 \% ; n=29)$. As características sociodemográficas, de formação e de atividade profissional estão descritas, detalhadamente, na Tabela 13. 
Tabela 13 - Características sociodemográficas, de formação e de atividade profissional dos enfermeiros, Portugal $(n=278)$

\begin{tabular}{|c|c|c|c|}
\hline Características & Categorias & n (\%) $)^{a}$ & Média \pm DP \\
\hline \multirow{2}{*}{ Gênero $^{b}$} & Feminino & $229(83,0)$ & \\
\hline & Masculino & $47(17,0)$ & \\
\hline \multirow[t]{2}{*}{ Idade } & & & $33,7 \pm 6,7$ \\
\hline & Casado(a)/união & $162(58,2)$ & \\
\hline \multirow{3}{*}{ Estado civil } & Solteiro(a) & $103(37,1)$ & \\
\hline & Separado(a)/divorciado(a) & $12(4,3)$ & \\
\hline & Viúvo(a) & $1(0,4)$ & \\
\hline \multirow{4}{*}{ Formação } & Graduação & $278(100)$ & \\
\hline & Pós-graduação & $138(49,6)$ & \\
\hline & Mestrado & $153(55,0)$ & \\
\hline & Doutoramento & $4(1,4)$ & \\
\hline \multirow{2}{*}{$\begin{array}{l}\text { Formação em ética no } \\
\text { último ano }\end{array}$} & Sim & $25(9,0)$ & \\
\hline & Não & $253(91,0)$ & \\
\hline $\begin{array}{l}\text { Tempo de trabalho como } \\
\text { enfermeiro }\end{array}$ & & & $6,0 \pm 5,1$ \\
\hline \multirow{5}{*}{ Tipo de contrato de trabalho ${ }^{c}$} & Sem contrato & $11(4,0)$ & \\
\hline & Liberal & $7(2,5)$ & \\
\hline & A termo & $31(11,2)$ & \\
\hline & Sem termo & $210(75,8)$ & \\
\hline & Outro & $18(6,5)$ & \\
\hline \multirow{4}{*}{ Carga horária semanal } & Até $35 \mathrm{~h}$ & $120(43,2)$ & \\
\hline & $36 h-40 h$ & $112(40,3)$ & \\
\hline & Mais de 40h & $37(13,3)$ & \\
\hline & Outro & $9(3,2)$ & \\
\hline \multirow{2}{*}{$\begin{array}{l}\text { Ultrapassa o número de } \\
\text { horas do contrato }^{\mathrm{d}}\end{array}$} & Sim & $223(81,1)$ & \\
\hline & Não & $52(18,9)$ & \\
\hline \multirow{2}{*}{$\begin{array}{l}\text { Se sim, as horas extras são } \\
\text { pagas }^{\mathrm{d}}\end{array}$} & Sim & $77(35,0)$ & \\
\hline & Não & $143(65,0)$ & \\
\hline \multirow{4}{*}{$\begin{array}{l}\text { Rendimento mensal } \\
(€ 1.020,06)^{\mathrm{c}}\end{array}$} & Inferior & $56(20,2)$ & \\
\hline & Igual & $61(22,0)$ & \\
\hline & Superior & $160(57,8)$ & \\
\hline & Cuidados de Saúde Primários & $45(16,5)$ & \\
\hline \multirow[t]{2}{*}{ Nível de atenção à saúde } & Hospitalar ou equivalente & $189(69,2)$ & \\
\hline & Outro & $39(14,3)$ & \\
\hline \multirow{15}{*}{$\begin{array}{l}\text { Região ou distrito onde } \\
\text { trabalha }^{\text {b }}\end{array}$} & Aveiro & $10(3,6)$ & \\
\hline & Beja & $1(0,4)$ & \\
\hline & Braga & $29(10,5)$ & \\
\hline & Bragança & $3(1,1)$ & \\
\hline & Castelo Branco & $0(0,0)$ & \\
\hline & Coimbra & $2(0,7)$ & \\
\hline & Évora & $0(0,0)$ & \\
\hline & Faro & $8(2,9)$ & \\
\hline & Guarda & $0(0,0)$ & \\
\hline & Leiria & $2(0,7)$ & \\
\hline & Lisboa & $40(14,5)$ & \\
\hline & Portalegre & $0(0,0)$ & \\
\hline & Porto & $164(59,4)$ & \\
\hline & Santarém & $1(0,4)$ & \\
\hline & Setúbal & $3(1,1)$ & \\
\hline
\end{tabular}


Viana do Castelo $\quad 4(1,4)$

Vila Real $4(1,4)$

Viseu $3(1,1)$

Região Autónoma dos Açores $1(0,4)$

Região Autónoma da Madeira $1(0,4)$

${ }^{a}$ não respondentes excluídos

${ }^{b}$ não respondentes $n=2{ }^{c}$ não respondentes $n=1{ }^{d}$ não respondentes $n=3{ }^{e}$ não respondentes $n=5$

Com relação às variáveis do local de trabalho, os enfermeiros demonstraram estar satisfeitos com o trabalho $(55,6 \% ; \mathrm{n}=154)$, com a qualidade dos cuidados $(63,3 \% ; \mathrm{n}=$ 176), com a colaboração entre profissionais $(60,6 \% ; n=168)$, com a comunicação entre profissionais $(54,7 \% ; \mathrm{n}=152)$, com o envolvimento nas decisões clínicas do cuidado $(50,0 \% ; n=139)$, com o envolvimento nas decisões éticas do cuidado $(46,0 \% ; n=128)$ e com a autonomia no trabalho $(52,5 \% ; \mathrm{n}=146)$.

Quando questionado aos enfermeiros se presenciam ou realizam ações contra seus valores, $53,2 \%(\mathrm{n}=142)$ refere nunca ou raramente vivenciar esse tipo de situação no dia a dia de trabalho, enquanto que 46,8\% $(n=125)$ refere vivenciar esse tipo de situação frequentemente ou sempre. Presenciar ou realizar ações contra seus valores no dia a dia de trabalho gera frustração para 49,3\% $(n=137)$, insatisfação para 46,78\% $(n=130)$, desconforto para $36,0 \%(n=100)$, impotência para $30,2 \%(n=84)$, tristeza para $30,2 \%$ $(\mathrm{n}=84)$ e angústia para $27,3 \%(\mathrm{n}=76)$, entre outros. Os resultados relativos às variáveis do local de trabalho são descritos na Tabela 14.

Tabela 14 - Variáveis relativas ao local de trabalho dos enfermeiros, Portugal $(\mathbf{n}=\mathbf{2 7 8})$

\begin{tabular}{|c|c|c|}
\hline Características & Categorias & n (\%) ${ }^{\mathrm{a}}$ \\
\hline \multirow{5}{*}{ Satisfação geral com o trabalho ${ }^{b}$} & Muito insatisfeito & $10(3,6)$ \\
\hline & Insatisfeito & $18(6,5)$ \\
\hline & Pouco satisfeito & $63(22,7)$ \\
\hline & Satisfeito & $154(55,6)$ \\
\hline & Muito satisfeito & $32(11,6)$ \\
\hline \multirow{5}{*}{$\begin{array}{l}\text { Satisfação com a qualidade dos } \\
\text { cuidados }\end{array}$} & Muito insatisfeito & $7(2,5)$ \\
\hline & Insatisfeito & $12(4,3)$ \\
\hline & Pouco satisfeito & $35(12,6)$ \\
\hline & Satisfeito & $176(63,3)$ \\
\hline & Muito satisfeito & $48(17,3)$ \\
\hline \multirow{5}{*}{$\begin{array}{l}\text { Satisfação com a colaboração } \\
\text { entre profissionais }{ }^{b}\end{array}$} & Muito insatisfeito & $6(2,2)$ \\
\hline & Insatisfeito & $16(5,8)$ \\
\hline & Pouco satisfeito & $48(17,3)$ \\
\hline & Satisfeito & $168(60,6)$ \\
\hline & Muito satisfeito & $39(14,1)$ \\
\hline
\end{tabular}




\begin{tabular}{|c|c|c|}
\hline \multirow{6}{*}{$\begin{array}{l}\text { Satisfação com a comunicação } \\
\text { entre profissionais }\end{array}$} & Muito insatisfeito & $6(2,2)$ \\
\hline & Insatisfeito & $19(6,8)$ \\
\hline & Pouco satisfeito & $66(23,7)$ \\
\hline & Satisfeito & $152(54,7)$ \\
\hline & Muito satisfeito & $35(12,6)$ \\
\hline & Muito insatisfeito & $12(4,3)$ \\
\hline \multirow{5}{*}{$\begin{array}{l}\text { Satisfação com o envolvimento } \\
\text { em decisões clínicas do cuidado }\end{array}$} & Insatisfeito & $32(11,5)$ \\
\hline & Pouco satisfeito & $62(22,3)$ \\
\hline & Satisfeito & $139(50,0)$ \\
\hline & Muito satisfeito & $33(11,9)$ \\
\hline & Muito insatisfeito & $21(7,6)$ \\
\hline \multirow{5}{*}{$\begin{array}{l}\text { Satisfação com o envolvimento } \\
\text { em decisões éticas do cuidado }\end{array}$} & Insatisfeito & $31(11,2)$ \\
\hline & Pouco satisfeito & $71(25,5)$ \\
\hline & Satisfeito & $128(46,0)$ \\
\hline & Muito satisfeito & $27(9,7)$ \\
\hline & Muito insatisfeito & $5(1,8)$ \\
\hline \multirow{4}{*}{$\begin{array}{l}\text { Satisfação com a autonomia no } \\
\text { trabalho }\end{array}$} & Insatisfeito & $16(5,8)$ \\
\hline & Pouco satisfeito & $44(15,8)$ \\
\hline & Satisfeito & $146(52,5)$ \\
\hline & Muito satisfeito & $67(24,1)$ \\
\hline \multirow{9}{*}{$\begin{array}{l}\text { No seu trabalho presencia ou } \\
\text { realiza ações contra seus valores }\end{array}$} & Nunca/Raramente & $142(53,2)$ \\
\hline & Frequentemente/sempre & $125(46,8)$ \\
\hline & Frustração & $137(49,3)$ \\
\hline & Insatisfação & $130(46,8)$ \\
\hline & Desconforto & $100(36,0)$ \\
\hline & Impotência & $84(30,2)$ \\
\hline & Tristeza & $84(30,2)$ \\
\hline & Angústia & $76(27,3)$ \\
\hline & Mal-estar & $72(25,9)$ \\
\hline \multirow{9}{*}{$\begin{array}{l}\text { Presenciar ou realizar esse tipo de } \\
\text { ações lhe provoca }\end{array}$} & Cansaço & $51(18,3)$ \\
\hline & Raiva & $41(14,7)$ \\
\hline & Sofrimento & $40(14,4)$ \\
\hline & Desesperança & $29(10,4)$ \\
\hline & Insónia & $24(8,6)$ \\
\hline & Dores de cabeça & $16(5,8)$ \\
\hline & Dor & $13(4,7)$ \\
\hline & Outros & $9(3,2)$ \\
\hline & Inapetência & $8(2,9)$ \\
\hline
\end{tabular}

${ }^{a}$ não respondentes excluídos

${ }^{\mathrm{b}}$ não respondentes $\mathrm{n}=1$

Os fatores de risco com maiores médias de frequência foram: falta de enfermeiros $(M=3,12)$, stress $(M=3,03)$, falta de tempo por excesso de trabalho $(M=3,02)$, mercantilização dos cuidados de saúde $(\mathrm{M}=2,93)$, número excessivo de utentes atribuídos a cada enfermeiro $(\mathrm{M}=2,91)$, esgotamento físico / mental / emocional $(\mathrm{M}=$ 2,76), desvalorização profissional $(M=2,72)$, falta de liderança eficaz no serviço $(M=$ $2,60)$, realização pessoal reduzida $(M=2,48)$, insatisfação com o trabalho $(M=2,47)$, uso inadequado dos recursos disponíveis $(\mathrm{M}=2,47)$, demora no atendimento $(\mathrm{M}=2,46)$ e não ser incluído na tomada de decisões $(\mathrm{M}=2,43)$. 
Os escores médios dos itens variaram entre 1,79 e 3,12. A média foi de 2,43, o que indica risco baixo para sofrimento moral. Os fatores de risco, os percentuais e as médias de frequência são descritos na Tabela 15.

Tabela 15 - Fatores de risco para sofrimento moral em enfermeiros: percentuais e médias de frequência, Portugal $(n=278)$

\begin{tabular}{|c|c|c|c|c|c|c|c|}
\hline \multirow{2}{*}{ Fator de risco } & \multicolumn{2}{|c|}{ Nunca } & \multicolumn{2}{|c|}{ Raramente } & \multicolumn{2}{|c|}{$\begin{array}{l}\text { Frequentemente/ } \\
\text { Sempre }\end{array}$} & \multirow[t]{2}{*}{ Média } \\
\hline & $\mathbf{n}$ & $(\%)$ & $\mathbf{n}$ & $(\%)$ & $\mathbf{n}$ & $(\%)$ & \\
\hline Falta de enfermeiros & 13 & 4,7 & 42 & 15,2 & 222 & 80,1 & 3,12 \\
\hline Stress & 4 & 1,5 & 44 & 16,0 & 227 & 82,5 & 3,03 \\
\hline $\begin{array}{l}\text { Falta de tempo por excesso de } \\
\text { trabalho }\end{array}$ & 5 & 1,8 & 46 & 16,8 & 223 & 81,4 & 3,02 \\
\hline $\begin{array}{l}\text { Mercantilização dos cuidados } \\
\text { de saúde }\end{array}$ & 16 & 5,8 & 55 & 20,0 & 204 & 74,2 & 2,93 \\
\hline $\begin{array}{l}\text { Número excessivo de utentes } \\
\text { atribuídos a cada enfermeiro }\end{array}$ & 22 & 8,0 & 55 & 20,1 & 197 & 71,9 & 2,91 \\
\hline $\begin{array}{l}\text { Esgotamento físico / mental / } \\
\text { emocional }\end{array}$ & 11 & 4,0 & 81 & 29,3 & 184 & 66,7 & 2,76 \\
\hline Desvalorização profissional & 23 & 8,3 & 69 & 24,8 & 186 & 66,9 & 2,72 \\
\hline $\begin{array}{l}\text { Falta de liderança eficaz no } \\
\text { serviço }\end{array}$ & 12 & 4,3 & 117 & 42,1 & 149 & 53,6 & 2,60 \\
\hline Realização pessoal reduzida & 24 & 8,6 & 119 & 42,8 & 135 & 48,6 & 2,48 \\
\hline Insatisfação com o trabalho & 34 & 12,5 & 106 & 38,8 & 133 & 48,7 & 2,47 \\
\hline $\begin{array}{l}\text { Uso inadequado dos recursos } \\
\text { disponíveis }\end{array}$ & 18 & 6,5 & 134 & 48,6 & 124 & 44,9 & 2,47 \\
\hline Demora no atendimento & 12 & 4,4 & 144 & 52,9 & 116 & 42,6 & 2,46 \\
\hline $\begin{array}{l}\text { Não ser incluído na tomada de } \\
\text { decisões }\end{array}$ & 25 & 9,2 & 129 & 47,3 & 119 & 43,6 & 2,43 \\
\hline $\begin{array}{l}\text { Observar cuidado inadequado } \\
\text { ou desnecessário }\end{array}$ & 18 & 6,6 & 159 & 58,2 & 96 & 35,2 & 2,36 \\
\hline $\begin{array}{l}\text { Ser obrigado a prestar cuidado } \\
\text { inadequado ou desnecessário }\end{array}$ & 53 & 19,2 & 147 & 53,3 & 76 & 27,5 & 2,11 \\
\hline $\begin{array}{l}\text { Desrespeito à vontade do } \\
\text { utente }\end{array}$ & 46 & 16,7 & 180 & 65,5 & 49 & 17,8 & 2,05 \\
\hline $\begin{array}{l}\text { Medo de notificar erros que } \\
\text { você cometeu }\end{array}$ & 83 & 30,2 & 128 & 46,5 & 64 & 23,3 & 1,95 \\
\hline $\begin{array}{l}\text { Medo de não ser aceito pela } \\
\text { equipe }\end{array}$ & 77 & 27,9 & 156 & 56,5 & 43 & 15,6 & 1,92 \\
\hline Questões de gênero & 88 & 32,1 & 137 & 50,0 & 49 & 17,9 & 1,90 \\
\hline $\begin{array}{l}\text { Ser forçado a transgredir as } \\
\text { regras }\end{array}$ & 99 & 36,3 & 141 & 51,6 & 33 & 12,1 & 1,79 \\
\hline
\end{tabular}

Com relação às variáveis de sofrimento moral, $46,8 \%(\mathrm{n}=125)$ dos enfermeiros diz que os fatores de risco da escala são, para eles, fonte frequente de sofrimento moral. Cerca de 23,4\% $(n=64)$ dos enfermeiros diz estar em sofrimento moral no momento do preenchimento da escala, enquanto os outros $76,6 \%(n=209)$ dizem não estar. Entretanto, 
a grande maioria dos enfermeiros diz já ter vivenciado o sofrimento moral em outra altura da vida profissional, seja uma vez $(17,6 \% ; n=48)$ ou mais do que uma vez $(56,4 \% ; n=$ 154).

Os enfermeiros raramente sentem liberdade para falar com a chefia sobre o sofrimento moral $(34,1 \% ; n=93)$ e frequentemente falam sobre o assunto com os colegas $(52,4 \% ; n=143)$. Cerca de $30,4 \%(n=82)$ dos enfermeiros diz que deixaria seu local de trabalho atual devido ao sofrimento moral e, destes, 53,8\% $(\mathrm{n}=43)$ procuraria emprego em outro tipo de serviço, $37,5 \%(n=30)$ procuraria trabalho não relacionado com a enfermagem e $8,8 \%(n=7)$ procuraria um trabalho em serviço semelhante. Ainda, $20,9 \%$ $(\mathrm{n}=57)$ dos participantes afirma já ter deixado algum trabalho anteriormente por sofrimento moral. As variáveis de sofrimento moral são descritas na Tabela 16.

Tabela 16 - Variáveis de sofrimento moral, Portugal $(n=278)$

\begin{tabular}{|c|c|c|}
\hline Perguntas & Categorias de resposta & n (\%) $)^{a}$ \\
\hline \multirow{3}{*}{$\begin{array}{l}\text { Diria que os fatores de risco da } \\
\text { escala são fontes de sofrimento } \\
\text { moral }^{\text {b }}\end{array}$} & Nunca & $9(3,4)$ \\
\hline & Raramente & $133(49,8)$ \\
\hline & Frequentemente/Sempre & $125(46,8)$ \\
\hline \multirow{3}{*}{$\begin{array}{l}\text { Diria que está em sofrimento moral } \\
\text { agora }^{c}\end{array}$} & Sim & $64(23,4)$ \\
\hline & Não & $209(76,6)$ \\
\hline & Nunca & $71(26,0)$ \\
\hline \multirow{2}{*}{ 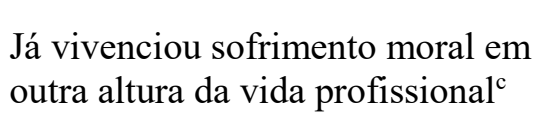 } & Uma vez & $48(17,6)$ \\
\hline & Mais de uma vez & $154(56,4)$ \\
\hline \multirow{5}{*}{$\begin{array}{l}\text { Sentiria liberdade para falar sobre } \\
\text { sofrimento moral com a chefia }\end{array}$} & Nunca & $44(16,1)$ \\
\hline & Raramente & $93(34,1)$ \\
\hline & Frequentemente & $86(31,5)$ \\
\hline & Sempre & $50(18,3)$ \\
\hline & Nunca & $5(1,8)$ \\
\hline \multirow{2}{*}{$\begin{array}{l}\text { Sentiria liberdade para falar sobre } \\
\text { sofrimento moral com os colegas }\end{array}$} & Raramente & $61(22,3)$ \\
\hline & $\begin{array}{l}\text { Frequentemente } \\
\text { Sempre }\end{array}$ & $\begin{array}{l}143(52,4) \\
64(23,4)\end{array}$ \\
\hline \multirow{5}{*}{$\begin{array}{l}\text { Se pudesse, deixaria seu local de } \\
\text { trabalho por sofrimento moral } \\
\text { Se sim, que tipo de trabalho iria } \\
\text { procurar }^{\mathrm{e}}\end{array}$} & $\operatorname{Sim}$ & $82(30,4)$ \\
\hline & Não & $188(69,6)$ \\
\hline & Em serviço semelhante & $7(8,8)$ \\
\hline & Em outro tipo de serviço & $43(53,8)$ \\
\hline & $\begin{array}{l}\text { Trabalho não relacionado com a } \\
\text { enfermagem }\end{array}$ & $30(37,5)$ \\
\hline \multirow{2}{*}{$\begin{array}{l}\text { Já deixou um local de trabalho por } \\
\text { sofrimento moral }\end{array}$} & Sim & $57(20,9)$ \\
\hline & Não & $216(79,1)$ \\
\hline
\end{tabular}

${ }^{a}$ não respondentes excluídos

${ }^{b}$ não respondentes $n=11^{c}$ não respondentes $n=5$ não respondentes $n=8{ }^{e}$ não respondentes $n=2$ 


\subsection{DISCUSSÃO}

O significativo número de publicações sobre o sofrimento moral na enfermagem, principalmente nos últimos anos, pode estar relacionado aos crescentes desafios da prática profissional, como o desenvolvimento tecnológico e a tensão financeira global (Vosner, Zeleznik, Kokol, Vosner, \& Zavrsnik, 2016). Nesse contexto de crescente complexidade, cumprir com o compromisso moral de prestar um cuidado seguro e eficaz exige cada vez mais dos enfermeiros, sendo o sofrimento moral um risco constante (Wolf, et al., 2016). Estudos com o intuito de enfrentar os desafios que demarcam a prática da enfermagem na atualidade devem ser incentivados (Vosner, Zeleznik, Kokol, Vosner, \& Zavrsnik, 2016).

A caracterização dos participantes do estudo, bem como dos seus contextos de trabalho, desde as características locais até o contexto político global, é crucial para a compreensão do sofrimento moral (Varcoe, Pauly, Webster, \& Storch, 2012). Nesse estudo, e na quase totalidade dos estudos encontrados na literatura, a maioria dos participantes são mulheres, o que se mostra representativo da enfermagem global, uma profissão majoritariamente feminina desde a antiguidade (Vieira, 2009). O percentual de mulheres e homens que participaram desse estudo se assemelha a distribuição total de enfermeiros, segundo o sexo, nos cenários de recolha de dados.

A literatura discute se a enfermagem estaria mais predisposta a vivência do sofrimento moral por ser uma profissão majoritariamente feminina. A ligação entre sofrimento moral e gênero não é clara, com estudos mostrando maiores índices em mulheres (Trautmann, Epstein, Rovnyak, \& Snyder, 2015), outros em homens (Dyo, Kalowes, \& Devries, 2016), enquanto que a maioria não demonstra diferenças significativas entre eles (Xiaoyan, Yufang, Lifeng, \& Congcong, 2016) (Woods, Rodgers, Towers, \& Grow, 2015) (Borhani, Mohammadi, \& Roshanzadeh, 2015).

Historicamente, esperava-se que os enfermeiros aceitassem a autoridade dos médicos e, portanto, não participassem no processo de tomada de decisão acerca do tratamento dos pacientes, em um tempo em que a medicina era, sobretudo, exercida por homens e a enfermagem por mulheres. Essa estrutura de poder associada ao gênero persiste ainda nos dias de hoje, mesmo já sendo maior o número de mulheres na medicina e de homens na enfermagem (Austin, Lemermeyer, Goldberg, Bergum, \& Johnson, 
2005). Em estudo realizado com enfermeiros do sul do Brasil, cerca de 65,8\% dos entrevistados diz já ter sofrido discriminação por gênero em seu ambiente de trabalho (Cofen, 2017).

Gutierrez (2005) relata que a percepção de que os médicos ocupam uma posição de maior poder, inibe a participação do enfermeiro no processo de tomada de decisão, fazendo-os perceberem-se como fracos ou com pouca autoridade. Essa construção social, reflete na organização do trabalho e remete a um sentimento de impotência, que pode contribuir para a ocorrência do sofrimento moral. O trabalho de Barlem \& Ramos (2015) incorpora essa reflexão em um novo modelo teórico, que expande o conceito de sofrimento moral, descrito como um sentimento de impotência que levaria o profissional a aceitar individualidades impostas e a reduzir a possibilidade de ação moral, o que resultaria em uma inexpressividade ética. $\mathrm{O}$ autor afirma que, nesse contexto, a autonomia profissional seria o elemento fundamental para o enfrentamento do sofrimento moral.

Em relação ao contexto de trabalho, as condições sob as quais os enfermeiros exercem a profissão também têm sido discutidas como fontes de sofrimento moral (Austin, 2016). É sabido que a crise financeira global, além de acentuar as desigualdades de saúde e de acesso aos serviços, determinou também novas formas de organização do trabalho (Wall, Austin, \& Garros, 2016). Na enfermagem, estudos apontam que a alta carga de trabalho pode ser uma das principais fontes de sofrimento moral da atualidade, uma vez que limita a capacidade do enfermeiro para fornecer cuidados seguros e eficazes (Wolf, et al., 2016). Nesse estudo o número de enfermeiros que costuma ultrapassar as horas do contrato e que não recebe essas horas extras pagas é elevado em ambas as amostras investigadas. A resposta do enfermeiro às condições de trabalho pode estar na manifestação de insatisfação em vários aspectos da prática (Sartoreto, 2013) e, também, na percepção do elevado desgaste profissional (Cofen, 2017).

Os ambientes de trabalho em saúde e a forma como estão organizados pode favorecer a vivência de situações moralmente problemáticas, fontes de desconforto, impotência, frustração e angústia (Weber, 2016). De fato, nesse estudo, os fatores de risco com as maiores médias de frequência estavam relacionados com aspectos organizacionais e das condições de trabalho, entre eles, os problemas estruturais, a desorganização do serviço, a falta de financiamento, a falta de enfermeiros e a mercantilização dos cuidados, resultando em uma percepção de estresse e esgotamento. 
A preocupação com o impacto dos fatores organizacionais sobre os enfermeiros tem se tornado alvo frequente de investigações no tema do sofrimento moral, principalmente porque, atualmente, já se considera que o sofrimento moral deriva mais de uma resposta negativa a problemas no ambiente de trabalho, do que a características individuais do profissional (Wall, Austin, \& Garros, 2016). Nesse contexto, o sucesso no enfrentamento do sofrimento moral estaria em atentar às estruturas mais amplas nas quais ele surge, e não focar a solução apenas no sujeito individual (Austin, 2016).

É importante considerar, entretanto, que além dos aspectos organizacionais, o sofrimento moral pode decorrer de outras fontes, entre elas, os fatores sociais e os fatores culturais (Weber, 2016). No âmbito dos fatores sociais, a desvalorização do enfermeiro e as expectativas de outros em relação ao seu trabalho têm sido descritos na literatura, bem como aparecem entre os fatores de risco com maiores médias de frequência nesta investigação. A má compreensão do público sobre o papel do enfermeiro, a injusta acusação pela má qualidade do cuidado e a falta de reconhecimento pelo seu esforço, foram citadas como fonte de sofrimento moral em um estudo realizado em Uganda (Harrowing \& Mill, 2010). A desvalorização do enfermeiro também vem à tona quando, apesar da sua experiência e conhecimento, sua opinião não é levada em consideração no processo de tomada de decisão (Maluwa, Andre, Ndebele, \& Chilemba, 2012).

No âmbito dos fatores culturais, há que se considerar a moralidade como um fenômeno socialmente construído (LaTaille, 2006) e, portanto, culturalmente sensível (Renaud \& Renaud, 1996). A literatura chama atenção para o papel das diferenças culturais na forma como cada enfermeiro vivencia o sofrimento moral (Dyo, Kalowes, \& Devries, 2016) e para a importância de considerar essas especificidades tanto na investigação das fontes do sofrimento moral, quanto no desenvolvimento de estratégias de enfrentamento (Trautmann, Epstein, Rovnyak, \& Snyder, 2015).

Os desafios morais, sejam eles de origem organizacional, social, cultural ou outra, sempre farão parte de um ambiente de saúde contemporâneo, marcado pela crescente complexidade e constante necessidade de adaptação (Wall, Austin, \& Garros, 2016). O esforço das investigações, na área do sofrimento moral, deve centrar-se em despertar o enfermeiro para essa realidade (Barlem \& Ramos, 2015). Nesse estudo, o sofrimento moral mostrou níveis de frequência baixa a moderada, resultado que vai ao encontro da 
maioria dos estudos disponíveis na literatura (Borhani, Abbaszadeh, Nakhaee, \& Roshanzadeh, 2014) (Lusignani, Gianni, Re, \& Buffon, 2016).

Muitas vezes, o receio de ser considerado fraco, incapaz de lidar com os problemas decorrentes do trabalho e de tolerar a pressão inerente a função de enfermeiro, pode condicionar o profissional a manter o silêncio, levando a uma aceitação desse sofrimento como parte da rotina de trabalho (Austin, 2016). Nossos resultados mostram que os enfermeiros tendem a ter maior liberdade para falar sobre sofrimento moral com os colegas, em comparação com a chefia. Esse tipo de resultado demonstra que a organização deve estar atenta às questões éticas difíceis que surgem diariamente, demonstrando interesse e abertura para que o profissional possa expressar suas incertezas e dificuldades, sem medo de retaliações (Austin, 2016).

Como consequência do sofrimento moral, uma significativa parcela dos participantes de ambos os países refere que deixaria o seu local de trabalho, se pudesse. Nessa realidade, evitar o envolvimento e distanciar-se dos pacientes é uma saída muito utilizada, o que pode ter reflexos para a qualidade do cuidado prestado (Wilson, Goettemoeller, Bevan, \& McCord, 2013).

A intenção de deixar o emprego foi significativamente relacionada com a ocorrência de sofrimento moral em estudo realizado com enfermeiros de cuidados críticos e não críticos, de cinco hospitais da Califórnia (Dyo, Kalowes, \& Devries, 2016). Segundo os autores, cada aumento unitário na frequência de sofrimento moral dobrou as chances da intenção de sair, em um modelo de análise ajustado para idade, gênero, etnia e área de especialidade.

Por fim, chama atenção o percentual de enfermeiros que considerou estar em sofrimento moral no momento do preenchimento da escala e o elevado percentual de enfermeiros que já vivenciou o sofrimento moral anteriormente, pelo menos uma vez. Os dados confirmam, portanto, que o sofrimento moral é parte da rotina de trabalho do enfermeiro, justificando a necessidade de investigar quais são os fatores de risco responsáveis por esse fenômeno, com objetivo de prevenir e evitar possíveis consequências.

A gestão desempenha um papel protagonista no processo de identificação desses fatores de risco e na discussão sobre o sofrimento moral com o pessoal de enfermagem. 
Quando o profissional se sente seguro para expressar suas angústias e levantar questões éticas, o sofrimento moral pode ser abordado de forma colaborativa (Austin, 2016). 


\section{ESTUDO IV - VERIFICAR A ASSOCIAÇÃO ENTRE O RISCO DE SOFRIMENTO MORAL E AS VARIÁVEIS SOCIODEMOGRÁFICAS, FORMAÇÃO, ATIVIDADE PROFISSIONAL E LOCAL DE TRABALHO}

O quinto capítulo da tese responde ao objetivo específico de verificar a associação entre o risco de sofrimento moral com as variáveis sociodemográficas, formação, atividade profissional e local de trabalho, em uma amostra de enfermeiros assistenciais do sul do Brasil e de Portugal. Os resultados evidenciam associações significativas que são descritas e fundamentadas com base na literatura científica de enfermagem.

\subsection{RESULTADOS BRASIL}

A média total da escala para a amostra investigada foi de 2,50 e as médias dos fatores variaram entre 2,00 e 2,82. O fator 'Questões organizacionais e de gestão: desafios no local de trabalho' apresentou média de 2,82; o fator 'Carga de trabalho: excessiva carga de trabalho' apresentou média de 2,80; o fator 'Recursos: falta de recursos' apresentou média de 2,62; o fator 'Conflitos: conflitos no cuidado' com média de 2,57; o fator 'Autonomia: reduzida autonomia profissional' obteve média de 2,44; o fator 'Fim de vida: dificuldade de realizar cuidado adequado no fim de vida' obteve média de 2,19; e o fator 'Segurança: falta de segurança profissional' obteve média de 2,00 (Tabela 17).

Tabela 17 - Média total e média dos fatores da Escala de Risco de Sofrimento

\section{Moral (Brasil)}

\begin{tabular}{lc}
\hline Fatores e respectivos itens & Média (DP) \\
\hline Questões organizacionais e de gestão: desafios no local de trabalho & $\mathbf{2 , 8 2}(\mathbf{0 , 7 0 )}$ \\
Esgotamento físico / mental / emocional & $2,97(0,64)$ \\
Estresse & $3,11(0,65)$ \\
Problemas na estrutura física da instituição & $3,00(0,81)$ \\
Insatisfação com o trabalho & $2,40(0,74)$ \\
Desvalorização profissional & $2,74(0,77)$ \\
Desorganização do sistema de saúde & $2,96(0,63)$ \\
Normas institucionais que dificultam o cuidado & $2,60(0,72)$ \\
Carga de trabalho: excessiva carga de trabalho & $\mathbf{2 , 8 0 ( 0 , 8 0 )}$ \\
Falta de enfermeiros & $2,75(0,83)$ \\
Mercantilização dos cuidados de saúde & $2,81(0,80)$
\end{tabular}


Número excessivo de pacientes atribuídos a cada enfermeiro

$2,77(0,84)$

Falta de tempo por excesso de trabalho

$2,90(0,75)$

Recursos: falta de recursos

$\mathbf{2 , 6 2}(\mathbf{0 , 8 1})$

Demora no atendimento

$2,55(0,70)$

Paciente sem condições de pagar pelo tratamento

$2,49(0,98)$

Falta de financiamento, recursos, equipamentos

$2,84(0,77)$

Conflitos: conflitos no cuidado

$\mathbf{2 , 5 7}(\mathbf{0 , 6 4 )}$

Presenciar comportamento inadequado de familiares

$2,71(0,65)$

Conflitos entre paciente, família, profissionais

$2,44(0,63)$

Autonomia: reduzida autonomia profissional

$\mathbf{2 , 4 4}(\mathbf{0 , 7 7 )}$

Pouca autonomia no trabalho

Não ser incluído na tomada de decisões

Estrutura hierárquica que determina a impotência e a subordinação do $2,44(0,76)$

enfermeiro ao médico

$2,50(0,90)$

Sentir-se impotente para mudar o contexto

$2,54(0,72)$

Fim de vida: dificuldade de realizar cuidado adequado no fim de vida

$\mathbf{2 , 1 9}(\mathbf{0 , 7 0 )}$

Falsas esperanças para pacientes e familiares

$1,94(0,65)$

Uso abusivo da alta tecnologia no prolongamento da vida

$2,16(0,86)$

Desrespeito à vontade do paciente

$2,09(0,64)$

Despreparo para lidar com a morte

$2,26(0,73)$

Uso inadequado dos recursos disponíveis

$2,56(0,70)$

Obstáculos linguísticos e culturais

$2,16(0,66)$

Segurança: falta de segurança profissional

$\mathbf{2 , 0 0}(\mathbf{0 , 7 4 )}$

Medo de notificar erros que você cometeu

$1,88(0,77)$

Ser questionado sobre informações que são sigilosas

$2,05(0,68)$

Medo de não ser aceito pela equipe

$2,06(0,65)$

Medo de perder o emprego

$2,03(0,86)$

Média total

$\mathbf{2 , 5 0}(\mathbf{0 , 7 3})$

$\mathrm{DP}=$ desvio padrão

A análise das variáveis sociodemográficas revelou que não há diferenças significativas na média total da escala para homens $(p=.810)$ e para mulheres $(p=.790)$. $O$ mesmo resultado foi observado em todos os fatores. A idade, referida em anos completos, foi categorizada por grupos etários, com base na análise dos quartis: até 30 anos, de 31 a 40 anos e mais que 40 anos. Não houve diferença significativa na média total da escala em nenhum dos grupos etários $(\mathrm{p}=1.00 ; \mathrm{p}=.145 ; \mathrm{p}=.623)$, entretanto, enfermeiros mais jovens, com até 30 anos, parecem ter maior risco para sofrimento moral relacionado com $\mathrm{o}$ fator 'segurança' $(\mathrm{p}=.004)$.

Nas variáveis de formação, houve diferença significativa entre os enfermeiros sem mestrado para uma maior média no fator 'conflitos' $(p=.019)$. Essa diferença não se manteve significativa para a média total da escala $(\mathrm{p}=.601)$. Não houve diferenças significativas na média total da escala para variáveis 'especialização' $(p=.950)$ e 'doutorado' $(p=.332)$.

O tempo de trabalho como enfermeiro foi categorizado em: até 4 anos, 5 a 10 anos e 11 anos ou mais, também com base na análise dos quartis. A análise mostra uma 
diferença significativa para o grupo com menos tempo de profissão no fator 'segurança', sendo a maior média encontrada no grupo com menos de 4 anos de profissão $(p=.041)$. Essa diferença não se manteve significativa para os outros fatores.

O tipo de vínculo empregatício apresentou diferença significativa para uma maior média total da escala no grupo com contrato CLT, quando comparado aos profissionais em regime estatutário $(\mathrm{p}=.008)$ e em outros tipos de vínculo $(\mathrm{p}=.003)$. Depois, nos fatores, os enfermeiros com vínculo CLT, quando comparados com os enfermeiros com vínculo estatutário, apresentaram médias significativamente maiores para 'autonomia' $(\mathrm{p}=.002) \mathrm{e}$ 'segurança' ( $p=.004)$. Os enfermeiros com vínculo CLT também apresentaram médias significativamente maiores quando comparados com os enfermeiros em outros tipos de vínculo, nos fatores 'questões organizacionais e de gestão' $(p=.011)$, 'autonomia' $(p=.012)$ e 'fim de vida' $(p=.009)$.

A média total da escala foi significativamente maior para os enfermeiros que diziam trabalhar 41 horas ou mais por semana, quando comparados com os enfermeiros que trabalham de 36 a 40horas por semana $(p=.020)$. Ainda houve diferença significativa entre os profissionais que trabalham 41 horas ou mais e os que trabalham entre $36 \mathrm{~h}$ e 40horas para o fator 'questões organizacionais e de gestão' $(p=.039)$ e 'carga de trabalho $(p=.020)$. Diferenças significativas também entre os enfermeiros que trabalham 41 horas ou mais e os que trabalham até 35horas para os fatores 'carga de trabalho' $(\mathrm{p}=.031) \mathrm{e}$ 'orientação interpessoal' ( $\mathrm{p}=.014)$. Em todos os casos, as maiores médias estão no grupo de enfermeiros que trabalham 41 horas ou mais por semana.

Em relação à realização de horas extras, a análise revela diferença significativa de média entre o grupo que faz horas extras e o grupo que não faz horas extras para a média total da escala, sendo a maior média pertencente ao grupo que diz fazer horas extras $(p=.003)$. Essa diferença se manteve significativa para os fatores 'carga de trabalho' $(\mathrm{p}=.000)$ e 'autonomia' $(\mathrm{p}=.001)$.

Os enfermeiros que trabalham nos serviços de atenção hospitalar apresentaram uma média total da escala significativamente maior, quando comparados com os enfermeiros da atenção básica/primária $(\mathrm{p}=.000)$. Essa diferença se manteve significativa para todos os fatores $(p=.009 ; p=.007 ; p=.011 ; p=.000 ; p=.000 ; p=.011)$, com exceção do fator 'carga de trabalho' $(p=.710)$. Houve diferença significativamente maior para a média do fator 'segurança' nos enfermeiros que estavam trabalhando no serviço há menos de 1 ano $(\mathrm{p}=.042)$. 
Das variáveis do local de trabalho, os enfermeiros que são forçados a presenciar ou a realizar ações contra seus valores 'frequentemente/sempre', tem a média total da escala significativamente maior, quando comparados com o grupo que respondeu 'raramente/nunca' vivenciar esse tipo de situação $(\mathrm{p}=.000)$. Essa diferença se manteve significativa para todos os fatores $(\mathrm{p}=.000 ; \mathrm{p}=.003 ; \mathrm{p}=.000 ; \mathrm{p}=.001 ; \mathrm{p}=.000 ; \mathrm{p}=.000$; $\mathrm{p}=.004)$.

Houve diferença significativa para a maior média da escala nos enfermeiros que responderam estar em sofrimento moral, quando comparados com os que responderam não estar $(p=.000)$. Essa diferença se manteve significativa para todos os fatores $(p=.000$; $\mathrm{p}=.000 ; \mathrm{p}=.000 ; \mathrm{p}=.045 ; \mathrm{p}=.000 ; \mathrm{p}=.004 ; \mathrm{p}=.001$ ), com exceção do fator 'orientação interpessoal' $(p=.229)$. Também, o grupo de enfermeiros que relata já ter vivido o sofrimento moral em outra altura da vida profissional, uma vez ou mais de uma vez, apresentou resultados significativos para maior média total da escala $(p=.005)$ e para maiores médias nos fatores 'questões organizacionais e de gestão' $(p=.005)$, 'recursos' $(\mathrm{p}=.006)$, e 'autonomia $(\mathrm{p}=.009)$.

Resultados significativos de maior média da escala foram encontrados no grupo de enfermeiros que afirma ter vontade de deixar o seu local de trabalho $(p=.000)$. $O$ resultado foi o mesmo para os fatores 'questões organizacionais e de gestão' $(p=.000)$, 'autonomia' ( $p=.000)$, 'fim de vida' $(p=.000)$ e 'segurança' $(p=.009)$. Em relação aos enfermeiros que efetivamente já deixaram um local de trabalho anteriormente por sofrimento moral, uma maior média significativa foi observada no fator 'recursos' $(\mathrm{p}=.003)$. Todas as comparações de médias estão descritas na Tabela 18 e os resultados significativos estão destacados em negrito. 
Tabela 18 - Diferenças na média total da escala e na média dos fatores em relação às variáveis sociodemográficas, formação, atividade profissional, local de trabalho e sofrimento moral, Rio Grande do Sul, Brasil $(\mathrm{n}=\mathbf{2 6 8})$

\begin{tabular}{|c|c|c|c|c|c|c|c|c|c|}
\hline & Variável & $\begin{array}{c}\text { MTE - DP } \\
\text { (p-valor) }\end{array}$ & $\begin{array}{c}\text { MF1 - DP } \\
\text { (p-valor) }\end{array}$ & $\begin{array}{c}\text { MF2 - DP } \\
\text { (p-valor })\end{array}$ & $\begin{array}{c}\text { MF3 - DP } \\
\text { (p-valor })\end{array}$ & $\begin{array}{c}\text { MF4 - DP } \\
\text { (p-valor) }\end{array}$ & $\begin{array}{c}\text { MF5 - DP } \\
\text { (p-valor) }\end{array}$ & $\begin{array}{c}\text { MF6 - DP } \\
\text { (p-valor })\end{array}$ & $\begin{array}{c}\text { MF7 - DP } \\
\text { (p-valor) }\end{array}$ \\
\hline \multirow{2}{*}{ Sexo } & Feminino & $\begin{array}{c}2.50-0.39 \\
(.790)\end{array}$ & $\begin{array}{c}2.82-0.50 \\
(.974)\end{array}$ & $\begin{array}{c}2.80-0.60 \\
(.925)\end{array}$ & $\begin{array}{c}2.62-0.60 \\
(.896)\end{array}$ & $\begin{array}{c}2.56-0.55 \\
(.753)\end{array}$ & $\begin{array}{c}2.44-0.63 \\
(.753)\end{array}$ & $\begin{array}{c}2.21-0.47 \\
(.137)\end{array}$ & $\begin{array}{c}1.99-0.51 \\
(.486)\end{array}$ \\
\hline & Masculino & $\begin{array}{c}2.48-0.44 \\
(.810)\end{array}$ & $\begin{array}{c}2.82-0.54 \\
(.975)\end{array}$ & $\begin{array}{c}2.81-0.69 \\
(.933)\end{array}$ & $\begin{array}{c}2.60-0.61 \\
\quad(.897)\end{array}$ & $\begin{array}{c}2.60-0.57 \\
(.761)\end{array}$ & $\begin{array}{c}2.40-0.63 \\
(.754)\end{array}$ & $\begin{array}{c}2.06-0.55 \\
(.196)\end{array}$ & $\begin{array}{c}2.06-0.58 \\
(.528)\end{array}$ \\
\hline \multirow{3}{*}{ Idade } & $\begin{array}{l}\text { Até } 30 \text { anos } \\
\begin{array}{l}31 \text { a } 40 \text { anos } \\
41 \text { ou mais }\end{array}\end{array}$ & $\begin{array}{c}2.56-0.42 \\
(1.00) \\
(.145)\end{array}$ & $\begin{array}{c}2.90-0.46 \\
(.997) \\
(.140)\end{array}$ & $\begin{array}{c}2.89-0.69 \\
(691) \\
(.578)\end{array}$ & $\begin{array}{c}2.55-0.61 \\
(.642) \\
(1.00)\end{array}$ & $\begin{array}{c}2.63-0.58 \\
(1.00) \\
(.238)\end{array}$ & $\begin{array}{c}2.53-0.68 \\
(.809) \\
(.588)\end{array}$ & $\begin{array}{c}2.22-0.48 \\
(1.00) \\
(1.00)\end{array}$ & $\begin{array}{c}2.13-0.59 \\
(.361) \\
(.004)\end{array}$ \\
\hline & $\begin{array}{c}31 \text { a } 40 \text { anos } \\
\text { Até } 30 \text { anos } \\
41 \text { ou mais }\end{array}$ & $\begin{array}{c}2.50-0.40 \\
(1.00) \\
(.623)\end{array}$ & $\begin{array}{c}2.83-0.51 \\
(.997) \\
(.631)\end{array}$ & $\begin{array}{c}2.78-0.59 \\
(.691) \\
(1.00)\end{array}$ & $\begin{array}{c}2.66-0.58 \\
(.642) \\
(1.00)\end{array}$ & $\begin{array}{c}2.60-0.51 \\
(1.00) \\
(.334)\end{array}$ & $\begin{array}{c}2.42-0.61 \\
(.809) \\
(1.00)\end{array}$ & $\begin{array}{c}2.20-0.49 \\
(1.00) \\
(1.00)\end{array}$ & $\begin{array}{c}2.01-0.48 \\
(.362) \\
(.125)\end{array}$ \\
\hline & $\begin{array}{l}41 \text { ou mais } \\
\text { Até } 30 \text { anos } \\
31 \text { a } 40 \text { anos }\end{array}$ & $\begin{array}{c}2.43-0.35 \\
(.145) \\
(.623)\end{array}$ & $\begin{array}{c}2.73-0.52 \\
(.140) \\
(.631)\end{array}$ & $\begin{array}{c}2.75-0.55 \\
(.578) \\
(1.00)\end{array}$ & $\begin{array}{c}2.61-0.63 \\
(1.00) \\
(1.00)\end{array}$ & $\begin{array}{c}2.47-0.57 \\
(.238) \\
(.334)\end{array}$ & $\begin{array}{c}2.39-0.59 \\
(.588) \\
(1.00)\end{array}$ & $\begin{array}{c}2.15-0.45 \\
(1.00) \\
(1.00)\end{array}$ & $\begin{array}{c}1.85-0.49 \\
\mathbf{( . 0 0 4 )} \\
(.125)\end{array}$ \\
\hline \multirow{2}{*}{ Especialização } & $\operatorname{Sim}$ & $\begin{array}{c}2.49-0.38 \\
(.946)\end{array}$ & $\begin{array}{c}2.82-0.50 \\
(.820)\end{array}$ & $\begin{array}{c}2.79-0.59 \\
(.521)\end{array}$ & $\begin{array}{c}2.63-0.58 \\
(.523)\end{array}$ & $\begin{array}{c}2.54-0.55 \\
(.153)\end{array}$ & $\begin{array}{c}2.43-0.62 \\
(.698)\end{array}$ & $\begin{array}{c}2.21-0.47 \\
(.370)\end{array}$ & $\begin{array}{c}1.99-0.50 \\
(.558)\end{array}$ \\
\hline & Não & $\begin{array}{c}2.50-0.44 \\
(.950)\end{array}$ & $\begin{array}{c}2.81-0.53 \\
(.826)\end{array}$ & $\begin{array}{c}2.85-0.68 \\
(.551)\end{array}$ & $\begin{array}{c}2.58-0.65 \\
(.545)\end{array}$ & $\begin{array}{c}2.65-0.55 \\
(.154)\end{array}$ & $\begin{array}{c}2.46-0.67 \\
(.710)\end{array}$ & $\begin{array}{c}2.14-0.50 \\
(.385)\end{array}$ & $\begin{array}{c}2.03-0.58 \\
(.589)\end{array}$ \\
\hline \multirow{2}{*}{ Mestrado } & Sim & $\begin{array}{c}2.48-0.39 \\
(.603)\end{array}$ & $\begin{array}{c}2.78-0.46 \\
(.319)\end{array}$ & $\begin{array}{c}2.79-0.60 \\
(.774)\end{array}$ & $\begin{array}{c}2.60-0.59 \\
(.795)\end{array}$ & $\begin{array}{c}2.45-0.53 \\
(.021)\end{array}$ & $\begin{array}{c}2.41-0.62 \\
(.636)\end{array}$ & $\begin{array}{c}2.23-0.52 \\
(.369)\end{array}$ & $\begin{array}{c}1.99-0.52 \\
(.871)\end{array}$ \\
\hline & Não & $\begin{array}{c}2.50-0.40 \\
(.601)\end{array}$ & $\begin{array}{c}2.84-0.52 \\
(.298)\end{array}$ & $\begin{array}{c}2.81-0.62 \\
(.771)\end{array}$ & $\begin{array}{c}2.62-0.61 \\
(.792)\end{array}$ & $\begin{array}{c}2.62-0.55 \\
(\mathbf{. 0 1 9})\end{array}$ & $\begin{array}{c}2.45-0.64 \\
(.632)\end{array}$ & $\begin{array}{c}2.17-0.46 \\
(.388)\end{array}$ & $\begin{array}{c}2.00-0.52 \\
(.870)\end{array}$ \\
\hline \multirow{2}{*}{ Doutorado } & Sim & $\begin{array}{c}2.41-0.38 \\
(.335)\end{array}$ & $\begin{array}{c}2.69-0.50 \\
(.265)\end{array}$ & $\begin{array}{c}2.85-0.64 \\
(.734)\end{array}$ & $\begin{array}{c}2.63-0.58 \\
(.950)\end{array}$ & $\begin{array}{c}2.39-0.56 \\
(.147)\end{array}$ & $\begin{array}{c}2.30-0.42 \\
(.328)\end{array}$ & $\begin{array}{c}2.17-0.53 \\
(.853)\end{array}$ & $\begin{array}{c}1.78-0.45 \\
(.064)\end{array}$ \\
\hline & Não & $\begin{array}{c}2.50-0.39 \\
(.332)\end{array}$ & $\begin{array}{c}2.83-0.50 \\
\quad(.277)\end{array}$ & $\begin{array}{c}2.80-0.61 \\
(.748)\end{array}$ & $\begin{array}{c}2.62-0.60 \\
(.949)\end{array}$ & $\begin{array}{c}2.58-0.55 \\
(.170)\end{array}$ & $\begin{array}{c}2.45-0.64 \\
(.171)\end{array}$ & $\begin{array}{c}2.19-0.48 \\
\quad(.867)\end{array}$ & $\begin{array}{c}2.02-0.52 \\
(.045)\end{array}$ \\
\hline $\begin{array}{l}\text { Tempo de } \\
\text { trabalho }\end{array}$ & $\begin{array}{l}\text { Até } 4 \text { anos } \\
5 \text { a } 10 \text { anos } \\
11 \text { ou mais }\end{array}$ & $\begin{array}{c}2.51-0.40 \\
(1.00) \\
(.822)\end{array}$ & $\begin{array}{c}2.86-0.51 \\
(1.00) \\
(1.00)\end{array}$ & $\begin{array}{c}2.85-0.69 \\
(1.00) \\
(.820)\end{array}$ & $\begin{array}{c}2.53-0.56 \\
(.526) \\
(1.00)\end{array}$ & $\begin{array}{c}2.65-0.55 \\
(1.00) \\
(.195)\end{array}$ & $\begin{array}{c}2.44-0.65 \\
(1.00) \\
(1.00)\end{array}$ & $\begin{array}{c}2.14-0.42 \\
(.462) \\
(1.00)\end{array}$ & $\begin{array}{c}2.09-0.56 \\
(1.00) \\
(.041)\end{array}$ \\
\hline
\end{tabular}




\begin{tabular}{|c|c|c|c|c|c|c|c|c|c|}
\hline & 5 a 10 anos & $2.52-0.39$ & $2.81-0.49$ & $2.82-0.57$ & $2.66-0.59$ & $2.58-0.52$ & $2.50-0.64$ & $2.25-0.45$ & $2.04-0.51$ \\
\hline & Até 4 anos & $(1.00)$ & $(1.00)$ & $(1.00)$ & $(.526)$ & (1.00) & $(1.00)$ & $(.462)$ & $(1.00)$ \\
\hline & 11 ou mais & $(.432)$ & $(1.00)$ & $(1.00)$ & $(1.00)$ & $(.792)$ & $(.328)$ & (.473) & (.128) \\
\hline & 11 ou mais & $2.44-0.39$ & $2.80-0.51$ & $2.74-0.59$ & $2.62-0.64$ & $2.50-0.54$ & $2.36-0.59$ & $2.15-0.52$ & $1.89-0.49$ \\
\hline & Até 4 anos & $(.822)$ & $(1.00)$ & $(.820)$ & (1.00) & (.195) & (1.00) & (1.00) & (.041) \\
\hline & 5 a 10 anos & $(.432)$ & $(1.00)$ & $(1.00)$ & $(1.00)$ & $(.792)$ & $(.328)$ & $(.473)$ & $(.128)$ \\
\hline & Estatutário & $2.41-0.39$ & $2.75-0.48$ & $2.74-0.61$ & $2.64-0.58$ & $2.51-0.51$ & $2.28-0.62$ & $2.12-0.47$ & $1.86-0.46$ \\
\hline & CLT & (.008) & $(.090)$ & $(.264)$ & (1.00) & $(.238)$ & $(.002)$ & $(.079)$ & (.004) \\
\hline & Outros & $(.565)$ & (.459) & $(.908)$ & $(.219)$ & $(.736)$ & $(1.00)$ & $(.442)$ & $(.666)$ \\
\hline & CLT & $2.57-0.37$ & $2.90-0.49$ & $2.88-0.60$ & $2.64-0.59$ & $2.64-0.55$ & $2.56-0.62$ & $2.27-0.47$ & $2.08-0.51$ \\
\hline Ifpo de & Estatutário & $(.008)$ & $(.090)$ & $(.264)$ & $(1.00)$ & $(.238)$ & $(.002)$ & $(.079)$ & (.004) \\
\hline & Outros & $(.003)$ & (.011) & $(.087)$ & (.174) & $(.056)$ & (.012) & (.009) & (1.00) \\
\hline & Outros & $2.30-0.41$ & $2.59-0.56$ & $2.60-0.64$ & $2.40-0.71$ & $2.37-0.64$ & $2.19-0.55$ & $1.97-0.46$ & $2.00-0.64$ \\
\hline & Estatutário & $(.565)$ & $(.459)$ & $(.908)$ & $(.219)$ & $(.736)$ & $(1.00)$ & $(.442)$ & $(.666)$ \\
\hline & CLT & $(.003)$ & $(.011)$ & $(.087)$ & $(.174)$ & $(.056)$ & $(.012)$ & (.009) & (1.00) \\
\hline & Até $35 \mathrm{~h}$ & $2.45-0.40$ & $2.71-0.43$ & $2.62-0.64$ & $2.70-0.69$ & $2.35-0.51$ & $2.33-0.54$ & $2.28-0.52$ & $2.10-0.57$ \\
\hline & $36 \mathrm{~h} \mathrm{a} 40 \mathrm{~h}$ & $(1.00)$ & $(1.00)$ & $(.950)$ & $(1.00)$ & $(.332)$ & $(1.00)$ & $(.904)$ & $(1.00)$ \\
\hline & 41 ou mais & $(.188)$ & $(.086)$ & (.031) & $(1.00)$ & (.014) & $(.244)$ & $(1.00)$ & (1.00) \\
\hline & $36 \mathrm{~h}$ a $40 \mathrm{~h}$ & $2.47-0.39$ & $2.79-0.50$ & $2.76-0.61$ & $2.60-0.60$ & $2.55-0.54$ & $2.42-0.66$ & $2.16-0.47$ & $1.98-0.51$ \\
\hline & Até $35 \mathrm{~h}$ & $(1.00)$ & $(1.00)$ & $(.950)$ & $(1.00)$ & $(.332)$ & $(1.00)$ & $(.904)$ & (1.00) \\
\hline & 41 ou mais & (.020) & (.039) & $(.020)$ & $(1.00)$ & $(.059)$ & $(.138)$ & $(.167)$ & $(.320)$ \\
\hline & $41 \mathrm{~h}$ ou mais & $2.66-0.38$ & $3.01-0.50$ & $3.05-0.57$ & $2.64-0.64$ & $2.78-0.62$ & $2.64-0.53$ & $2.32-0.48$ & $2.12-0.52$ \\
\hline & Até $35 \mathrm{~h}$ & $(.188)$ & $(.086)$ & (.031) & $(1.00)$ & $(.014)$ & $(.244)$ & $(1.00)$ & $(1.00)$ \\
\hline & $36 \mathrm{~h}$ a $40 \mathrm{~h}$ & $(.020)$ & $(.039)$ & $(.020)$ & $(1.00)$ & $(.059)$ & $(.138)$ & (.167) & $(.320)$ \\
\hline & Sim & $\begin{array}{c}2.55-0.35 \\
\quad(.003)\end{array}$ & $\begin{array}{c}2.86-0.47 \\
(.123)\end{array}$ & $\begin{array}{c}2.94-0.55 \\
\quad(.000)\end{array}$ & $\begin{array}{c}2.65-0.58 \\
\quad(.367)\end{array}$ & $\begin{array}{c}2.58-0.57 \\
\quad(.543)\end{array}$ & $\begin{array}{l}2.54-0.60 \\
\quad(.001)\end{array}$ & $\begin{array}{c}2.23-0.45 \\
\quad(.076)\end{array}$ & $\begin{array}{c}2.04-0.51 \\
\quad(.085)\end{array}$ \\
\hline Horas extras & Não & $\begin{array}{c}2.40-0.43 \\
(.004)\end{array}$ & $\begin{array}{c}2.76-0.54 \\
(.134)\end{array}$ & $\begin{array}{c}2.60-0.65 \\
(.000)\end{array}$ & $\begin{array}{c}2.58-0.64 \\
(.377)\end{array}$ & $\begin{array}{c}2.54-0.53 \\
(.537)\end{array}$ & $\begin{array}{c}2.28-0.64 \\
(.001)\end{array}$ & $\begin{array}{c}2.13-0.52 \\
\quad .086)\end{array}$ & $\begin{array}{c}1.93-0.53 \\
(.087)\end{array}$ \\
\hline & Atenção hospitalar & $\begin{array}{c}2.58-0.35 \\
(.000)\end{array}$ & $\begin{array}{c}2.88-0.48 \\
\quad(.009)\end{array}$ & $\begin{array}{c}2.88-0.58 \\
\mathbf{( . 0 0 7 )}\end{array}$ & $\begin{array}{c}2.63-0.59 \\
(.710)\end{array}$ & $\begin{array}{c}2.63-0.53 \\
(.011)\end{array}$ & $\begin{array}{c}2.61-0.56 \\
\mathbf{( . 0 0 0 )}\end{array}$ & $\begin{array}{c}2.29-0.47 \\
(.000)\end{array}$ & $\begin{array}{c}2.06-0.52 \\
(.011)\end{array}$ \\
\hline serviço & $\begin{array}{l}\text { Atenção } \\
\text { básica/primária }\end{array}$ & $\begin{array}{c}2.35-0.42 \\
(.000)\end{array}$ & $\begin{array}{c}2.71-0.53 \\
(.011)\end{array}$ & $\begin{array}{c}2.67-0.64 \\
(.009)\end{array}$ & $\begin{array}{c}2.60-0.62 \\
(.713)\end{array}$ & $\begin{array}{c}2.45-0.57 \\
(.013)\end{array}$ & $\begin{array}{c}2.13-0.63 \\
(.000)\end{array}$ & $\begin{array}{c}2.01-0.44 \\
(.000)\end{array}$ & $\begin{array}{c}1.89-0.50 \\
(.010)\end{array}$ \\
\hline & Mais de 1 ano & $2.50-0.39$ & $2.83-0.51$ & $2.82-0.60$ & $2.60-0.59$ & $2.57-0.56$ & $2.44-0.64$ & $2.20-0.46$ & $1.97-0.51$ \\
\hline
\end{tabular}




\begin{tabular}{|c|c|c|c|c|c|c|c|c|c|}
\hline \multirow[b]{2}{*}{$\begin{array}{c}\text { Tempo no } \\
\text { serviço atual }\end{array}$} & & 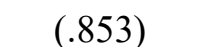 & $($. & (. & ( & $($. & & & \\
\hline & Menos de 1 ano & $\begin{array}{c}2.48-0.43 \\
(.864)\end{array}$ & $\begin{array}{c}2.77-0.48 \\
(.464)\end{array}$ & $\begin{array}{c}2.75-0.67 \\
(.566)\end{array}$ & $\begin{array}{c}2.69-0.66 \\
(.413)\end{array}$ & $\begin{array}{c}2.59-0.50 \\
(.762)\end{array}$ & $\begin{array}{c}2.39-0.60 \\
(.617)\end{array}$ & $\begin{array}{c}2.10-0.57 \\
(.305)\end{array}$ & $\begin{array}{c}2.17-0.56 \\
\quad(.042)\end{array}$ \\
\hline \multirow{2}{*}{$\begin{array}{l}\text { Ações contra } \\
\text { valores }\end{array}$} & Nunca/raramente & $\begin{array}{c}2.39-0.37 \\
(.000)\end{array}$ & $\begin{array}{c}2.70-0.50 \\
(.000)\end{array}$ & $\begin{array}{c}2.73-0.61 \\
\quad(.003)\end{array}$ & $\begin{array}{c}2.52-0.59 \\
(.000)\end{array}$ & $\begin{array}{c}2.49-0.52 \\
(.000)\end{array}$ & $\begin{array}{c}2.27-0.60 \\
(.000)\end{array}$ & $\begin{array}{c}2.07-0.42 \\
(.000)\end{array}$ & $\begin{array}{c}1.93-0.48 \\
(.002)\end{array}$ \\
\hline & Frequentemente/sempre & $\begin{array}{c}2.73-0.34 \\
\mathbf{( . 0 0 0 )}\end{array}$ & $\begin{array}{c}3.08-0.40 \\
\quad(.000)\end{array}$ & $\begin{array}{c}2.97-0.58 \\
\mathbf{( . 0 0 3 )}\end{array}$ & $\begin{array}{c}2.83-0.58 \\
\quad(.000)\end{array}$ & $\begin{array}{c}2.75-0.58 \\
\quad(.001)\end{array}$ & $\begin{array}{c}2.81-0.53 \\
(\mathbf{. 0 0 0})\end{array}$ & $\begin{array}{c}2.45-0.49 \\
\quad(.000)\end{array}$ & $\begin{array}{c}2.14-0.57 \\
\quad(.004)\end{array}$ \\
\hline \multirow[b]{2}{*}{ Está em SM } & Sim & $\begin{array}{r}2.70- \\
\quad .00\end{array}$ & $\begin{array}{c}3,12-0,45 \\
\quad(.000)\end{array}$ & $\begin{array}{c}3,00-0,57 \\
(\mathbf{. 0 0 0})\end{array}$ & $\begin{array}{c}2,73-0,63 \\
(\mathbf{. 0 4 5 )}\end{array}$ & $\begin{array}{c}2,63-0,56 \\
(.233)\end{array}$ & $\begin{array}{c}2,81-0,58 \\
(\mathbf{. 0 0 0})\end{array}$ & $\begin{array}{r}2,31- \\
\quad \mathbf{. 0}\end{array}$ & $\begin{array}{c}2,14-0,45 \\
\quad(.001)\end{array}$ \\
\hline & Não & $\begin{array}{r}2.40 \\
(.0\end{array}$ & $\begin{array}{r}2,68 \\
(.0\end{array}$ & $\begin{array}{r}2,71 \\
\quad .0\end{array}$ & $\begin{array}{r}2,56 \\
(.0\end{array}$ & $\begin{array}{r}2,54 \\
(.2\end{array}$ & $\begin{array}{r}2,25 \\
(.0\end{array}$ & $\begin{array}{r}2,13 \\
(.0\end{array}$ & $\begin{array}{r}1,93 \\
(.0\end{array}$ \\
\hline \multirow{2}{*}{$\begin{array}{l}\text { Viveu outras } \\
\text { vezes }\end{array}$} & Uma vez ou mais & $\begin{array}{r}2.53- \\
\quad .0\end{array}$ & $\begin{array}{r}2.87 \\
\quad(.0\end{array}$ & $\begin{array}{r}2.84 \\
\quad(.1\end{array}$ & $\begin{array}{r}2.68 \\
\mathbf{( . 0}\end{array}$ & $\begin{array}{r}2.57 \\
(.9\end{array}$ & $\begin{array}{r}2.50 \\
\mathbf{( . 0}\end{array}$ & $\begin{array}{r}2.22 \\
(.0\end{array}$ & $\begin{array}{r}2.03 \\
(.1\end{array}$ \\
\hline & Nunca & $\begin{array}{r}2.38- \\
(.01\end{array}$ & $\begin{array}{r}2.67- \\
\quad .01\end{array}$ & $\begin{array}{c}2.71-0.74 \\
(.175)\end{array}$ & $\begin{array}{c}2.45-0.60 \\
(.007)\end{array}$ & $\begin{array}{r}2.57 \\
(.9\end{array}$ & $\begin{array}{c}2.27-0.71 \\
(.018)\end{array}$ & $\begin{array}{c}2.10-0.49 \\
(.092)\end{array}$ & $\begin{array}{c}1.92-0.59 \\
(.180)\end{array}$ \\
\hline \multirow{2}{*}{$\begin{array}{c}\text { Deixaria o } \\
\text { trabalho }\end{array}$} & Sin & $\begin{array}{r}2.64- \\
\quad .00\end{array}$ & $\begin{array}{r}3.03 \\
\quad .0\end{array}$ & $\begin{array}{c}2.87-0.60 \\
(.171)\end{array}$ & $\begin{array}{r}2.70 \\
\quad .0\end{array}$ & $\begin{array}{r}2.60- \\
(.4\end{array}$ & $\begin{array}{r}2.67 \\
(.0\end{array}$ & $\begin{array}{r}2.34 \\
\quad(.0\end{array}$ & $\begin{array}{r}2.11 \\
\quad .0\end{array}$ \\
\hline & Não & $\begin{array}{c}2.41-0.39 \\
\quad(.000)\end{array}$ & $\begin{array}{c}2.70-0.49 \\
(.000)\end{array}$ & $\begin{array}{c}2.76-0.62 \\
\quad(.167)\end{array}$ & $\begin{array}{l}2.57-0.61 \\
\quad(.079)\end{array}$ & $\begin{array}{c}2.55-0.54 \\
(.459)\end{array}$ & $\begin{array}{c}2.30-0.61 \\
\quad .000)\end{array}$ & $\begin{array}{c}2.10-0.47 \\
(.000)\end{array}$ & $\begin{array}{c}1.94-0.50 \\
(.011)\end{array}$ \\
\hline \multirow{2}{*}{$\begin{array}{c}\text { Já deixou um } \\
\text { trabalho }\end{array}$} & Sim & $\begin{array}{l}2.55-0.41 \\
\quad(.116)\end{array}$ & $\begin{array}{l}2.88-0.51 \\
\quad(.216)\end{array}$ & $\begin{array}{c}2.83-0.59 \\
(.618)\end{array}$ & $\begin{array}{c}2.78-0.67 \\
\quad(.003)\end{array}$ & $\begin{array}{c}2.56-0.55 \\
(.792)\end{array}$ & $\begin{array}{c}2.51-0.60 \\
(.186)\end{array}$ & $\begin{array}{c}2.25-0.53 \\
(.192)\end{array}$ & $\begin{array}{c}2.02-0.48 \\
(.695)\end{array}$ \\
\hline & Não & $\begin{array}{c}2.47-0.38 \\
(.124)\end{array}$ & $\begin{array}{c}2.79-0.50 \\
(.221)\end{array}$ & $\begin{array}{c}2.79-0.63 \\
(.611)\end{array}$ & $\begin{array}{c}2.55-0.55 \\
(.006)\end{array}$ & $\begin{array}{c}2.58-0.54 \\
(.793)\end{array}$ & $\begin{array}{c}2.40-0.64 \\
(.176)\end{array}$ & $\begin{array}{c}2.17-0.45 \\
(.218)\end{array}$ & $\begin{array}{c}1.98-0.54 \\
(.682)\end{array}$ \\
\hline
\end{tabular}

MTE: média total da escala. MF1: média fator 1 (questões organizacionais e de gestão); MF2: média fator 2 (carga de trabalho); MF3: média fator 3 (recursos); MF4: média fator 4 (conflitos); MF5: média fator 5 (autonomia); MF6: média fator 6 (fim de vida); MF7: média fator 7 (segurança). DP: desvio padrão. 


\subsection{RESULTADOS PORTUGAL}

A média total da escala para a amostra investigada foi de 2,43 e as médias dos fatores variaram entre 1,93 e 2,97. O fator 'Carga de trabalho: excessiva carga de trabalho' apresentou média de 2,97; o fator 'Cuidado: dificuldade para prestar cuidado' obteve média de 2,24; o fator 'Questões organizacionais e de gestão: desafios no local de trabalho' obteve média de 2,57; e o fator 'Segurança: falta de segurança profissional' obteve média de 1,93 (Tabela 19).

Tabela 19 - Média total e média dos fatores da Escala de Risco de Sofrimento Moral (Portugal)

\begin{tabular}{|c|c|}
\hline Fatores e respectivos itens & Média (DP) \\
\hline Carga de trabalho: excessiva carga de trabalho & $2,97(0,55)$ \\
\hline Falta de enfermeiros & $3,12(0,77)$ \\
\hline Mercantilização dos cuidados de saúde & $2,93(0,75)$ \\
\hline Falta de tempo por excesso de trabalho & $3,01(0,67)$ \\
\hline Stress & $3,03(0,62)$ \\
\hline Esgotamento físico / mental / emocional & $2,76(0,70)$ \\
\hline Número excessivo de utentes atribuídos a cada enfermeiro & $2,91(0,82)$ \\
\hline Cuidado: dificuldade para prestar cuidado & $2,24(0,47)$ \\
\hline Ser obrigado a prestar cuidado inadequado ou desnecessário & $2,11(0,70)$ \\
\hline Vontade do utente não é respeitada & $2,05(0,59)$ \\
\hline Uso inadequado dos recursos disponíveis & $2,47(0,67)$ \\
\hline Observar cuidado inadequado ou desnecessário & $2,36(0,63)$ \\
\hline Não ser incluído na tomada de decisões & $2,43(0,74)$ \\
\hline Demora no atendimento & $2,46(0,60)$ \\
\hline Ser forçado a transgredir as regras & $1,79(0,69)$ \\
\hline Questões organizacionais e de gestão: desafios no local de trabalho & $2,57(0,62)$ \\
\hline Falta de liderança eficaz no serviço & $2,60(0,71)$ \\
\hline Realização pessoal reduzida & $2,48(0,78)$ \\
\hline Desvalorização profissional & $2,72(0,81)$ \\
\hline Insatisfação com o trabalho & $2,47(0,79)$ \\
\hline Segurança: falta de segurança profissional & $1,93(0,59)$ \\
\hline Medo de não ser aceito pela equipe & $1,92(0,71)$ \\
\hline Medo de notificar erros que você cometeu & $1,95(0,80)$ \\
\hline Questões de gênero & $1,90(0,76)$ \\
\hline Média total & $2,43(0,56)$ \\
\hline
\end{tabular}

A análise das variáveis sociodemográficas revelou que não há diferenças significativas na média total da escala para homens $(\mathrm{p}=.050)$ e para mulheres $(\mathrm{p}=.052)$. Foi, entretanto, significativamente maior a média de risco de sofrimento moral para as 
mulheres no fator 'Carga de trabalho' $(\mathrm{p}=.042)$. A idade, referida em anos completos, foi categorizada por grupos etários, com base na análise dos quartis: até 30 anos, de 31 a 40 anos e 41 anos ou mais. Houve diferença significativa na média total da escala quando comparados os participantes mais jovens (até 30 anos) com os mais velhos (41 anos ou mais) ( $\mathrm{p}=.039)$. A mesma diferença significativa foi encontrada nos fatores 'Questões organizacionais e de gestão' ( $p=.044)$ e 'Segurança' $(\mathrm{p}=.000)$. Maior média de risco de sofrimento moral também para os mais jovens (até 30 anos) quando comparados com os participantes entre 31 e 40 anos para o fator 'Segurança' $(p=.005)$.

Nas variáveis de formação, houve diferença significativa entre os enfermeiros sem mestrado para uma maior média no fator 'segurança' $(p=.008)$. Essa diferença não se manteve significativa para a média total da escala $(p=.271)$. Não houve diferenças significativas na média total da escala para a variável 'especialização' ( $p=.658)$.

O tempo de trabalho como enfermeiro foi categorizado em: até 4 anos, 5 a 10 anos e 11 anos ou mais, também com base na análise dos quartis. A análise mostra uma diferença significativa de média para o grupo com menos tempo de profissão e o grupo com mais anos de profissão no fator 'segurança', sendo a maior média encontrada no grupo com menos de 4 anos de profissão ( $p=.037)$. Essa diferença não foi significativa para a média total da escala $(\mathrm{p}=.501)$.

O tipo de contrato de trabalho incluía as opções 'sem contrato', 'liberal', 'a termo', 'sem termo' ou 'outro'. Foi verificada apenas uma associação significativa entre profissionais com contrato sem termo e sem contrato $(\mathrm{p}=.046)$.

A média total da escala foi significativamente maior para os enfermeiros que diziam trabalhar 41 horas ou mais por semana, quando comparados com os enfermeiros que trabalham até 35 horas por semana $(p=.036)$. Também foi significativamente maior nos fatores 'carga de trabalho' e 'segurança' ( $p=.027 ; p=.007)$.

Em relação à realização de horas extras, a análise revela diferença significativa de média entre o grupo que faz horas extras e o grupo que não faz horas extras para a média total da escala, sendo a maior média pertencente ao grupo que diz fazer horas extras $(\mathrm{p}=.000)$. Essa diferença se manteve significativa para os fatores 'carga de trabalho' $(p=.000)$, ‘cuidado’ $(p=.012)$ e ‘questões organizacionais e de gestão’ $(p=.000)$.

Os enfermeiros que trabalham em hospital ou serviço equivalente apresentaram uma média total da escala significativamente maior, quando comparados com os enfermeiros dos cuidados de saúde primários $(\mathrm{p}=.000)$. Essa diferença se manteve 
significativa para o fator 'carga de trabalho' $(p=.000)$, 'cuidado' $(p=.005)$ e 'questões organizacionais e de gestão' $(\mathrm{p}=.000)$.

Das variáveis do local de trabalho, os enfermeiros que disseram presenciar ou realizar ações contra seus valores 'frequentemente/sempre', tem a média total da escala significativamente maior do que aqueles profissionais que presenciam ou realizam esse tipo de ações 'nunca/raramente' $(p=.000)$. O resultado foi igualmente significativo para todos os outros fatores da escala $(p=.000 ; p=.000 ; p=.000 ; p=.000)$.

Houve diferença significativa para a maior média da escala nos enfermeiros que responderam estar em sofrimento moral, quando comparados com os que responderam não estar $(\mathrm{p}=.000)$. Essa diferença também se manteve significativa para todos os fatores $(p=.000 ; p=.000 ; p=.000 ; p=.000)$. Ter vivenciado o sofrimento moral anteriormente não mostrou estar significativamente associado a maiores médias de risco de sofrimento moral $(p=.781)$.

Resultados significativos de maior média da escala foram encontrados no grupo de enfermeiros que afirma ter vontade de deixar o seu local de trabalho $(p=.000)$. $O$ resultado foi o mesmo para todos os fatores da escala $(p=.000 ; p=.000 ; p=.000 ; p=.000)$. Em relação aos enfermeiros que efetivamente já deixaram um local de trabalho anteriormente, não foram encontradas diferenças significativas. Os resultados são descritos na Tabela 20, sendo as associações significativas destacadas em negrito. 
Tabela 20 - Diferenças na média total da escala e na média dos fatores em relação às variáveis sociodemográficas, formação, atividade profissional, local de trabalho e sofrimento moral, Portugal $(\mathrm{n}=\mathbf{2 7 8})$

\begin{tabular}{|c|c|c|c|c|c|c|}
\hline & Variável & $\begin{array}{c}\text { MTE - DP } \\
\text { (p-valor) }\end{array}$ & $\begin{array}{c}\text { MF1 - DP } \\
\text { (p-valor) }\end{array}$ & $\begin{array}{c}\text { MF2 - DP } \\
\text { (p-valor) }\end{array}$ & $\begin{array}{c}\text { MF3 - DP } \\
\text { (p-valor) }\end{array}$ & $\begin{array}{c}\text { MF4 - DP } \\
\text { (p-valor) }\end{array}$ \\
\hline \multirow{2}{*}{ Sexo } & Feminino & $\begin{array}{c}2.37-0.35 \\
\quad(.052)\end{array}$ & $\begin{array}{c}2.74-0.38 \\
\quad(.042)\end{array}$ & $\begin{array}{c}2.19-0.42 \\
\quad(.271)\end{array}$ & $\begin{array}{c}2.47-0.50 \\
(.164)\end{array}$ & $\begin{array}{c}1.91-0.54 \\
(.079)\end{array}$ \\
\hline & Masculino & $\begin{array}{c}2.26-0.35 \\
(.050)\end{array}$ & $\begin{array}{c}2.61-0.38 \\
(.039)\end{array}$ & $\begin{array}{c}2.11-0.43 \\
(.258)\end{array}$ & $\begin{array}{c}2.36-0.48 \\
(.173)\end{array}$ & $\begin{array}{c}1.76-0.51 \\
(.087)\end{array}$ \\
\hline \multirow{7}{*}{ Idade } & $\begin{array}{l}\text { Até } 30 \text { anos } \\
31 \text { a } 40 \text { anos }\end{array}$ & $\begin{array}{c}2.39-0.34 \\
(.829)\end{array}$ & $\begin{array}{c}2.73-0.37 \\
(.998)\end{array}$ & $\begin{array}{c}2.17-0.42 \\
(.953) \\
(.804)\end{array}$ & $\begin{array}{c}\mathbf{2 . 5 0}-\mathbf{0 . 4 8} \\
(.934) \\
(.044)\end{array}$ & $\begin{array}{c}2.05-0.54 \\
(.005) \\
(.000)\end{array}$ \\
\hline & 41 ou mais & (.039) & $(.182)$ & $(.804)$ & $(.044)$ & $(.000)$ \\
\hline & 31 a 40 anos & $2.36-0.37$ & $2.73-0.38$ & $2.19-0.44$ & $2.48-0.49$ & $1.83-0.52$ \\
\hline & $\begin{array}{l}\text { Até } 30 \text { anos } \\
41 \text { ou mais }\end{array}$ & $\begin{array}{l}(.829) \\
(.094)\end{array}$ & $\begin{array}{l}(.998) \\
(.176)\end{array}$ & $\begin{array}{l}(.953) \\
(.655)\end{array}$ & $\begin{array}{l}(.934) \\
(.070)\end{array}$ & $\begin{array}{l}(.005) \\
(.164)\end{array}$ \\
\hline & 41 ou mais & $2.24-0.32$ & $2.61-0.40$ & $2.13-0.39$ & $2.29-0.54$ & $1.67-0.45$ \\
\hline & Até 30 anos & $(.039)$ & $(.182)$ & $(.804)$ & $(.044)$ & $(.000)$ \\
\hline & 31 a 40 anos & $(.094)$ & $(.176)$ & $(.655)$ & $(.070)$ & (.164) \\
\hline \multirow{2}{*}{ Especialização } & Sim & $\begin{array}{c}2.37-0.39 \\
(.635)\end{array}$ & $\begin{array}{c}2.71-0.40 \\
(.985)\end{array}$ & $\begin{array}{c}2.23-0.43 \\
\quad(.292)\end{array}$ & $\begin{array}{c}2.41-0.54 \\
(.396)\end{array}$ & $\begin{array}{c}1.99-0.56 \\
(.099)\end{array}$ \\
\hline & Não & $\begin{array}{c}2.35-0.35 \\
(.658)\end{array}$ & $\begin{array}{c}2.71-0.37 \\
(.986)\end{array}$ & $\begin{array}{c}2.16-0.42 \\
(.298)\end{array}$ & $\begin{array}{c}2.47-0.49 \\
(.424)\end{array}$ & $\begin{array}{c}1.86-0.52 \\
(.115)\end{array}$ \\
\hline \multirow{2}{*}{ Mestrado } & Sim & $\begin{array}{c}2.33-0.35 \\
(.271)\end{array}$ & $\begin{array}{c}2.69-0.38 \\
(.373)\end{array}$ & $\begin{array}{c}2.18-0.42 \\
\quad(.766)\end{array}$ & $\begin{array}{c}2.44-0.48 \\
(.477)\end{array}$ & $\begin{array}{c}1.81-0.51 \\
(.008)\end{array}$ \\
\hline & Não & $\begin{array}{c}2.38-0.36 \\
\quad(.271)\end{array}$ & $\begin{array}{c}2.74-0.38 \\
(.373)\end{array}$ & $\begin{array}{c}2.16-0.43 \\
\quad(.766)\end{array}$ & $\begin{array}{l}2.48-0.52 \\
\quad(.481)\end{array}$ & $\begin{array}{c}1.98-0.54 \\
(.008)\end{array}$ \\
\hline \multirow{3}{*}{$\begin{array}{l}\text { Tempo de } \\
\text { trabalho }\end{array}$} & $\begin{array}{l}\text { Até } 4 \text { anos } \\
5 \text { a } 10 \text { anos } \\
11 \text { ou mais }\end{array}$ & $\begin{array}{c}2.39-0.31 \\
\quad(.183) \\
(.501)\end{array}$ & $\begin{array}{c}2.76-0.34 \\
\quad(.136) \\
(.395)\end{array}$ & $\begin{array}{c}2.19-0.41 \\
\quad(.516) \\
(.940)\end{array}$ & $\begin{array}{c}2.50-0.46 \\
\quad(.320) \\
(.652)\end{array}$ & $\begin{array}{c}1.97-0.51 \\
(.075) \\
(.037)\end{array}$ \\
\hline & $\begin{array}{l}5 \text { a } 10 \text { anos } \\
\text { Até } 4 \text { anos } \\
11 \text { ou mais }\end{array}$ & $\begin{array}{l}2.31-0.43 \\
(.183) \\
(.917)\end{array}$ & $\begin{array}{c}2.66-0.43 \\
\quad(.136) \\
(.934)\end{array}$ & $\begin{array}{c}2.13-0.48 \\
\quad(.516) \\
(.451)\end{array}$ & $\begin{array}{c}2.40-0.58 \\
\quad(.320) \\
(.932)\end{array}$ & $\begin{array}{c}1.81-0.54 \\
(.075) \\
(.872)\end{array}$ \\
\hline & 11 ou mais & $2.33-0.32$ & $2.68-0.36$ & $2.22-0.38$ & $2.43-0.46$ & $1.77-0.52$ \\
\hline
\end{tabular}




\begin{tabular}{|c|c|c|c|c|c|c|}
\hline & Até 4 anos & $(.501)$ & $(.395)$ & $(.940)$ & $(.652)$ & $(.037)$ \\
\hline & 5 a 10 anos & (.917) & $(.934)$ & $(.451)$ & $(.932)$ & $(.872)$ \\
\hline & Sem contrato & $2.31-0.33$ & $2.69-0.43$ & $1.85-0.48$ & $2.54-0.47$ & $2.30-0.60$ \\
\hline & Liberal & $(1.00)$ & $(.512)$ & $(.975)$ & $(.916)$ & $(.676)$ \\
\hline & A termo & $(1.00)$ & (.991) & $(.382)$ & $(.814)$ & (.146) \\
\hline & Sem termo & (.986) & (.999) & $(.046)$ & $(.985)$ & $(.071)$ \\
\hline & Outro & (.998) & (1.00) & $(.815)$ & $(.962)$ & $(.121)$ \\
\hline & Liberal & $2.29-0.36$ & $2.40-0.61$ & $1.97-0.34$ & $2.75-0.32$ & $1.94-0.53$ \\
\hline & Sem contrato & $(1.00)$ & $(.512)$ & $(.975)$ & $(.916)$ & $(.676)$ \\
\hline & A termo & (1.00) & $(.180)$ & $(.929)$ & (.327) & (.998) \\
\hline & Sem termo & (.984) & (.189) & $(.578)$ & $(.574)$ & (.997) \\
\hline & Outro & $(1.00)$ & (.483) & (.999) & $(.567)$ & $(.986)$ \\
\hline & A termo & $2.31-0.32$ & $2.75-0.33$ & $2.12-0.37$ & $2.35-0.50$ & $1.87-0.48$ \\
\hline & Sem contrato & $(1.00)$ & $(.991)$ & $(.382)$ & $(.814)$ & $(.146)$ \\
\hline o de & Liberal & $(1.00)$ & $(.180)$ & (.929) & $(.327)$ & (.998) \\
\hline & Sem termo & (.946) & (.992) & $(.752)$ & $(.785)$ & (1.00) \\
\hline & Outro & (.991) & $(.962)$ & $(.952)$ & (.994) & (.997) \\
\hline & Sem termo & $2.37-0.36$ & $2.72-0.37$ & $2.21-0.42$ & $2.46-0.51$ & $1.87-0.53$ \\
\hline & Sem contrato & $(.986)$ & (.999) & (.046) & $(.985)$ & $(.071)$ \\
\hline & Liberal & $(.984)$ & (.189) & $(.578)$ & $(.574)$ & (.997) \\
\hline & A termo & $(.946)$ & (.992) & $(.752)$ & $(.785)$ & (1.00) \\
\hline & Outro & $(.791)$ & $(.990)$ & $(.372)$ & (.995) & (.993) \\
\hline & Outro & $2.27-0.35$ & $2.68-0.44$ & $2.03-0.42$ & $2.41-0.37$ & $1.81-0.57$ \\
\hline & Sem contrato & $(.998)$ & $(1.00)$ & $(.815)$ & $(.962)$ & $(.121)$ \\
\hline & Liberal & (1.00) & (.483) & (.999) & $(.567)$ & $(.986)$ \\
\hline & A termo & (.991) & $(.962)$ & $(.952)$ & (.994) & (.997) \\
\hline & Sem termo & $(.791)$ & (.990) & $(.372)$ & (.995) & (.993) \\
\hline & Até 35h & $2.29-0.37$ & $2.63-0.41$ & $2.14-0.42$ & $2.42-0.51$ & $1.80-0.55$ \\
\hline & $36 \mathrm{~h}$ a $40 \mathrm{~h}$ & $(.411)$ & $(.036)$ & $(.910)$ & $(.941)$ & $(.745)$ \\
\hline Horas de & 41 ou mais & $(.036)$ & $(.027)$ & $(.429)$ & $(.296)$ & $(.007)$ \\
\hline trabalho & $36 \mathrm{~h}$ a $40 \mathrm{~h}$ & $2.37-0.33$ & $2.76-0.35$ & $2.18-0.39$ & $2.45-0.48$ & $1.87-0.50$ \\
\hline & Até $35 \mathrm{~h}$ & $(.411)$ & $(.036)$ & $(.910)$ & $(.941)$ & $(.745)$ \\
\hline & 41 ou mais & $(.375)$ & $(.797)$ & $(.726)$ & $(.533)$ & $(.058)$ \\
\hline
\end{tabular}




\begin{tabular}{|c|c|c|c|c|c|c|}
\hline & $\begin{array}{l}1 \mathrm{~h} \text { ou mais } \\
\text { Até } 35 \mathrm{~h} \\
36 \mathrm{~h} \text { a } 40 \mathrm{~h}\end{array}$ & $\begin{array}{c}2.47-0.33 \\
\quad(.036) \\
(.375)\end{array}$ & $\begin{array}{c}\mathbf{2 . 8 3}-\mathbf{0 . 2 6} \\
(.027) \\
(.797)\end{array}$ & $\begin{array}{c}2.26-0.50 \\
\quad(.429) \\
(.726)\end{array}$ & $\begin{array}{c}2.58-0.49 \\
(.296) \\
(.533)\end{array}$ & $\begin{array}{c}\mathbf{2 . 1 2}-\mathbf{0 . 4 8} \\
(.007) \\
(.058)\end{array}$ \\
\hline \multirow{2}{*}{ Horas extras } & Sim & $\begin{array}{c}2.39-0.33 \\
(.000)\end{array}$ & $\begin{array}{c}2.75-0.35 \\
(.000)\end{array}$ & $\begin{array}{l}2.20-0.42 \\
\quad(.012)\end{array}$ & $\begin{array}{l}2.52-0.46 \\
(.000)\end{array}$ & $\begin{array}{c}1.88-0.52 \\
(.682)\end{array}$ \\
\hline & Não & $\begin{array}{c}2.19-0.39 \\
(.002)\end{array}$ & $\begin{array}{c}2.55-0.45 \\
(.003)\end{array}$ & $\begin{array}{c}2.04-0.40 \\
(.011)\end{array}$ & $\begin{array}{c}2.20-0.56 \\
(.000)\end{array}$ & $\begin{array}{c}1.85-0.56 \\
(.699)\end{array}$ \\
\hline \multirow{2}{*}{$\begin{array}{l}\text { Tipo de } \\
\text { serviço }\end{array}$} & $\begin{array}{l}\text { Cuidados de Saúde } \\
\text { Primários }\end{array}$ & $\begin{array}{l}2.17-0.36 \\
\quad(.000)\end{array}$ & $\begin{array}{l}2.52-0.47 \\
\quad(.000)\end{array}$ & $\begin{array}{l}2.03-0.37 \\
\quad(.005)\end{array}$ & $\begin{array}{l}2.21-0.50 \\
\quad(.000)\end{array}$ & $\begin{array}{l}1.74-0.56 \\
\quad(.128)\end{array}$ \\
\hline & Hospital ou equivalente & $\begin{array}{c}2.42-0.33 \\
\quad(.000)\end{array}$ & $\begin{array}{c}2.79-0.31 \\
\quad(.000)\end{array}$ & $\begin{array}{l}2.24-0.41 \\
\quad(.005)\end{array}$ & $\begin{array}{l}2.52-0.47 \\
\quad(.000)\end{array}$ & $\begin{array}{l}1.91-0.51 \\
\quad(.128)\end{array}$ \\
\hline \multirow{2}{*}{$\begin{array}{l}\text { Ações contra } \\
\text { valores }\end{array}$} & Nunca/raramente & $\begin{array}{l}2.20-0.34 \\
\quad .000)\end{array}$ & $\begin{array}{l}2.60-0.44 \\
\quad(.000)\end{array}$ & $\begin{array}{l}2.00-0.37 \\
\quad(.000)\end{array}$ & $\begin{array}{l}2.32-0.51 \\
\quad(.000)\end{array}$ & $\begin{array}{c}1.73-0.50 \\
\quad(.000)\end{array}$ \\
\hline & Frequentemente/sempre & $\begin{array}{c}2.52-0.29 \\
(.000)\end{array}$ & $\begin{array}{c}2.84-0.26 \\
\quad(.000)\end{array}$ & $\begin{array}{c}2.38-0.39 \\
(.000)\end{array}$ & $\begin{array}{c}2.62-0.42 \\
(.000)\end{array}$ & $\begin{array}{c}2.07-0.52 \\
\quad(.000)\end{array}$ \\
\hline \multirow{2}{*}{ Está em SM } & Sim & $\begin{array}{l}2.65-0.24 \\
\quad(.000)\end{array}$ & $\begin{array}{l}2.90-0.22 \\
\quad(.000)\end{array}$ & $\begin{array}{l}2.53-0.35 \\
\quad(.000)\end{array}$ & $\begin{array}{c}2.83-0.29 \\
\quad(.000)\end{array}$ & $\begin{array}{l}2.12-0.58 \\
\quad(.000)\end{array}$ \\
\hline & Não & $\begin{array}{l}2.26-0.33 \\
(.000)\end{array}$ & $\begin{array}{l}2.65-0.40 \\
\quad(.000)\end{array}$ & $\begin{array}{l}2.06-0.38 \\
\quad(.000)\end{array}$ & $\begin{array}{l}2.33-0.49 \\
\quad(.000)\end{array}$ & $\begin{array}{l}1.81-0.50 \\
\quad(.000)\end{array}$ \\
\hline \multirow{2}{*}{$\begin{array}{l}\text { Viveu outras } \\
\text { vezes }\end{array}$} & Nunca & $\begin{array}{l}2.34-0.33 \\
\quad(.790)\end{array}$ & $\begin{array}{l}2.72-0.34 \\
\quad(.814)\end{array}$ & $\begin{array}{l}2.16-0.39 \\
\quad(.717)\end{array}$ & $\begin{array}{l}2.40-0.52 \\
\quad(.340)\end{array}$ & $\begin{array}{c}1.92-0.49 \\
(.565)\end{array}$ \\
\hline & Uma vez ou mais & $\begin{array}{c}2.35-0.36 \\
(.781)\end{array}$ & $\begin{array}{c}2.71-0.39 \\
\quad(.802)\end{array}$ & $\begin{array}{c}2.18-0.43 \\
\quad(.705)\end{array}$ & $\begin{array}{c}2.47-0.49 \\
(.354)\end{array}$ & $\begin{array}{c}1.87-0.55 \\
(.543)\end{array}$ \\
\hline \multirow{2}{*}{$\begin{array}{c}\text { Deixaria o } \\
\text { trabalho }\end{array}$} & Sim & $\begin{array}{l}2.57-0.29 \\
\quad(.000)\end{array}$ & $\begin{array}{l}2.85-0.27 \\
\quad(.000)\end{array}$ & $\begin{array}{l}2.42-0.42 \\
(.000)\end{array}$ & $\begin{array}{l}2.74-0.38 \\
\quad(.000)\end{array}$ & $\begin{array}{l}2.12-0.53 \\
\quad(.000)\end{array}$ \\
\hline & Não & $\begin{array}{l}2.25-0.34 \\
(.000)\end{array}$ & $\begin{array}{l}2.65-0.41 \\
\quad(.000)\end{array}$ & $\begin{array}{l}2.07-0.38 \\
\quad(.000)\end{array}$ & $\begin{array}{l}2.32-0.49 \\
\quad(.000)\end{array}$ & $\begin{array}{l}1.78-0.50 \\
\quad(.000)\end{array}$ \\
\hline \multirow{2}{*}{$\begin{array}{c}\text { Já deixou um } \\
\text { trabalho }\end{array}$} & Sim & $\begin{array}{c}2.36-0.40 \\
(.863)\end{array}$ & $\begin{array}{l}2.70-0.44 \\
\quad(.779)\end{array}$ & $\begin{array}{l}2.17-0.48 \\
\quad(1.00)\end{array}$ & $\begin{array}{l}2.41-0.57 \\
\quad(.498)\end{array}$ & $\begin{array}{l}1.97-0.60 \\
\quad(.172)\end{array}$ \\
\hline & Não & $\begin{array}{c}2.35-0.34 \\
(.875)\end{array}$ & $\begin{array}{c}2.72-0.36 \\
(.802) \\
\end{array}$ & $\begin{array}{c}2.17-0.41 \\
(1.00)\end{array}$ & $\begin{array}{c}2.46-0.48 \\
(.542)\end{array}$ & $\begin{array}{c}1.86-0.51 \\
(.215)\end{array}$ \\
\hline
\end{tabular}

MTE: média total da escala. MF1: média fator 1 (carga de trabalho); MF2: média fator 2 (cuidado); MF3: média fator 3 (questões organizacionais e de gestão); MF4: média fator 4 (segurança). DP: desvio padrão. 


\subsection{DISCUSSÃO}

A utilização de escalas para medir ou quantificar fenômenos sociais ou comportamentais pode ser um facilitador no processo de aquisição do conhecimento, desde que a ferramenta utilizada seja verdadeiramente confiável. A validade de uma escala é determinada pela sua capacidade em medir o que pretende (DeVellis, 2016).

Nesse estudo, o sofrimento moral é considerado como um fenômeno subjetivo, que os enfermeiros podem vivenciar quando encontram barreiras que impedem a realização de uma ação considerada moralmente apropriada (Jameton, 1984) (McCarthy \& Gastmans, 2015). Nessas situações, o enfermeiro percebe uma ameaça aos valores fundamentais da sua prática, contra a qual não consegue lançar uma defesa eficaz (Musto, Rodney, \& Vanderheide, 2015).

Os participantes que afirmam presenciar ou executar ações contra seus valores frequentemente em sua rotina de trabalho, apresentaram maiores médias para risco de sofrimento moral. Esses resultados foram estatisticamente significativos tanto para a média total da escala, quanto para todos os fatores analisados, na amostra brasileira e portuguesa. Além disso, os participantes que afirmaram estar em sofrimento moral no momento do preenchimento da escala, apresentaram resultados estatisticamente significativos para maiores médias de risco de sofrimento moral em todos os fatores, em ambas as amostras. Essas associações significativas confirmam a evidência de validade da escala, demonstrando que ela é capaz de medir o que pretende (DeVellis, 2016).

Dentre as variáveis de caracterização, a idade e o tempo de trabalho como enfermeiro apresentaram alguns resultados significativos. $\mathrm{O}$ risco de sofrimento moral foi maior em enfermeiros com menos idade e com menos tempo de trabalho para o fator 'segurança' em ambos os países. Enfermeiros mais experientes parecem ter menor risco para sofrimento moral, mas a literatura não é clara sobre as relações entre essas variáveis e o sofrimento moral, ora demonstrando associações significativas (Woods, Rodgers, Towers, \& Grow, 2015), ora não (Lusignani, Gianni, Re, \& Buffon, 2016). Veer, Francke, Struijs \& Willemsv (2013) já levantavam essa discussão, destacando que as variáveis idade e experiência profissional são as que mais variam entre os estudos.

A partir da análise dos resultados é possível identificar as principais variáveis associadas ao maior risco de sofrimento moral, quais sejam, o tipo de contrato de trabalho 
no Brasil, o número de horas de trabalho semanais, a realização de horas extras, o contexto de trabalho, estar em sofrimento moral, ter vivido o sofrimento moral anteriormente e ter a intenção de deixar a profissão, em ambos os países. Para a amostra brasileira, ter um contrato de trabalho regido pela Consolidação das Leis do Trabalho CLT e trabalhar mais de $41 \mathrm{~h}$ por semana estava associado ao maior risco de sofrimento moral.

Para analisar a associação entre o maior risco de sofrimento moral em enfermeiros com contrato CLT pode-se considerar alguns fatores, entre eles, a estabilidade. Um servidor em regime estatutário, regulamentado pela Lei $\mathrm{n}^{\circ} 8.112$, de 11 de dezembro de 1990 (BRASIL, 1990), adquire estabilidade no serviço público ao completar dois anos de efetivo exercício (Art. 21) e só perderá o cargo em virtude de sentença judicial ou de processo administrativo disciplinar (Art. 22). O mesmo não se aplica ao regime CLT, aprovado pelo Decreto-Lei $n^{\circ} 5.452$, de $1^{\circ}$ de maio de 1943 (BRASIL, 1943).

Poder-se-ia considerar que a estabilidade ou, mais precisamente, a ausência dela, estaria de alguma forma contribuindo para a maior média de risco de sofrimento moral. De fato, um estudo realizado com enfermeiros em um hospital universitário brasileiro mostra que, quando foram comparadas as respostas dos profissionais estatutários e celetistas, os primeiros se mostraram mais seguros em relação ao emprego, tanto pela estabilidade, quanto pelo plano de carreira, o que interferiu na satisfação relacionada ao trabalho (Alves, Neves, Coleta, \& Oliveira, 2012). A literatura confirma, ainda, que a instabilidade pode gerar insegurança e medo profissional, relacionados com a possibilidade da perda do emprego (Wisniewski, Silva, Évora, \& Matsuda, 2015).

Por outro lado, estudo realizado no sul do Brasil encontrou resultados contraditórios, com maiores níveis de sofrimento moral relatados pelos enfermeiros concursados, com estabilidade profissional (Barlem, et al., 2013). O autor justifica esse achado considerando que os profissionais com estabilidade empregatícia teriam mais possibilidade de enfrentar os fatores de risco para sofrimento moral e reivindicar melhorias, enquanto que os enfermeiros sem estabilidade apelariam à mortificação de seus desejos e à renúncia pessoal. A literatura internacional também chama atenção para o silenciamento do sofrimento moral por parte dos enfermeiros, que pode estar relacionado tanto com uma falta de confiança individual, quanto com o medo de ser considerado fraco pela instituição e, assim, colocar sua posição em risco (Austin, 2016). 
Outro fator a se considerar é que o tipo de contrato CLT é o que costuma regulamentar as relações de trabalho das instituições privadas, enquanto que o vínculo estatutário é exclusivo das instituições públicas. Nesse contexto, cabe analisar as condições de trabalho nesses tipos de serviço para perceber se o maior risco de sofrimento moral nos enfermeiros com vínculo CLT está relacionado com o fato destes atuarem em instituições de saúde do setor privado.

Segundo pesquisa recente, realizada pelo Conselho Federal de Enfermagem, o percentual de enfermeiros que trabalha mais de $41 \mathrm{~h}$ semanais é superior no setor privado (28,5\%), quando comparado com o setor público (20,8\%). Na mesma linha, o percentual de enfermeiros com rendimento mensal acima dos 4.001,00 reais é de 43,5\% no setor público e de 19,9\% no setor privado (Cofen, 2017). Se considerarmos que cerca de um terço dos enfermeiros atuantes no setor público também possuem contrato em regime celetista (32\%), pode-se considerar que o maior risco de sofrimento moral parece ser mais decorrente das condições de trabalho, do que efetivamente do tipo de contrato de trabalho. A literatura sustenta a hipótese de que um maior risco de sofrimento moral possa ser determinado pelas condições de trabalho mais do que qualquer outra variável, quando não encontra diferenças significativas nos níveis de sofrimento moral entre enfermeiros de instituições públicas, privadas ou filantrópicas (Barlem, Lunardi, Lunardi, Dalmolin, \& Tomaschewski, 2012).

Em ambos os países, realizar horas extras e exercer a profissão em contexto hospitalar foi significativamente associado ao maior risco de sofrimento moral. Segundo a literatura, a associação entre o número de horas de trabalho, a realização de horas extras e o sofrimento moral está ancorada, principalmente, na alta carga de trabalho vivenciada por esses profissionais. Esse tipo de sobrecarga cria um desajuste no cuidado, impedindo o enfermeiro de prestar um cuidado com a qualidade considerada adequada, o que pode colocar em risco a segurança do paciente (Wolf, et al., 2016). A principal causa da sobrecarga de trabalho é a falta de pessoal, que pode ser observada em estudos realizados tanto no Brasil (Barlem, et al., 2013), quanto no exterior (Atabay, Cangarli, \& Penbek, 2015).

O contexto de trabalho hospitalar se mostrou significativamente associado a maiores médias de risco de sofrimento moral em vários aspectos da escala, como as questões organizacionais e de gestão, a carga de trabalho e a autonomia. O estudo de 
Eizenberg, Desivilya \& HIrschfeld (2009), realizado com enfermeiras israelenses, é um dos poucos que investigou, simultaneamente, diferentes contextos de trabalho, a saber, hospital, comunidade, homecare, hospital psiquiátrico e um serviço de cuidados de doenças crônicas. Seus resultados corroboram o achado de que os maiores níveis de sofrimento moral ocorrem no contexto hospitalar, pelo menos para preocupações relacionadas com a escassez de tempo e as relações de trabalho, quando comparado com o contexto dos cuidados de saúde primários.

Os resultados mostram que um enfermeiro que já passou pela experiência do sofrimento moral em outra altura da vida profissional, tem maior risco de o vivenciar novamente. Essa associação pode ser explicada pelo que Epstein \& Hamric (2009) chamam de 'crescendo effect'. Segundo os autores, existe uma relação entre a vivência de repetidas experiências de sofrimento moral e a intensidade do fenômeno. Tal efeito se daria pelos resíduos morais que permanecem com o profissional de saúde após cada ocorrência de sofrimento moral, acumulando-se.

Em relação à intenção de deixar a posição atual, existem muitos estudos que corroboram ao demonstrar a associação dessa variável com o sofrimento moral. Em estudo realizado no departamento de emergência, Trautman, Epstein, Rovnyak \& Snyder (2015) encontraram maiores escores de sofrimento moral naqueles enfermeiros que haviam considerado deixar ou que efetivamente haviam deixado uma posição de trabalho devido ao sofrimento moral e escores menores para aqueles que nunca consideraram deixar uma posição de trabalho por sofrimento moral. As variações dos escores foram significativas para ambos os grupos. Resultados semelhantes foram encontrados em estudo realizado na Nova Zelândia (Woods, Rodgers, Towers, \& Grow, 2015), em estudo realizado com enfermeiros de Unidades de Terapia Intensiva (Dodek, et al., 2016) e em enfermeiros de cuidados adultos e pediátricos (Dyo, Kalowes, \& Devries, 2016).

Esses resultados reiteram a importância de discutir o sofrimento moral nos locais de trabalho, principalmente devido à relação direta entre a escassez de enfermeiros e um nível de sofrimento moral mais elevado (Borhani, Abbaszadeh, Mohamadi, Ghasemi, \& Hoseinabad-Farahani, 2015). Neste contexto, também é importante pensar sobre os profissionais que permanecem em seus empregos, mesmo com o desejo de sair, por causa de fatores contextuais como as condições organizacionais, os processos legais e a escassez de outros empregos (Borhani, Abbaszadeh, Nakhaee, \& Roshanzadeh, 2014). O objetivo 
é fortalecer o trabalho conjunto de pesquisadores, gerentes e líderes de enfermagem para identificar e propor maneiras de lidar com o sofrimento moral, no intuito de melhorar não apenas a retenção, mas também a satisfação no trabalho em enfermagem (Trautmann, Epstein, Rovnyak, \& Snyder, 2015). 


\section{CONCLUSÕES}

A enfermagem é uma profissão muito sensível ao sofrimento moral, fato evidenciado tanto pelo crescente número de estudos publicados na literatura científica acerca do tema, como também pelos resultados dessa investigação. O intuito de construir e buscar evidências de validade de escalas é contribuir para o desenvolvimento da enfermagem enquanto profissão e para a melhoria da qualidade e da satisfação relacionadas ao trabalho, entre outros.

A revisão da literatura analisou uma ampla gama de estudo acerca do sofrimento moral, realizados com enfermeiros dos mais variados serviços de saúde. Os fatores de risco identificados são, por isso, representativos da heterogeneidade dos contextos de atuação e das diferentes formas de organização do trabalho.

A aplicação de diferentes etapas de validação, como a validação aparente, de conteúdo e de constructo, tem por objetivo garantir que a escala, que passa agora a estar disponível para ser utilizada por outros investigadores em outros contextos, tenha a maior evidência de validade possível, para que seus resultados sejam considerados fidedignos. Tanto a versão brasileira, quanto a versão portuguesa da Escala de Risco de Sofrimento Moral alcançaram evidências aceitáveis de validação.

A descrição das amostras de enfermeiros assistenciais de ambos os países revela características da força de trabalho dos enfermeiros, bem como as dificuldades que podem estar relacionadas com o maior risco para a vivência de sofrimento moral no dia a dia de trabalho da enfermagem.

Investigações nessa temática podem representar um auxílio substancial na identificação dos principais problemas que preocupam os enfermeiros, bem como promover a discussão sobre o sofrimento moral com o pessoal de enfermagem, prevenindo a aceitação ou a naturalização do sofrimento na rotina de trabalho. Quando o profissional se sente seguro para expressar suas angústias e levantar questões éticas, o sofrimento moral pode ser abordado de forma colaborativa. 


\section{REFERÊNCIAS}

AACN - American Association of Critical-Care Nurses. (2008). Retrieved from http://www.aacn.org/WD/practice/Docs/moral_distress.pdf

Alexandre, N. M., \& Coluci, M. Z. (2011). Validade de conteúdo nos processos de construção e adaptação de instrumentos de medidas. Ciência \& Saúde Coletiva, 16(7), 3061-3068.

Alves, P. C., Neves, V. F., Coleta, M. F., \& Oliveira, Á. F. (2012). Avaliação do bemestar no trabalho entre profissionais de enfermagem de um hospital universitário. Rev. Latino-Am. Enfermagem, 20(4), [08 telas]. doi:10.1590/S010411692012000400010

Arksey, H., \& O’Malley, L. (2005). Scoping studies: towards a methodological framework. International Journal of Social Research Methodology, 8(1), 19-32.

Armstrong, R., Hall, B. J., Doyle, J., \& Waters, E. (2011). 'Scoping the scope' of a cochrane review. Journal of Public Health, 33(1), 147-150.

doi:10.1093/pubmed/fdr015

Atabay, G., Cangarli, B. G., \& Penbek, S. (2015). Impact of ethical climate on moral distress revisited: Multidimensional view. Nursing Ethics, 22(1), 103-116. doi:10.1177/0969733014542674

Austin, W. (2016). Contemporary healthcare practice and the risk of moral distress. Healthcare Management Forum, 29(3), 131-133. doi: $10.1177 / 0840470416637835$

Austin, W., Lemermeyer, G., Goldberg, L., Bergum, V., \& Johnson, M. S. (2005). Moral Distress in Healthcare Practice: The Situation of Nurses. HEC Forum, 17(1), 33-48.

Barchifontaine, C. d. (2014). Formação cidadã do enfermeiro : estudo comparativo sobre a capacitação do enfermeiro para a cidadania, na formação graduada, em Portugal e no Brasil (cidade de São Paulo). Porto: Universidade Católica Portuguesa.

Barlem, E. L., \& Ramos, F. R. (2015). Constructing a theoretical model of moral distress. Nursing Ethics, 22(5), 608-6015. doi:10.1177/0969733014551595

Barlem, E. L., Lunardi, V. L., Lunardi, G. L., Dalmolin, G. d., \& Tomaschewski, J. G. (2012). Vivência do sofrimento moral na enfermagem: percepção da enfermeira. Rev Esc Enferm USP, 46(3), 681-688.

Barlem, E. L., Lunardi, V. L., Lunardi, G. L., Tomaschewski-Barlem, J. G., \& Silveira, R. S. (2013). Sofrimento moral no cotidiano da enfermagem: traços ocultos de poder e resistência. Rev. Latino-Am. Enfermagem, 21(1), [08 telas]. doi:10.1590/S0104-11692013000100002

Barlem, E. L., Lunardi, V. L., Lunardi, G. L., Tomaschewski-Barlem, J. G., Silveira, R. S., \& Dalmolin, G. d. (2013). Sofrimento moral em trabalhadores de enfermagem. Rev. Latino-Am. Enfermagem, 21(Spec), [09 telas]. 
Borhani, F., Abbaszadeh, A., Mohamadi, E., Ghasemi, E., \& Hoseinabad-Farahani, M. J. (2015). Moral sensitivity and moral distress in Iranian critical care nurses. Nursing Ethics, 1-9. doi:10.1177/0969733015604700

Borhani, F., Abbaszadeh, A., Nakhaee, N., \& Roshanzadeh, M. (2014). The relationship between moral distress, professional stress, and intent to stay in the nursing profession. Journal of Medical Ethics and History of Medicine, 7(4), 1-8.

Borhani, F., Mohammadi, S., \& Roshanzadeh, M. (2015). Moral distress and perception of futile care in intensive care nurses. J Med Ethics Hist Med, 8(2), [07 telas].

BRASIL. (1943). Decreto-Lei N. ${ }^{\circ} 5.452$, de $1^{\circ}$ de Maio de 1943. Brasília, Distrito Federal, Brasil.

BRASIL. (1990). Lei 8080/90. Lei Orgânica da Saúde. Brasília: Ministério da Saúde. Retrieved Fevereiro 16, 2011, from http://portal.saude.gov.br/portal/arquivos/pdf/lei8080.pdf

BRASIL. (1990). Lei 8142/90. Lei Orgânica da Saúde. Brasília: Ministério da Saúde. Retrieved Fevereiro 16, 2011, from http://portal.saude.gov.br/portal/arquivos/pdf/Lei8142.pdf

BRASIL. (1990). Lei no 8.112, de 11 de Dezembro de 1990. Brasília, Distrito Federal, Brasil.

Brasil. (2001). RESOLUÇÃO CNE/CES N 3, DE 7 DE NOVEMBRO DE 2001. Institui Diretrizes Curriculares Nacionais do Curso de Graduação em Enfermagem. Brasília: Conselho Nacional De Educação Câmara de Educação Superior. Retrieved Janeiro 16, 2017, from http://www.cofen.gov.br/wpcontent/uploads/2012/03/resolucao_CNE_CES_3_2001Diretrizes_Nacionais_C urso_Graduacao_Enfermagem.pdf

Cofen. (2017). Conselho Federal de Enfermagem. Retrieved from Quantitativo de Profissionais por Regional: http://www.cofen.gov.br/

CONASS. (2011). Sistema Único de Saúde (Vol. 1). Brasília: Ministério da Saúde.

Coombs, M. (2015). A scoping review of family experience and need during end of life care in intensive care. Nursing Open, 21(1), 24-35. doi:10.1002/nop2.14

Corley, M. (2002). Nurse moral distress: a proposed theory and research agenda. Nursing Ethics, 9(6), 636-650. doi:10.1191/0969733002ne557oa

Corley, M. C., Elswick, R. K., Gorman, M., \& Clor, T. (2001). Development and evaluation of a moral distress scale. Journal of Advanced Nursing, 33(2), 250256.

Corley, M. C., Minick, P., Elswick, R., \& Jacobs, M. (2005). Nurse Moral Distress and Ethical Work Environment. Nursing Ethics, 12(4), 381-390. doi:10.1191/0969733005ne809oa

Dalmolin, G. d., Lunardi, V. L., \& Filho, W. D. (2009). Moral distress of nursing workers in their professional exercise. UERJ Nursing Journal, 17, 35-40. 
Deady, R., \& McCarthy, J. (2010). A study of the situations, features, and coping mechanisms experienced by Irish psychiatric nurses experiencing moral distress. Perspectives in Psychiatric Care, 46(3), 209-220. doi:10.1111/j.17446163.2010.00260.x

DeVellis, R. F. (2016). Scale Development: theory and applications (4 ${ }^{\mathrm{a}} \mathrm{ed}$.). California: SAGE Publications.

Dodek, P. M., Wong, H., Norena, M., Ayas, N., Reynolds, S. C., Keenan, S. P., Alden, L. (2016). Moral distress in intensive care unit professionals is associated with profession, age, and years of experience. Journal of Critical Care, 31(1), 178182. doi:10.1016/j.jcrc.2015.10.011

Dyo, M., Kalowes, P., \& Devries, J. (2016). Moral distress and intention to leave: A comparison of adult and paediatric nurses by hospital setting. Intensive Crit Care Nurs , 36(1), 42-48. doi:10.1016/j.iccn.2016.04.003

Eizenberg, M. M., Desivilya, H. S., \& Hirschfeld, M. J. (2009). Moral distress questionnaire for clinical nurses: instrument development. Journal of Advanced Nursing, 65(4), 885-892. doi:10.1111/j.1365-2648.2008.04945.x

Epstein, E. G., \& Hamric, A. B. (2009). Moral Distress, Moral Residue, and the Crescendo Effect. J Clin Ethics, 20(4), 330-342.

Ermel, R. C. (2012). Qualidade de vida da pessoa idosa: comparação Brasil - Portugal. São Paulo: Escola de Enfermagem da USP.

Ferreira, M. A., Pereira, A. M., Martins, J. C., \& Barbieri-Figueiredo, M. d. (2016). Cuidados paliativos e enfermagem nas dissertações e teses em Portugal: um estudo bibliométrico. REEUSP, 50(2), 317-323. doi:10.1590/S0080623420160000200019

Ferrell, B. R. (2006). Understanding the Moral Distress of Nurses Witnessing Medically Futile Care. Oncology Nursing Forum, 33(5), 922-930.

Fry, S. T., Harvey, R. M., Hurley, A. C., \& Foley, B. J. (2002). Development of a model of moral distress in military nursing. Nursing Ethics, 9, 373-387. doi:10.1191/0969733002ne522oa

Galdeano, L. E., \& Rossi, L. A. (2006). Validação de conteúdo diagnóstico: critérios para seleção de expertos. Ciência, Cuidado e Saúde, 5(1), 60-66. doi:10.4025/cienccuidsaude.v5i1.5112

Ghislandi, C. M. (2012). Interface between mental health damages, working conditions and moral distress in nursing. Santa Catarina: Universidade Federal de Santa Catarina. Retrieved from https://repositorio.ufsc.br/xmlui/handle/123456789/132953

Giovanella, L., \& Mendonça, M. H. (2008). Atenção Primária à Saúde. In L. Giovanella, \& M. H. Mendonça, Políticas e Sistemas de Saúde no Brasil. Rio de Janeiro: Fiocruz. 
Gutierrez, K. M. (2005). Critical Care Nurses' Perceptions of and Responses to Moral Distress. Dimensions of Critical Care Nursing, 24(5), 229-241.

Hamric, A. B., Borchers, C. T., \& Epstein, E. G. (2012). Development and Testing of an Instrument to Measure Moral Distress in Healthcare Professionals. $A J O B$ Primary Research, 3(2), 1-9. doi:10.1080/21507716.2011.652337

Hanna, D. R. (2005). The Lived Experience of Moral Distress: Nurses Who Assisted With Elective Abortions. Research and Theory for Nursing Practice: An Intematiorvd Journal, 19(1), 95-124.

Harrowing, J. N., \& Mill, J. (2010). Moral distress among Ugandan nurses providing HIV care: a critical ethnography. International Journal of Nursing Studies, 47(6), 723-731. doi:10.1016/j.ijnurstu.2009.11.010

Hulley, S. B., Cummings, S. R., Browner, W. S., \& Grady, D. G. (2015). Delineando a Pesquisa Clínica (4 $4^{\mathrm{a}}$ ed.). Porto Alegre: Artmed.

IBGE. (2017). Instituto Brasileiro de Geografia e Estatística. Retrieved from http://www.ibge.gov.br/estadosat/perfil.php?sigla=rs

Jameton, A. (1984). Nursing practice: the ethical issues. Englewood Cliffs: PrenticeHall.

Jameton, A. (1993). Dilemmas of moral distress: moral responsibility and nursing practice. AWHONNS Clin Issues Perinat Womens Health Nurs, 4(4), 542-551.

Jameton, A. (2013). A Reflection on Moral Distress in Nursing Together With a Current Application of the Concept. Bioethical Inquiry, 10(1), 297-308. doi:10.1007/s11673-013-9466-3

Janvier, A., Nadeau, S., Deschênes, M., Couture, E., \& Barrington, K. (2007). Moral distress in the neonatal intensive care unit: Caregiver's experience. Journal of Perinatal Nursing, 27, 203-208. doi:10.1038/sj.jp.7211658

Johnstone, M. J., \& Hutchinson, A. (2015). 'Moral distress' - time to abandon a flawed nursing construct? Nursing Ethics, 22(1), 5-14. doi:10.1177/0969733013505312

Kälvemark, S., Höglund, A. T., Hansson, M. G., Westerholm, P., \& Arnetz, B. (2004). Living with conflicts-ethical dilemmas and moral distress in the health care system. Social Science \& Medicine, 58, 1075-1084. doi:10.1016/S02779536(03)00279-X

Kelly, B. (1998). Preserving moral integrity: A follow-up study with new graduated nurses. Journal of Advanced Nursing, 28(5), 1134-1145. doi:10.1046/j.13652648.1998.00810.x

Knight, R., Shoveller, J., Greyson, D., Kerr, T., Gilbert, M., \& Shannon, K. (2014). Advancing population and public health ethics regarding HIV testing: A scoping review. Critical Public Health, 24(3), 283-295.

doi:10.1080/09581596.2013.800188 
Laabs, C. A. (2005). Moral Problems and Distress among Nurse Practitioners in Primary Care. Journal of the American Academy of Nurse Practitioners, 17, 7684. doi:10.111/j.1041-2972.2005.0014.x

LaTaille, Y. d. (2006). Moral e Ética: dimensões intelectuais e afetivas. Porto Alegre: Artmed.

Lawrence, L. A. (2011). Work Engagement, Moral Distress, Education Level, and Critical Reflective Practice in Intensive Care Nurses. Nursing Forum, 46(4), 256-268.

Levac, D., Colquhoun, H., \& O'Brien, K. K. (2010). Scoping studies: advancing the methodology. Implementation Science, 5(69), 1-9.

Lunardi, V. L., Barlem, E. L., Bulhosa, M. S., Santos, S. S., Filho, W. D., Silveira, R. S., Dalmolin, G. d. (2009). Moral distress and the ethical dimension in nursing work. Brazilian Journal of Nursing, 62, 599-603. doi:10.1590/S003471672009000400018

Lusignani, M., Gianni, M. L., Re, L. G., \& Buffon, M. L. (2016). Moral distress among nurses in medical, surgical and intensive-care units. Journal of Nursing Management, 1-9. doi:10.1111/jonm.12431

Lützén, K., \& Kvist, B. E. (2012). Moral Distress: A Comparative Analysis of Theoretical Understandings and Inter-Related Concepts. HEC Forum, 1, 13-25. doi:10.1007/s10730-012-9178-9

Maluwa, V. M., Andre, J., Ndebele, P., \& Chilemba, E. (2012). Moral distress in nursing practice in Malawi. Nursing Ethics, 19(2), 196-207. doi:10.1177/0969733011414968

McAndrew, N. S., Leske, J., \& Schroeter, K. (2016). Moral distress in critical care nursing: The state of the science. Nursing Ethics, 1-19. doi:10.1177/0969733016664975

McCarthy, J., \& Gastmans, C. (2015). Moral distress: a review of the argument-based nursing ethics literature. Nursing Ethics, 22(1), 131-152. doi:10.1177/0969733014557139

McClendon, H., \& Buckner, E. B. (2007). Distressing Situations in the Intensive Care Unit: A Descriptive Study of Nurses' Responses. Dimensions of Critical Care Nursing, 26(5), 199-206. doi:10.1097/01.DCC.0000286824.11861.74

Medeiros, R. K., Júnior, M. A., Pinto, D. P., Vitor, A. F., Santos, V. E., \& Barichello, E. (2015). Modelo de validação de conteúdo de Pasquali nas pesquisas em Enfermagem. Revista de Enfermagem Referência, IV(4), 127-135. doi:10.12707/RIV14009

Meltzer, L. S., \& Huckabay, L. M. (2004). Critical care nurses' perceptions of futile care and its effect on burnout. American Journal of Critical Care, 13, 202-208.

Mobley, M. J., Rady, M. Y., Verheijde, J. L., Patel, B., \& Larson, J. S. (2007). The relationship between moral distress and perception of futile care in the critical 
care unit. Intensive and Critical Care Nursing, 23, 256-263.

doi:10.1016/j.iccn.2007.03.011

Monteiro, B. A., \& Oguisso, T. (2007). Aspectos do desenvolvimento da enfermagem no Brasil e em Portugal. Anais (p. s.n.). São Paulo: Simpósio Ibero-americano de História da Enfermagem.

Morris, P. E., \& Dracup, K. (2008). Time for a Tool to Measure Moral Distress? American Journal of Critical Care, 17, 398-401.

Musto, L. C., Rodney, P. A., \& Vanderheide, R. (2015). Toward interventions to address moral distress: Navigating structure and agency. Nursing Ethics, 22(1), 91-102. doi:10.1177/0969733014534879

Musto, L., \& Schreiber, R. S. (2012). Doing the Best I Can Do: Moral Distress in Adolescent Mental Health Nursing. Issues in Mental Health Nursing, 33(1), 137-144. doi:10.3109/01612840.2011.641069

Nora, C. R., Zoboli, E. L., \& Vieira, M. (2015). Problemas éticos vivenciados por enfermeiros na atenção primária à saúde: revisão integrativa da literatura. Revista Gaúcha de Enfermagem, 36(1), 112-121.

Nunes, L. (2006). Justiça, Poder e Responsabilidade: Articulação e Mediações nos Cuidados de Enfermagem. Loures: Lusociência.

Oberle, K., \& Hughes, D. (2008). Doctors' and nurses' perceptions of ethical problems in end-of-life decisions. Journal of Advanced Nursing, 33, 707-715. doi:10.1046/j.1365-2648.2001.01710.x

Oguisso, T. (2001). História da legislação do exercício da enfermagem no Brasil. Revista Brasileira de Enfermagem, 53(4), 197-207.

Ohnishi, K., Ohgushi, Y., Nakano, M., Fujii, H., Tanaka, H., Kitaoka, K., Narita, Y. (2010). Moral distress experienced by psychiatric nurses in Japan. Nursing Ethics, 17, 726-740. doi:10.1177/0969733010379178

Olson, L. (1995). Ethical climate in health care organizations. International Nursing Review, 42(1), 85-90.

OPSS. (2016). Saúde: procuram-se novos caminhos. Relatório de Primavera 2016. Lisboa: Observatório Português dos Sistemas de Saúde.

Ordem dos Enfermeiros. (2004). As condições de trabalho dos enfermeiros portugueses. Lisboa: Ordem dos Enfermeiros.

Ordem dos Enfermeiros. (2017). Retrieved from http://www.ordemenfermeiros.pt/membros/Documents/2015_DadosEstatisticos 00_Nacionais_vf.pdf

Paim, J., Travassos, C., Almeida, C., Bahia, L., \& Macinko, J. (2011). O sistema de saúde brasileiro: história, avanços e desafios. The Lancet, 11-31. doi:10.1016/S0140-6736(11)60054-8 
Papathanassoglou, E. D., Karanikola, M. N., Kalafati, M., Giannakopoulou, M., Lemonidou, C., \& Albarran, J. W. (2012). Professional autonomy, collaboration with physicians, and moral distress among European intensive care nurses. American Journal of Critical Care, 21, e41-e52. doi:10.4037/ajcc2012205

Pasquali, L. (2009). Psicometria. Rev Esc Enferm USP, 43(Esp), 992-999.

Pauly, B., Varcoe, C., Storch, J., \& Newton, L. (2009). Registered nurses' perceptions of moral distress and ethical climate. Nursing Ethics, 16, 561-573. doi:10.1177/0969733009106649

Pavlish, C., Brown-Saltzman, K., Hersh, M., Shirk, M., \& Rounkle, A.-M. (2011). Nursing priorities, actions, and regrets for ethical situations in clinical practice. Journal of Nursing Scholarship, 43, 385-395. doi:10.1111/j.15475069.2011.01422.x

Pestana, M. H., \& Gageiro, J. N. (2014). Análise de dados para Ciências Sociais: a complementaridade do SPSS (6 ${ }^{\mathrm{a}} \mathrm{ed}$.). Lisboa: Sílabo.

Peter, E., \& Liaschenko, J. (2004). Perils of proximity: A spatiotemporal analysis of moral distress and moral ambiguity. Nursing Inquiry, 11, 218-225. doi:10.1111/j.1440-1800.2004.00236.x

Piers, R. D., Eynde, M. V., Steeman, E., Vlerick, P., Benoit, D. D., \& Noortgate, N. J. (2012). End-of-Life Care of the Geriatric Patient and Nurses' Moral Distress. $J$ Am Med Dir Assoc, 13(1), 80.e7-13. doi:10.1016/j.jamda.2010.12.014

Polit, D. F., \& Beck, C. T. (2011). Fundamentos de Pesquisa em Enfermagem: avaliação de evidência para a prática da enfermagem ( $7^{\mathrm{a}}$ ed.). Porto Alegre: Artmed.

Rathert, C., May, D. R., \& Chung, H. S. (2016). Nurse moral distress: A survey identifying predictors and potential interventions. International Journal of Nursing Studies, 53(1), 39-49. doi:10.1016/j.ijnurstu.2015.10.007

Renaud, I., \& Renaud, M. (1996). Fundamentos éticos. Em L. Archer, J. Biscaia, \& W. Osswald, Bioética (pp. 34-58). Lisboa: Editorial Verbo.

Rice, E. M., Rady, M. Y., Hamrick, A., Verheijde, J. L., \& Pendergast, D. K. (2008). Determinants of moral distress in medical and surgical nurses at an adult acute tertiary care hospital. Journal of Nursing Management, 16, 360-373. doi:10.1111/j.1365-2834.2007.00798.x

Sartoreto, I. S. (2013). Satisfação e Insatisfação no trabalho dos enfermeiros: revisão integrativa da literatura. São Paulo: Escola de Enfermagem da Universidade de São Paulo.

Schaefer, R., \& Vieira, M. (2015). Competência ética como recurso de enfrentamento do sofrimento moral em enfermagem. Texto \& Contexto Enfermagem, 24(2), 563-573. doi:10.1590/0104-07072015001032014 
Schaefer, R., Zoboli, E. L., \& Vieira, M. M. (2016). Identification of risk factors for moral distress in nurses: basis. Nursing Inquiry, 23(4), 346-357.

doi:10.1111/nin. 12156

Schaefer, R., Zoboli, E. L., \& Vieira, M. M. (2017). Psychometric evaluation of the Moral Distress Risk Scale: A methodological study. Nursing Ethics, [Epub ahead of print]. doi:10.1177/0969733017707347

Silva, C. R., \& Costa, M. A. (2010). Concepções de saúde na educação em enfermagem em escolas de graduação do Brasil e Portugal. Rev. Latino-Am. Enfermagem, 18(6), [08 telas]. doi:10.1590/S0104-11692010000600011

Spenceley, S., Witcher, C. S., Hagen, B., Hall, B., \& Kardolus-Wilson, A. (2015). Sources of moral distress for nursing staff providing care to residents with dementia. Dementia, 1-20. doi:10.1177/1471301215618108

Sporrong, S. K., Höglund, A. T., \& Arnetz, B. (2006). Measuring moral distress in pharmacy and clinical practice. Nursing Ethics, 13, 416-427.

doi:10.1191/0969733006ne880oa

Trautmann, J., Epstein, E., Rovnyak, V., \& Snyder, A. (2015). Relationships Among Moral Distress, Level of Practice Independence, and Intent to Leave of Nurse Practitioners in Emergency Departments: Results From a National Survey. Advanced Emergency Nursing Journal, 37(2), 134-145. doi:10.1097/TME.0000000000000060

Varcoe, C., Pauly, B., Webster, G., \& Storch, J. (2012). Moral Distress: Tensions as Springboards for Action. HEC Forum, 24(1), 51-62. doi:10.1007/s10730-0129180-2

Veer, A. J., Francke, A. L., Struijs, A., \& Willemsv, D. L. (2013). Determinants of moral distress in daily nursing practice: A cross sectional correlational questionnaire survey. International Journal of Nursing Studies, 50(1), 100-108. doi:10.1016/j.ijnurstu.2012.08.017

Vieira, M. (2009). Ser Enfermeiro: da Compaixão à Proficiência (2ºd.). Lisboa: Universidade Catolica Editora.

Villers, M. J., \& DeVon, H. A. (2013). Moral distress and avoidance behavior in nurses working in critical care and noncritical care units. Nursing Ethics, 20(5), 589603. doi:10.1177/0969733012452882

Vosner, H. B., Zeleznik, D., Kokol, P., Vosner, J., \& Zavrsnik, J. (2016). Trends in nursing ethics research: Mapping the literature production. Nursing Ethics, 1-16. doi:10.1177/0969733016654314

Wall, S., Austin, W. J., \& Garros, D. (2016). Organizational Influences on Health Professionals' Experiences of Moral Distress in PICUs. HEC Forum, 28(1), 5367. doi:10.1007/s10730-015-9266-8

Weber, E. (2016). Moral distress, workplace health and intrinsic harm. Bioethics, 30(4), 244-250. doi:10.1111/bioe.12181 
WHO. (2004). Highlights on health in Portugal. Copenhagen: World Health Organization.

Wilkinson, J. M. (1987). Moral distress in nursing practice: experience and effect. Nurs Forum, 23(1), 16-29.

Wilson, M. A., Goettemoeller, D. M., Bevan, N. A., \& McCord, J. M. (2013). Moral distress: levels, coping and preferred interventions in critical care and transitional care nurses. Journal of Clinical Nursing, 22(1), 1455-1466. doi:10.1111/jocn.12128

Winters, R., \& Neville, S. (2012). Registered nurse perspectives on delayed or missed nursing cares in a new zealand hospital. Nursing Praxis in New Zealand, 28, 1928.

Wisniewski, D., Silva, E. S., Évora, Y. D., \& Matsuda, L. M. (2015). Satisfação profissional da equipe de enfermagem x condições e relações de trabalho: estudo relacional. Texto Contexto Enferm, 24(3), 850-858. doi:10.1590/0104070720150000110014

Wocial, L. D., \& Weaver, M. T. (2013). Development and psychometric testing of a new tool for detecting moral distress: the Moral Distress Thermometer. Journal of Advanced Nursing, 69(1), 167-174. doi:10.1111/j.1365-2648.2012.06036.x

Wolf, L. A., Perhats, C., Delao, A. M., Moon, M. D., Clark, P. R., \& Zavotsky, K. E. (2016). "It's a Burden You Carry": Describing Moral Distress in Emergency Nursing. Journal of Emergency Nursing, 42(1), 37-46. doi:10.1016/j.jen.2015.08.008

Woods, M., Rodgers, V., Towers, A., \& Grow, S. L. (2015). Researching moral distress among New Zealand nurses: A national survey. Nursing Ethics, 22(1), 117-130. doi:10.1177/0969733014542679

Xiaoyan, W., Yufang, Z., Lifeng, C., \& Congcong, S. (2016). Moral distress and its influencing factors: A crosssectional study in China. Nursing Ethics, 1-11. doi:10.1177/0969733016658792

Zuzelo, P. R. (2007). Exploring the Moral Distress of Registered Nurses. Nursing Ethics, 14(3), 344-359. 
APÊNDICES 


\section{APÊNDICE A - CARTA CONVITE PARA PERITOS}

Prezado(a),

Esta pesquisa insere-se no curso de Doutoramento/Doutorado em Enfermagem da Universidade Católica Portuguesa - Porto e da Escola de Enfermagem da Universidade de São Paulo, sob orientação e co-orientação das professoras Margarida Vieira e Elma Zoboli, tendo por finalidade identificar fatores de risco para sofrimento moral em enfermeiros trabalhadores de instituições de saúde em Portugal e no Brasil. Peço a sua colaboração no processo de obtenção de consenso e validação dos itens identificados na literatura como possíveis fatores de risco para sofrimento moral.

Caso tenha interesse, basta clicar no link apresentado ao final do e-mail, o qual irá direcioná-lo para o questionário.

Pedimos a gentileza que, se possível, envie sua resposta no prazo de 15 dias a partir do recebimento deste convite.

Este é um convite para preencher o formulário SOFRIMENTO MORAL EM ENFERMAGEM. Para preenchê-lo. visite:

https://docs.google.com/forms/d/1wNX8PRROW95s96oCxKNJznja4_mcLRvAuYzQo $\underline{0 \mathrm{cCcGA} / \text { viewform? } \mathrm{usp}=\text { send form }}$

Agradecemos a vossa valiosa colaboração. 


\section{APÊNDICE B - TERMO DE CONSENTIMENTO LIVRE E ESCLARECIDO (BRASIL)}

Você está sendo convidado a participar da pesquisa 'Sensibilidade Moral e Sofrimento Moral dos enfermeiros brasileiros', cujo objetivo é verificar a correlação entre a sensibilidade moral e o sofrimento moral dos enfermeiros a ser realizado nas diversas instituições de saúde do Rio Grande do Sul. Esta pesquisa justifica-se pela necessidade dos enfermeiros trabalhadores de instituições de saúde desenvolverem a sensibilidade moral para reconhecer, interpretar e responder de forma apropriada aos problemas éticos, evitando o sofrimento moral e melhorando a qualidade do atendimento.

Para a coleta de dados será utilizado um questionário, que levará cerca de 20 minutos para ser respondido, de forma online. As respostas serão armazenas por um software em um banco de dados estatístico. Os dados ficarão sob a responsabilidade da pesquisadora principal por um período de 5 anos e após serão destruídos.

Tal pesquisa não envolve riscos previsíveis de acordo com a Res. 466/12, inciso $\mathrm{V}$, mas pode recordar sentimento e experiências relacionados com problemas éticos ou sofrimento moral e gerar algum grau de angústia. Os participantes não receberão qualquer remuneração pela participação, assim como poderão retirar seu consentimento em qualquer momento do estudo, cessando sua participação. Neste caso, qualquer informação dos mesmos não será utilizada, sem prejuízo para a pesquisa ou para os desistentes. Esta pesquisa trará contribuições relacionadas com a satisfação e a qualidade do trabalho em enfermagem. Os resultados deste estudo serão utilizados exclusivamente para fins acadêmicos, sendo garantido o sigilo da identidade dos participantes.

Caso você tenha dúvidas ou necessite algum esclarecimento, entrar em contato com o pesquisador responsável Rafaela Schaefer, pelo telefone (51) 35893564, e-mail rafaelaschaefer1988@gmail.com, como também com o Comitê de Ética na Pesquisa da Escola de Enfermagem da Universidade de São Paulo, pelo telefone (11) 3061-7548.

$\square$ Sim, aceito participar da pesquisa.

$\square$ Não, não aceito participar da pesquisa.

\section{Este TCLE respeita a Resolução 466/12 do Conselho Nacional de Saúde.}

Comitê de Ética na Pesquisa da Escola de Enfermagem da Universidade de São Paulo. Av. Dr. Enéas de Carvalho Aguiar. CEP 419 - 05403-000. São Paulo. SP.

Fone: (11) 3061-7548 E-mail: edipesq@usp.br 
APÊNDICE C - TERMO DE CONSENTIMENTO LIVRE E ESCLARECIDO (PORTUGAL) 


\section{Anexo I}

Colaboração em Projeto de pesquisa Brasil e Portuga

1. Carlise Dalla Nora <carliserdn@gmail.com>

$13 / 01 / 2015$

para gabinete, Cco:mim -

Prezado Presidente do Coren/RS

Escrevo para pedir a colaboração do Coren/RS em um projeto de pesquisa realizado no âmbito do doutorado em enfermagem na Universidade Católica Portuguesa na Cidade do Porto, Portugal (período de 2014 a 2017). A pesquisa é desenvolvida sob a modalidade Bolsa de Doutorado Pleno no Exterior, concedida pela Coordenação de Aperfeiçoamento de Pessoal de Nivel Superior - CAPES.

A pesquisa tem como objetivo avaliar a sensibilidade moral dos enfermeiros e caracterizar os fatores que influenciam o nivel de sensibilidade moral dos enfermeiros em Portugal e no Brasil.

Sabendo que o Coren/RS não disponibiliza os e-mails cadastrados, gostaria que o conselho colaborasse com a pesquisa Luso-brasileira, enviando um e-mail convidando todos os enfermeiros cadastrados responder de forma online o questionário. $\mathrm{O}$ e-mail poderia enviado através do e-mail de notícias (imprensa@portalcoren-rs.gov.br).

Caso o Coren/RS tenha interesse em estabelecer essa parceria enviarei o projeto de pesquisa completo, ressalto que o Coren/RS será citado em todas as publicações que decorrerem desse projeto.

Atenciosamente

Carlise Rigon Dalla Nora

Doutoranda em enfermagem Universidade Católica Portuguesa

Mestre em Saúde Coletiva na Unisinos

Especialista em Saúde da Família

Enfermeira

Currículo Lattes: http://buscatextual.cnpq.br/buscatextual/visualizacv.do?id=K4481644J1

Contato: (351) 916884441

Prezada Carlise

Para podermos avaliar sua solicitação, necessitamos de um resumo do projeto, cópia daaprovação na Comissão de Ética e um link para o questionário.

Att

Denise Campão

Coordenadora da Assessoria de Comunicação | Coren - RS

Telefone: 51 3378-5553

De: gabinete@portalcoren-rs.gov.br

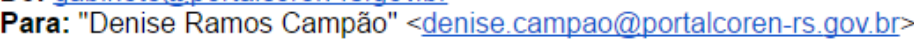

Enviadas: Terça-feira, 31 de marco de 2015 13:45:37

Assunto: Fwd: Colaboração em Projeto de pesquisa Brasil e Portugal 


\section{Anexo II}

Bom dia, Carlise.

Tudo bem?

Aqui quem escreve é a Joanna Ferraz, jornalista, colega da Denise Campão, com quem você estava em contato.

Está tudo OK para a divulgação.

Ficamos no aguardo do link com o questionário da pesquisa para os(as) enfermeiros(as) responderem.

Atenciosamente,

COren ${ }^{\circledR S}$ Assessoria de Comunicação

(51) 3378.5500 | (51) 3378.5553

http://www.portalcoren-rs.gov.br 


\section{Anexo III}

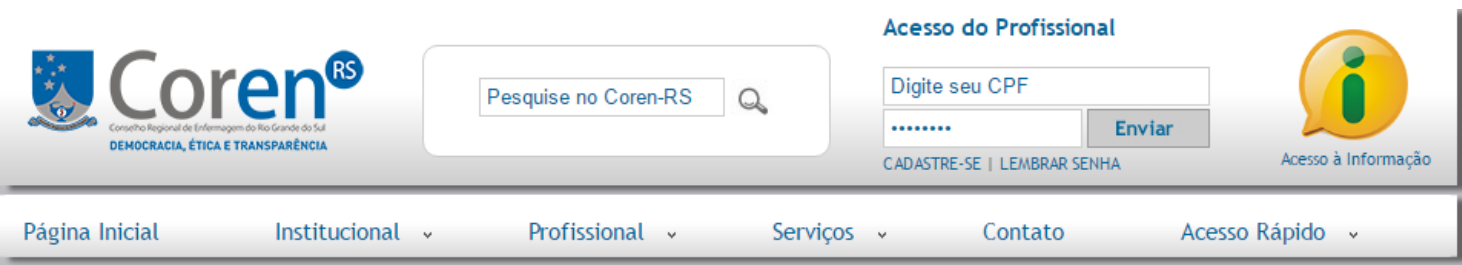

Página inicial $\gg>$ SERVIÇOS $\gg>$ Notícias

versão para impressão

$11 / 03 / 2016$

Pesquisa avalia situações da prática de enfermeiros(as) no RS

A Escola de Enfermagem da Universidade de São Paulo (EEUSP) e a Universidade Católica Portuguesa (UCP) realizam uma pesquisa que visa avaliar as situações da prática dos(as) enfermeiros(as) trabalhadores(as) de instituições de saúde do Rio Grande do Sul.

Podem participar enfermeiros(as) do Rio Grande do Sul que atuam em qualquer campo assistencial ou serviço da rede de saúde, respondendo o

instrumento eletrônico e divulgando em suas redes sociais e profissionais a pesquisa.

O questionário está disponível no link abaixo:

https://docs.google.com/forms/d/1nv96cxgiaRukz6bmlF7huGqlqHvY92sfe2Q8GWbsjjc/viewform?c=0\&w=1\&usp=mail_form_link

Compartilhe esta notícia com outras pessoas: 
Anexo IV 


\section{Pesquisa sobre situações da prática de trabalho das(os) enfermeiras(os)}

Obrigada por ter acessado o link do nosso instrumento.

Esse estudo tem como objetivo avaliar situações da prática das(os) enfermeiras(os)

trabalhadoras(es) de instituições de saúde do Rio Grande do Sul. Nosso propósito é dar voz para

as(os) enfermeiras(os) expressarem o que sentem nas vivências do trabalho. Com esta preocupação, construímos o instrumento que convidamos você a responder.

As questốes são fechadas e, por isso, apesar do número de itens, não é difícil ou demorado

respondê-lo. É importante que você responda as questões na ordem, sem pular nenhuma, pois

isso pode prejudicar os resultados.

Você terá maiores detalhes no Termo de Consentimento Livre e Esclarecido que é apresentado a seguir.

Agradecemos o apoio. Sua experiência vai ajudar a compreender aspectos importantes acerca do trabalho das(os) enfermeiras(os) em diferentes contextos e cenários assistenciais.

*Obrigatório

\section{Universidades relacionadas com a pesquisa}

Instituto de Ciências da Saúde da Universidade Católica Portuguesa, Porto (UCP).

Escola de Enfermagem da Universidade de São Paulo (EEUSP).

\section{TERMO DE CONSENTIMENTO LIVRE E ESCLARECIDO}

Você pode imprimir uma via do TCLE: basta clicar sobre o texto com o botão direito do mouse e enviar para impressão.

Leia com Atenção:

Você está sendo convidada(o) a participar do projeto de pesquisa de Carlise Rigon Dalla Nora e Rafaela Schaefer, enfermeiras, alunas do doutorado em enfermagem pela Universidade Católica Portuguesa - Porto (UCP) e pela Escola de Enfermagem da Universidade de São Paulo (EEUSP), sob orientação e co-orientação das enfermeiras professoras Margarida Vieira e Elma Zoboli, que propõem a pesquisa: "Sensibilidade Moral e Sofrimento Moral dos Enfermeiros Brasileiros". O objetivo geral é analisar a sensibilidade moral e o sofrimento moral nos enfermeiros trabalhadores de instituições de saúde no Rio Grande do Sul.

Trata-se de uma pesquisa de natureza quantitativa, sendo um estudo transversal, observacional e correlacional descritivo. A pesquisa trará benefícios indiretos aos profissionais de enfermagem, uma vez que seus resultados poderão ser utilizados para evitar as consequências da vivência do sofrimento moral e disponibilizar à comunidade científica, aos gestores e aos profissionais instrumentos de avaliação válidos para identificação das questões éticas dos serviços com vistas à proposta de intervenções que promovam a sensibilidade moral dos profissionais. Trata-se de pesquisa aprovada pelo Comitê de Ética em Pesquisa da EEUSP (Parecer n²1.180.518) e conta com o apoio/financiamento da Coordenação de Aperfeiçoamento de Pessoal de Nível Superior (CAPES).

Você está sendo convidado a participar do estudo através do preenchimento de um questionário abordando a caracterização dos enfermeiros, seu contexto de trabalho, a sensibilidade moral e o sofrimento moral, com duração aproximada de 15 minutos.

Sinta-se totalmente livre em participar e só depois de entender bem o estudo, decida a sua participação. Você pode decidir retirar-se do estudo a qualquer momento e ter esclarecimentos sempre que julgar necessário. Em caso de dúvida ou para conhecimento posterior dos resultados, pode entrar em contato com as pesquisadoras responsáveis, Rafaela Schaefer, telefone (51) 92070484, email: rafaelaschaefer1988@gmail.com ou Carlise Rigon Dalla Nora, telefone (55) 99627551, email: carliserdn@gmail.com 
Com que frequência vivencia as seguintes situações em seu dia a dia de trabalho:

Falta de liderança eficaz no serviço *

Nunca

Raramente

Frequentemente

Sempre

Falta de diálogo / comunicação entre profissionais *

Nunca

Raramente

Frequentemente

Sempre

Realização pessoal reduzida *

Nunca

Raramente

Frequentemente

Sempre

Desorganização do sistema de saúde *

Nunca

Raramente

Frequentemente

Sempre

Medo de atuar profissionalmente *

Nunca

Raramente

Frequentemente

Sempre

Desvalorização profissional *

Nunca

Raramente

Frequentemente

Sempre

Falta de enfermeiros *

Nunca

Raramente

Frequentemente

Sempre 
Mercantilização dos cuidados de saúde que aumenta a carga de trabalho *

Nunca

Raramente

Frequentemente

Sempre

Falta de competência pessoal *

Nunca

Raramente

Frequentemente

Sempre

Ser obrigado a prestar cuidado inadequado ou desnecessário *

Nunca

Raramente

Frequentemente

Sempre

Obstáculos linguísticos e culturais *

Nunca

Raramente

Frequentemente

Sempre

Falta de discussão sobre questões éticas no serviço *

Nunca

Raramente

Frequentemente

Sempre

Expectativas de outros em relação à atuação do enfermeiro *

Nunca

Raramente

Frequentemente

Sempre

Inexistência de comissões de ética *

Nunca

Raramente

Frequentemente

Sempre

Falta de tempo por excesso de trabalho *
Nunca
Raramente
Frequentemente
Sempre 
Falta de financiamento, recursos, equipamentos *

Nunca

Raramente

Frequentemente

Sempre

Falta de consideração pelos seus conhecimentos *

Nunca

Raramente

Frequentemente

Sempre

Despreparo para lidar com a morte *

Nunca

Raramente

Frequentemente

Sempre

Desrespeito à vontade do paciente *

Nunca

Raramente

Frequentemente

Sempre

Falsas esperanças para pacientes e familiares *

Nunca

Raramente

Frequentemente

Sempre

Estresse *

Nunca

Raramente

Frequentemente

Sempre

Problemas na estrutura física da instituição *

Nunca

Raramente

Frequentemente

Sempre

Medo de perder o emprego *

Nunca

Rarament

Frequentemente

Sempre 
Presenciar comportamento inadequado de familiares *

Nunca

Raramente

Frequentemente

Sempre

Falta de competência de outros profissionais *

Nunca

Raramente

Frequentemente

Sempre

Uso abusivo da alta tecnologia no prolongamento da vida *

Nunca

Raramente

Frequentemente

Sempre

Impossibilidade de crescimento profissional *

Nunca

Raramente

Frequentemente

Sempre

Esgotamento físico / mental / emocional *
Nunca
Raramente
Frequentemente
Sempre

Normas institucionais que dificultam o cuidado *
Nunca
Raramente
Frequentemente
Sempre

Uso inadequado dos recursos disponíveis *

Nunca

Raramente

Frequentemente

Sempre

Medo de não ser aceito pela equipe *
Nunca
Raramente
Frequentemente
Sempre 
Medo de notificar erros que você cometeu *

Nunca

Raramente

Frequentemente

Sempre

Ser questionado sobre informações que são sigilosas *

Nunca

Raramente

Frequentemente

Sempre

Sentir-se impotente para mudar o contexto *
Nunca
Raramente
Frequentemente
Sempre

Estrutura hierárquica que determina a impotência e a subordinação do enfermeiro ao médico *
Nunca
Raramente
Frequentemente
Sempre

Número excessivo de pacientes atribuídos a cada enfermeiro *
Nunca
Raramente
Frequentemente
Sempre

Observar cuidado inadequado ou desnecessário feito por outros profissionais *
Nunca
Raramente
Frequentemente
Sempre
Conflitos entre paciente, família, profissionais *
Nunca
Raramente
Frequentemente
Sempre

Questões de gênero pelo estereótipo de poder que associa o masculino à medicina e o feminino à enfermagem *
Nunca
Raramente
Frequentemente
Sempre 
Ser forçado a não contar a verdade ao paciente *

Nunca

Raramente

Frequentemente

Sempre

Não ser incluído na tomada de decisões *
Nunca
Raramente
Frequentemente
Sempre

Demora no atendimento *

Nunca

Raramente

Frequentemente

Sempre

Paciente sem condições de pagar pelo tratamento *

Nunca

Raramente

Frequentemente

Sempre

Falta de apoio da instituição *
Nunca
Raramente
Frequentemente
Sempre

Impotência para contestar decisões de outros profissionais *

Nunca

Raramente

Frequentemente

Sempre

Insatisfação com o trabalho *

Nunca

Raramente

Frequentemente

Sempre

Ser forçado a transgredir as regras *

Nunca

Raramente

Frequentemente

Sempre 
Ser forçado a quebrar confidencialidade e sigilo *

Nunca

Raramente

Frequentemente

Sempre

Medo de não terminar o trabalho a tempo *

Nunca

Raramente

Frequentemente

Sempre

Pouca autonomia no trabalho *

Nunca

Raramente

Frequentemente

Sempre

Ter que decidir pelo paciente *

Nunca

Raramente

Frequentemente

Sempre

Conflitos religiosos / espirituais *

Nunca

Raramente

Frequentemente

Sempre

VOLTAR PRÓXIMA 


\section{Anexo V}

\section{EE TSP}

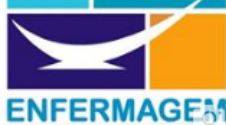

Pesquisa sobre

situações da prática

de trabalho dos

enfermeiros do RS

Criar@nome de usuário

da Página

Página inicial
CATOLICA

INSTITUTO DE CIÊNCIAS DA SAÚDE

LISBOA.PORTO $\cdot V I S E L$

\section{트 TISP}

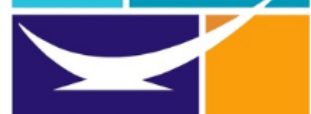

ENFERMAGEM 


\section{Anexo VI}

Pesquisa sobre situações da prática de trabalho / COREN RS

Entrada $x$

可豆回

- Aline Pierotto<APIEROTTO@unisinos.br>

03/06/2016

a para enfpaulo, fabricio.ev, emarchiori, doroveda, maroso17, adribandeira, valquiria43739., orivalbonico, a.p.w, alemarqu :

Prezad@s Colegas, boa tarde !

Estamos enviando, em anexo, o email encaminhado pela ex-aluna Rafaela Schaefer, solicitando um apoio especial para responder e também divulgar para os colegas enfermeiros o instrumento de coleta da sua pesquisa do doutorado.

Reforçamos o pedido da Enfermeira Rafaela "Por favor, podem responder para qualificar a pesquisa. Estou com dificuldade para fechar a amostra necessária."

o prazo de coleta finda no final do mês de junho.

Colegas que tiverem contatos com alunos do curso da Pós graduação, por favor repassem.

Muito obrigado especial pela colaboração.

Coordenação de Enfermagem 


\section{Anexo VII}

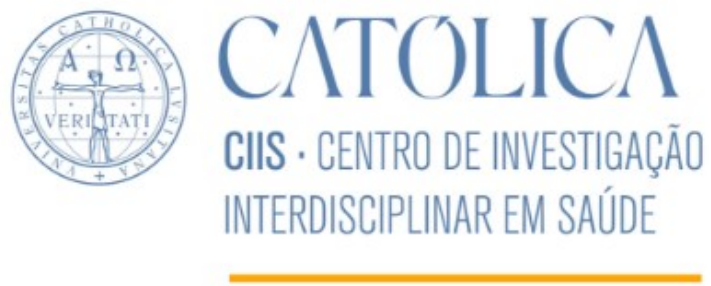

LISBOA · PORTO · VISEU

\section{APRESENTAÇÃO}

Solicitamos que se já respondeu a este questionário não o faça novamente.

\section{Aceito os termos}

Não aceito os termos

Q6.5. Com que frequência vivencia as seguintes situações no seu dia a dia de trabalho?

nunca

raramente

frequentemente

sempre

Falta de liderança

eficaz no serviço

Falta de diálogo /

comunicação entre

profissionais

Realização pessoal reduzida

Má organização do sistema de saúde

Falta de apoio dos colegas

Medo de atuar profissionalmente

Desvalorização

profissional

Falta de enfermeiros 
nunca raramente frequentemente sempre

Empresarialização dos cuidados de saúde que aumenta a carga de trabalho

Falta de competência pessoal

Ser obrigado a prestar cuidado inadequado

ou desnecessário

\section{Obstáculos}

linguísticos e culturais

Falta de discussão

sobre questões éticas

no serviço

Expectativas de outros em relação à atuação

do enfermeiro

Inexistência de

comissões de ética

Falta de tempo por

excesso de trabalho

nunca raramente frequentemente sempre

Falta de

financiamento,

recursos,

equipamentos

Falta de consideração

pelos seus

conhecimentos

Não estar preparado

para lidar com a morte

Vontade do utente não

é respeitada

Dar falsas esperanças

para utentes e

familiares

Stress

Problemas na

estrutura física da

instituição

Medo de perder o

emprego 
nunca raramente frequentemente sempre

Observar

comportamento

inadequado de

familiares

Falta de competência

de outros profissionais

Alta tecnologia no

prolongamento da

vida

Impossibilidade de

crescimento

profissional

Esgotamento físico / mental / emocional

Normas institucionais que dificultam o

cuidado

Uso inadequado dos recursos disponíveis

Medo de não ser aceito pela equipe

Medo de reportar a ocorrência de erros

Ser questionado sobre informações que não possa transmitir

Impotente para mudar o contexto

Estrutura hierárquica a determinar impotência e subordinação do enfermeiro ao médico

Número excessivo de utentes atribuídos a cada enfermeiro

Observar cuidado inadequado ou desnecessário

Conflitos entre utente, família, profissionais

Questões de gênero pelo estereótipo de poder associado ao masculino da medicina e ao

feminino da

enfermadem 
nunca raramente frequentemente sempre

Ser forçado a não

contar a verdade ao

utente

Não ser incluído na

tomada de decisões

Demora no

atendimento

Utente sem condições

de pagar pelo

tratamento

Falta de apoio da

instituição

Impotente para

contestar decisões de

outros profissionais

Baixa satisfação em

relação ao trabalho

Ser forçado a

transgredir as regras

Quebrar

confidencialidade $\mathrm{e}$

sigilo

Medo de não terminar

o trabalho a tempo

Baixa autonomia

Ter que decidir pelo utente

Conflitos religiosos / espirituais 
ANEXO VIII 
ANEXO IX

SOFRIMENTO MORAL EM ENFERMAGEM

D. rafaelaschaefer1988@gmail.com

$20 / 05 / 2015$

para mim

Prezado (a),

Esta pesquisa insere-se no curso de Doutorado em Enfermagem da Universidade Católica Portuguesa - Porto, sob orientação da professora Margarida Vieira e coorientação da professora Elma Zoboli (USP), tendo por finalidade a construção e a validação de um instrumento para avaliar o risco de sofrimento moral em enfermeiros trabalhadores de instituições de saúde. Peço a sua colaboração no processo de obtenção de consenso e validação dos itens identificados na literatura como possíveis fatores de risco para sofrimento moral.

Agradecemos a sua colaboração e pedimos que, com base em sua experiência e conhecimento, participe desta pesquisa. Caso tenha

interesse, basta clicar no link apresentado ao final do e-mail, o qual irá direcioná-lo para o Termo de Consentimento Livre e Esclarecido e para o questionário.

Pedimos a gentileza que, se possivel, envie sua resposta no prazo de 15 dias, até 4 de junho

Rafaela Schaefer

Enfermeira

Mestre em Saúde Coletiva

Doutoranda em Enfermagem

ICS - UCP

Este é um convite para preencher o formulário SOFRIMENTO MORAL EM ENFERMAGEM. Para preenchê-lo, visite: https://docs.google.com/forms/d/1wNX8PRROW95s96oCxKNJznja4_mcLRvAuYzQ00cCcGA/viewform?c=0\&w=1\&usp=mail_form_link 
ANEXO X

\begin{tabular}{|c|c|c|}
\hline$\equiv \equiv$ & ISSP & $\begin{array}{c}\text { ESCOLA DE ENFERMAGEM DA } \\
\text { UNIVERSIDADE DE SÃO } \\
\text { PAULO - EEUSP }\end{array}$ \\
\hline
\end{tabular}

\section{PARECER CONSUBSTANCIADO DO CEP}

\section{DADOS DO PROJETO DE PESQUISA}

Título da Pesquisa: SENSIBILIDADE MORAL E SOFRIMENTO MORAL DOS ENFERMEIROS Pesquisador: Rafaela Schaefer

Área Temática:

Versäo: 2

CAAE: 45957915.4 .0000 .5392

Instituição Proponente: Escola de Enfermagem da USP

Patrocinador Principal: Financiamento Próprio

DADOS DO PARECER

Número do Parecer: 1.180 .518

Data da Relatoria: 11/08/2015

\section{Recomendações:}

Não há.

Conclusões ou Pendências e Lista de Inadequações:

O projeto não apresenta pendências.

Situação do Parecer:

Aprovado

Necessita Apreciação da CONEP:

Não

Considerações Finais a critério do CEP:

Este CEP informa a necessidade de registro dos resultados parciais e finais na Plataforma Brasil.

Esta aprovação não substitui a autorização da instituição coparticipante, antes do início da coleta de dados. 
ANEXO XI 